University of San Diego

Digital USD

2007-08-01

\title{
Parental Decision Making in the Administration of Stimulant Medication for their Latency Age Children with Attention Deficit Hyperactivity Disorder (ADHD)
}

Randye Kay PhD, MSN, RN

University of San Diego

Follow this and additional works at: https://digital.sandiego.edu/dissertations

Part of the Nursing Commons

\section{Digital USD Citation}

Kay, Randye PhD, MSN, RN, "Parental Decision Making in the Administration of Stimulant Medication for their Latency Age Children with Attention Deficit Hyperactivity Disorder (ADHD)" (2007). Dissertations. 353.

https://digital.sandiego.edu/dissertations/353

This Dissertation: Open Access is brought to you for free and open access by the Theses and Dissertations at Digital USD. It has been accepted for inclusion in Dissertations by an authorized administrator of Digital USD. For more information, please contact digital@sandiego.edu. 
UNIVERSITY OF SAN DIEGO

Hahn School of Nursing and Health Science

PARENTAL DECISION MAKING IN THE ADMINISTRATION OF STIMULANT MEDICATION FOR THEIR LATENCY AGE CHILDREN WITH ATTENTION DEFICIT HYPERACTIVITY DISORDER (ADHD)

By

Randye Kay MSN, RN

A dissertation presented to the

FACULTY OF THE HAHN SCHOOL OF NURSING AND HEALTH SCIENCE UNIVERSITY OF SAN DIEGO

In partial fulfillment of the requirements for the degree of DOCTOR OF PHILOSOPHY IN NURSING

August 2007

Dissertation Committee

Cynthia D. Connelly PhD, RN, FAAN, Chair

Jane M. Georges PhD, RN

A. Hunter PhD, RN, CPNP 


\section{COPYRIGHT $2007 \mathrm{BY}$}

Kay, Randye

\section{All Rights Reserved.}




\begin{abstract}
The purpose of this study was to examine parental decision making in the administration of stimulant medication to their latency age children with Attention Deficit Hyperactivity Disorder (ADHD). Research has shown that psychostimulants, used to treat ADHD are effective for $75-90 \%$ of children (US Department of Health and Human Services, 2001), however children do not take their medication from $20-65 \%$ of the time.

A qualitative study using a type of grounded theory, dimensional analysis (Schatzman, 1991), was conducted to study the experiences of fourteen parents whose children began medication treatment between the ages of 5 and 12. Semi stuctured, audiotaped interviews were utilized to obtain the narratives of parents, and the interview content was transcribed verbatim, analyzed, and placed into a matrix.

The central dimension was: finding the best fit for the child specific to the school setting. A cluster of symptoms, a prompt for evaluation, and parent's acceptance of, or agreement with the diagnosis predated the treatment interval. Context/environmental dimensions included: doing what's right for my child, personal qualities of the child, parental assessment of intellectual abilities of the child, not getting along with the other children/not fitting in and public or private school setting. Conditions dimensions were: relationship of the parent with the school/school staff, stigma, and having no choice/feeling pressured. Processes or intented/unintended actions included: requesting/ making modifications and learning curve, and the consequences dimension included: tradeoffs.
\end{abstract}


The primary relationship of the parent was with the school, and that with the health care provider was secondary. Medication treatment was viewed as only one of several treatments utilized by parents for treatment of the condition. A disparity in power between the physician and parent may have contributed to decisions regarding medication treatment, and this is considered in the conceptual model of decision making presented in the study.

The results of the study suggest that educating school staff and improving communication between the school, provider and family, making the goals for treatment explicit, and scheduling more frequent appointments have the potential to improve treatment outcomes. Further research is indicated to determine the criteria parents use to assess "fit". 


\section{Dedication}

This work is dedicated to my parents, Bernard and Beatrice Kay (Toronto, Canada) whose love and support through this lengthy, rewarding journey, has been truly inspirational. Historical events of the mid 20th century prevented both of them from seeing their educational dreams come to fruition, and my greatest wish would have been to see them resume their studies so that they, too, could enjoy this experience.

Throughout my life my parents have instilled in me the value of education - the greatest public good. I am very appreciative that they have been able to share this experience with me.

Over the years I have been fortunate to have the support and friendship of three remarkable physicians who love working with children, Dr. Lucia Grayson, Dr. Maureen Saunders and Dr. Marvin Tan, of Kaiser Permanente, the Brookshire Clinic. Their contribution to this study was considerable. In addition, I would also like to dedicate this work to three exemplary physicians whose committment to the highest standard of clincal care for their patients is unparalleled: Dr. Carlos Figueroa, Dr. Gerald Windler, and Dr. Daniel Arkfeld. 
Acknowledgments

I would like to thank Dr. Cynthia Connelly, PhD, RN, FAAN, Dissertation Committee Chairperson, for her support, patience, optimism, wonderful sense of humor and encouragement throughout the dissertation process.

I would also like to thank my Dissertation Committee members Dr. Anita Hunter, $\mathrm{PhD}$, RN, CPNP and Dr. Jane Georges, PhD, RN for their support, helpful suggestions, comments and patience during the writing of my dissertation.

In addition, I would like to acknowledge and thank Dr. Patricia Roth, EdD, RN, for her wisdom, guidance, support and assistance over the past eight years.

A thank you is in order to Dr. Irene Palmer, PhD, RN, FAAN, first Dean of the Hahn School of Nursing at USD for establishing a home for moving our discipline forward. Thank you to my professors and friends at the following schools: California State University Departments of Public Administration, Nursing and Health Science and California State University Los Angeles Department of Political Science. My gratitude is extended to our librarians whose invaluable assistance often goes unmentioned, especially those at: Gerstein Medical Library (University of Toronto), California State University Los Angeles, Norris Medical Library (USC), and Copley Library (USD).

In appreciation of parents of children with ADHD everywhere whose tireless work in helping their children achieve success in their lives is truly remarkable. 
Table of Contents

Dedication ii

Acknowledgements ..............................................................................................ii

Table of Contents ...................................................................................................... iv

List of Appendices ....................................................................................................... v

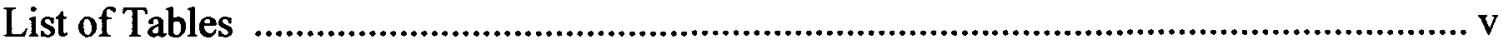

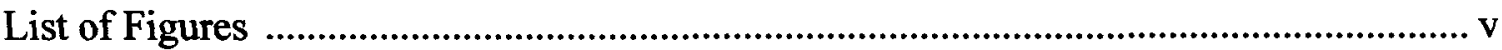

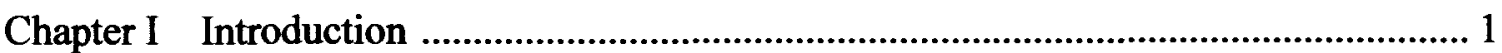

Significance to Nursing .................................................................................. 5

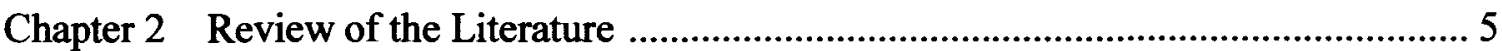

Attention Deficit Hyperactivity Disorder ............................................................. 7

Subtypes and Diagnosis ........................................................................... 7

Differential Diagnosis and Treatment Monitoring .................................... 9

Stimulant Medication .............................................................................. 11

Other Medications Used to Treat ADHD ………………...................... 15

Medication Adherence ....................................................................... 16

Parental Discontinuation of Prescribed Treatment .................................. 34

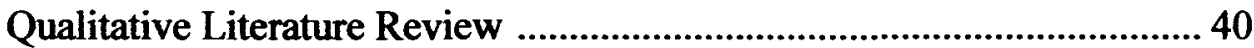

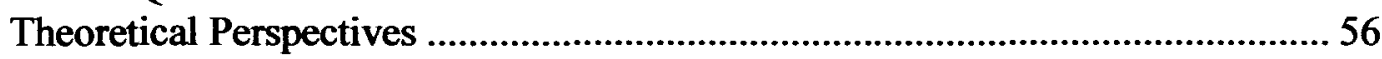

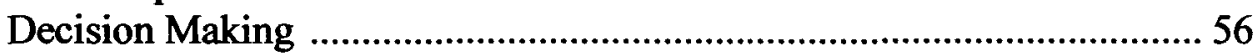

Quantitative Theoretical Approaches ...................................................... 57

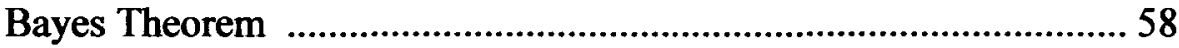

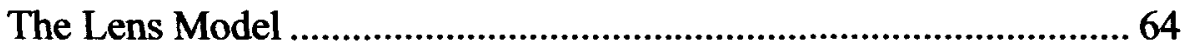

The Theory of Reasoned Action ............................................................ 76

Qualitative Theoretical Approaches.................................................... 84

Feminist Theory ........................................................................... 84

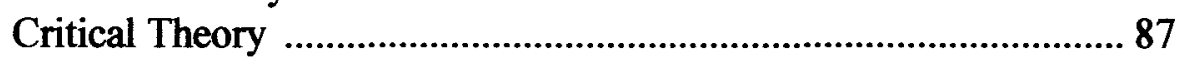

Power in Social Theory ................................................................... 89

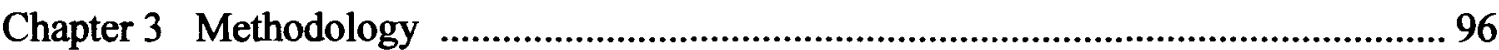

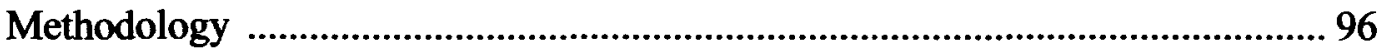

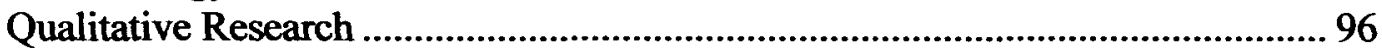

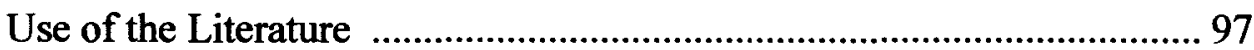

Controlling for Bias and Establishing Rigor in Qualitative Research ...... 99

Dimensional Analysis and Grounded Theory ………………................. 103

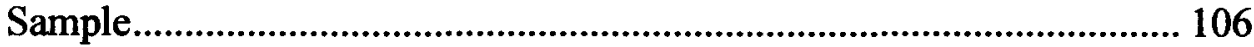

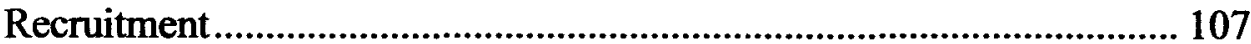

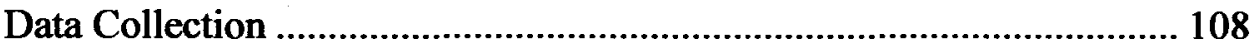

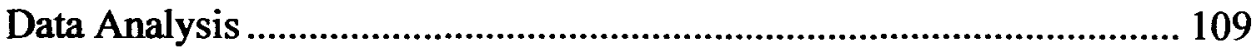

Protection of Human Subjects................................................................. 110

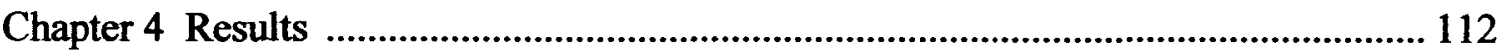

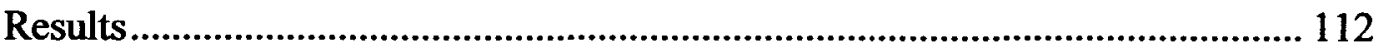




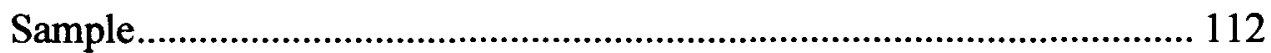

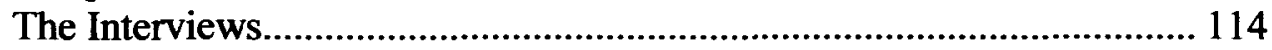

The Context of Decision Making............................................................ 114

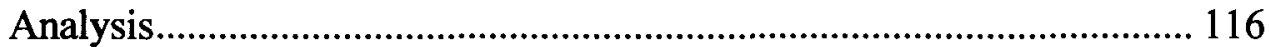

Antecedents to Treatment ...................................................................... 117

The Child's Own Decision Making Treatment Interval/Lifeways ......... 121

The Parental Decision Making Treatment Interval ................................... 122

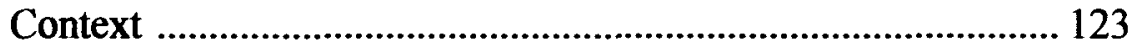

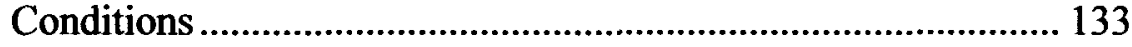

Processes ......................................................................... 138

Consequences....................................................................... 143

Chapter 5 Conclusions and Implications for Practice, Education and Research ............ 146

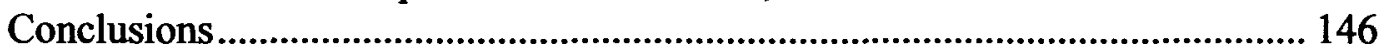

Implications for Nursing Practice ..................................................................... 154

Implications for Nursing Education............................................................... 157

Implications for Nursing Research ............................................................ 158

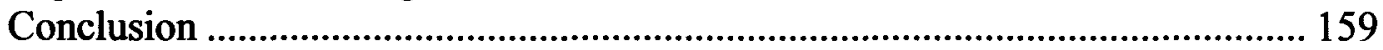

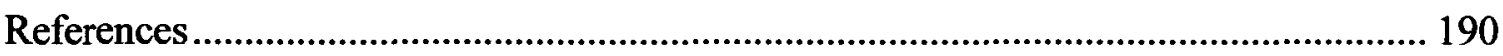

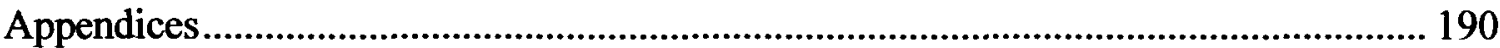

Appendix A Interview Guide ...................................................................... 190

Appendix B Inclusion/Exclusion Criteria .......................................................... 193

Appendix C Demographic Questionnaire ...................................................... 195

Appendix D Flyer............................................................................................. 199

Appendix E Research Participant Consent Form................................................. 200

Appendix F IRB Approval Form .................................................................. 202

Appendix G Copyright Permission Letter .......................................................... 203

List of Tables

Table 1. Revision of Diagnostic Decision Making Utilizing Bayes Theorem.................... 63

List of Figures

Figure 1. Conceptual Model ADHD Treatment Time Intervals .................................. 123

Figure 2. Power Relationships and Mediators ........................................................ 149 
Chapter One

Introduction

The 2001 United States (U.S.) Department of Health and Human Services (DHHS) Report of the Surgeon General on Children and Mental Health stated that psychostimulants, the most common class of medications used to treat Attention Deficit Hyperactivity Disorder (ADHD), improve the symptoms of ADHD and are effective for $75 \%$ - 90\% of children with this diagnosis (U.S. DHHS, 2001). Swanson's (2003) seminal review of studies of stimulant use in ADHD, indicates, however, that children do not take their medication from 20 to $65 \%$ of the time. For example, despite the high rates of success with stimulant treatment, parents and primary caretakers make decisions to discontinue, even temporarily, their children's medications.

According to the National Institutes of Health (NIH) (2000), the prevalence of ADHD in school age children is between $3 \%$ and $5 \%$ with these rates varying geographically (American Academy of Pediatrics (AAP), 2000; American Psychiatric Association (APA), 2000). More boys than girls are diagnosed with $\mathrm{ADHD}$ with a ratio of elementary school age boys to girls in a referred setting of 9:1 and a ratio in a community setting of 4:1 (APA, 1994). These gender ratios may be due to differences in the presentation of the disorder, as well as differences in detection and referral. The results of a recent study with a large nonreferred sample of siblings of children diagnosed with ADHD and 
comparison children of school age $(n=577)$ suggest that gender differences may be less than previously thought and in actuality may reflect referral bias (Biederman et al., 2005). Rather, study findings indicated the male to female ratio was closer to 2.4 to 1 (T. McCracken, personal communication, October 29, 2005). In addition, these authors also estimated the prevalence of the disorder in school age children to be higher than originally thought, at $8 \%-10 \%$.

The costs of ADHD in psychological, social and financial terms are significant; for example, the additional expense to schools to support children with ADHD may have exceeded \$3 billion in 1995 (NIH, 2000). The results of Chan, Zhan, and Homer's (2002) study indicated that the 1996 adjusted cost of care for the ADHD child exceeded that of a healthy child by $\$ 479$; whereas the cost of care for the asthmatic child exceeded this cost by $\$ 437$. Prescriptions amounted to $36 \%$ of the total cost of care for a child with $A D H D$, whereas for the asthmatic child they accounted for only $16 \%$ of the total cost (inpatient care was excluded).

Analysis of the cost effectiveness of various treatments assigned to the children who participated in the Multimodal Treatment Study (MTA) revealed that medication management was the least expensive treatment followed by behavioral treatment (Jensen et al., 2005). In a few instances where combined treatment was indicated due to comorbid conditions, that treatment was found to be more cost effective than both medication management and behavioral treatment. The cost per child over the 14 month period of the study was $\$ 1,180$ for medication management, $\$ 6,988$ for behavioral treatment and $\$ 7$, 827 for combined treatment, with a significant difference in cost between medication management and other treatments. For those children without insurance, regardless of the 
type of treatment prescribed, health care costs are significant and must be subsidized by society.

Functional problems in children with ADHD include academic underachievement, poor peer relationships, emotional problems and family difficulties (Barkley, DuPaul, \& McMurray, 1990; Wilens, Biderman, \& Spencer, 2002). According to the NIH Consensus Development Conference Statement (2000), families of children with ADHD have higher rates of divorce and more family problems. The costs of lost potential and productivity over the lifetime of an individual with untreated ADHD are incalculable. The voluminous research and vast amount of resources utilized to understand, detect, evaluate and treat ADHD underscore the tremendous impact of this diagnosis.

Treatment of the child with ADHD is based on symptoms, comorbid diagnoses and abilities of the family, school and community to intervene (American Academy of Child and Adolescent Psychiatry (AACAP), 1997). The most effective treatments for the combined type of ADHD, based on a long term study conducted by the international Multimodal Treatment Study group (MTA) with a large sample of 579 children include medication, or a combination of medication and psychosocial interventions (MTA, 1999). Yet, despite the high rate of success with stimulant treatment, parents and primary caretakers make decisions to discontinue, even temporarily, their children's medications. Little empirical research however has been conducted in discerning why such medications are discontinued.

It is evident that there is simply not enough information available about parental decision making in discontinuing medical treatment to be able to determine the reasons 
why this is occurring at such at high rate in this population. Most of the previous research has had a quantitative orientation and multiple tests of child related, parent related and family factors that might account for lack of adherence to a medical regimen has not provided answers to the reasons "why" parents discontinue medication. The relationships tested were not significant for the most part and the paucity of studies over a considerable period of time is a testament to the difficulties associated with the study of this phenomenon. Quantitative research is not adequately geared to be able to respond appropriately to the question "why". Instead of progressing deductively along this line of research, it may be beneficial to work inductively. Once this work is complete, a second look at existing theory can be undertaken with the purpose of gaining a better understanding of decision making.

To date there are no published studies specifically addressing the reasons why parents decide to discontinue treatment with stimulant medication. In fact, in a critical appraisal of extended treatment studies Schachar and colleagues (2002) identified studies lack information about the reasons why medication was discontinued. The discontinuation of prescribed medication is problematic in pediatrics and psychiatry, therefore a better understanding of parental decision making is integral to a full understanding of the dynamics and successful treatment of the diagnosis. The proposed investigation utilizing a qualitative methodology and grounded theory approach will include data collection obtained through individual semi-structured parent interviews useful to substantive theory development in the area of parental decision making in the school age population with ADHD (Strauss, 1987). 
Children with ADHD are seen in many treatment settings, and parents have many different ideas about specific medications, providers and therapies. The overall purpose of this study is to examine the phenomenon of $\mathrm{ADHD}$ and the history of administration of stimulant medication in families with latency age children from the age of seven to twelve years. Parental decision making to continue or discontinue prescribed treatment if only for a short time will also be explored. This empirical information has the potential to enhance the development of effective nursing interventions that will benefit children with ADHD and their families.

Meichenbaum and Turk's 1987 publication entitled Facilitating Treatment Adherence: A Practitioner's Guidebook, includes a discussion of the differences between the terms compliance and adherence. The authors indicate that some references utilize the term compliance while others use adherence in discussions of whether or not patients follow a particular course of medical treatment. The authors associate the term compliance with a pejorative connotation, one originating in an unequal, status based relationship between a health care provider and patient, whereas adherence refers to a more collaborative working relationship where the patient is both a party to and is in agreement with a mutually established course of treatment (Meichenbaum \& Turk, 1987, p. 20). The second term, adherence, will be utilized throughout this paper with the exception of instances where the term compliance appears in the title of a research article.

\section{Significance to Nursing}

The development of the science of nursing requires the establishment of a strong theoretical base upon which to develop knowledge, conduct research, and guide nursing practice (Chinn \& Kramer, 1995; Kim \& Kollak, 1999). This ongoing development 
requires the identification of new and established concepts (Reynolds, 1971). The specific aim of the proposed study is to investigate parental decision making in the administration of medically prescribed stimulant medication treatment that was begun at some point between the ages of 5 and 12 child diagnosed with ADHD and to develop new knowledge which will enhance the understanding of treatment and to increase positive health outcomes in these children. 


\section{Chapter Two}

Review of the Literature

This review of the literature provides the following: (a) a description of the subtypes of ADHD and the methods utilized to establish the diagnosis, (b) a brief review of commonly used rating scales, (c) an overview of the medications used to treat ADHD, (d) an analysis of studies designed to examine adherence to stimulant medication in school aged children diagnosed with $\mathrm{ADHD}$, and (e) the significance of extending prior research qualitatively, from a nursing perspective, to develop mid range theory.

\section{Attention Deficit Hyperactivity Disorder}

\section{Subtypes and Diagnosis}

ADHD is a phenomenon characterized by hyperactivity, inattention, or both. In order for a diagnosis to be made, children must be symptomatic prior to the age of seven. The symptoms of ADHD, primarily hyperactivity, inattention and impulsivity may persist into adulthood, however hyperactivity appears to wane with increasing age. Symptoms of hyperactivity in school age ADHD children are manifested as restlessness or fidgeting in the adolescent population (American Academy of Child and Adolescent Psychiatry (AACAP), 1997). A definitive diagnosis can be made utilizing the criteria in the APA Diagnostic and Statistical Manual of Mental Disorders IV Treatment Revision (DSM-IVTR) (2000). There are three subtypes of ADHD, inattentive, hyperactive/inattentive and combined. In order to be diagnosed with $\mathrm{ADHD}$, a child must have functional impairment in at least two settings, for example, school and home (APA, 2000). A 
definitive diagnosis is usually made from information obtained from several sources including parents, teachers, school reports, rating scales and patient interviews (AAP, 2000).

A single, satisfactory explanation for the presence of this diagnosis has not been found and over the years this cluster of symptoms has been attributed to many different causes, including brain injury, minimal brain dysfunction (AACAP, 1997; Volkmar, 2003) problems with cerebral glucose metabolism (Zametkin et al., 1990), genetic heritability (Smalley et al., 2002; Wilens, Biederman, \& Spencer, 2002), poor parenting practices (Willis \& Lovaas, 1977) or environmental factors such as elevated lead levels (Whalen \& Henker, 1980). The inability to identify a single causative factor in conjunction with the lack of a definitive objective test for diagnosis has contributed to considerable controversy with respect to the treatment of ADHD (Silver, 2004). Historically, the very existence of $\mathrm{ADHD}$ as a medical condition was challenged, as demonstrated by the book title The Myth of the Hyperactive Child and Other Means of Child Control (Schrag \& Divoky, 1975).

Diagnostic terminology has changed with the passage of time. As a result, in the 1960s the condition known as minimal brain damage was renamed minimal brain dysfunction (MBD). By the late 1960s, increased recognition of hyperactive behavior led to a recategorization of symptoms, resulting in new terminology that included hyperactive descriptors. The DSM III (APA, 1980) described the diagnosis as attention deficit disorder (ADD) without, or with hyperactivity (ADDH). It was with the revision of the DSM-III, the DSM-III-R (APA, 1987), that the terminology used today was introduced (ADHD). 
In recent years the media has continued to fuel the controversy of whether or not to medicate children with stimulant medication with widely reported treatment alternatives such as structured behavioral programs and advocacy of a multitude of patented herbal remedies. The media attention included televised news reports of the temporary suspension of the sale of Adderall XR in Canada during 2005. It was reported by the FDA (2005a) that Health Canada suspended marketing as there had been cases of sudden and unexplained deaths in children who had been taking the drug. While the suspension of sales was widely reported in the US news media, the US Food and Drug Administration (FDA) did not withdraw the drug from the US market. The Canadian Drug Directorate has since reversed its decision, however additional warnings to consumers and providers about the safety of the drug are now required. It is not surprising that both health care providers and parents are often left in a quandary in assessing the issues associated with the treatment of ADHD.

\section{Differential Diagnosis and Treatment Monitoring}

Rating scales assist clinicians with differential diagnosis, treatment monitoring and evaluation. It is recommended that rating scales should be used diagnostically as part of a broader, multi informant assessment (Barkley, 1998). A full assessment should include a qualitative component (interviews with parents, teachers and the child when possible), a medical examination, medical history and use of rating scales. Broad band rating scales elicit information about symptoms that assist clinicians in making diagnostic decisions about a fairly wide range of psychological problems in children. On the other hand, narrow band rating scales are more specific to one particular condition and as a result are commonly used for the purposes of monitoring treatment and assessing 
treatment efficacy (Barkley, 1998). Commonly used broad band rating scales include the Behavioral Assessment System for Children (BASC), described in Diagnosis of Attention-Deficit/ Hyperactivity Disorder (DHHS, 1999) and the Child Behavior Checklist (CBCL) (Crijnen, Achenbach, \& Verhulst, 1999). Examples of narrow band ADHD specific rating scales appropriate for use in the latency age child population include the Vanderbilt Attention Deficit/Hyperactivity Disorder Parent Rating Scale (VADPRS) (Wolraich et al., 2003b), the Swanson, Nolan, and Pelham IV Questionnaire (SNAP-IV), and the ADDES (DHHS, 1999) (for a full description of these scales see Collett, Ohan, \& Myers, 2003). The Strengths and Weakness of ADHD-Symptoms and Normal-behaviors Rating Scale (SWAN) is a revised version of the SNAP-IV and resembles a broad, rather than a narrow band scale. It was developed to address psychometric problems that resulted in the over identification of the diagnosis and to avoid the utilization of possible inaccurate cut off points that are used to make a diagnosis of ADHD in other rating scales (Swanson et al., 2001).

The most valid and widely used combination broad and narrow band rating scale is the Conners' Rating Scale (CRS). As a broad band scale, the Conners is able to make the distinction between the ADHD and non ADHD child, and as a narrow band scale it can be utilized to evaluate symptoms specific to the diagnosis of ADHD (Conners, Sitarenios, Parker, \& Epstein, 1998). The long version, CRS-R:L is well suited for the comprehensive evaluation, whereas the short form CRS-R:S is better for treatment monitoring and evaluation, where frequent re- evaluation is necessary (Conners, 2001).

Conners' Scales are used for children from 3 to 17 . The short, revised version is brief, simple to use and appropriate for providers who have time constraints. It is a 
revision of the 1989 version, and the scale items are linked to the DSM-IV. There are three short scales, the parent, teacher and Conners-Wells adolescent self-report, each of which takes approximately five to ten minutes to complete. A total of seven factors were selected for the scale, including cognitive problems, oppositional, psychosomatic, hyperactivity/impulsivity, anxious/shy, social problems and perfectionism.

In a comparative analysis of the correlations of the subscales between the teacher and parent versions of the revised short versions of the scale, Conners reports that there is "considerable variability" in the scores. In saying this, the author of the instrument makes reference to an observation made several years earlier (Schwartz Gould, Wunsch-Hitzig, \& Dohwenrend, 1981) that supports the notion that teachers and parents often perceive a group of children differently. This is evident in the correlations on the CPRS R:S where the fairly wide range of scores extended from .33 to .47 for males and on the CTRS R:S from .18 to .52 for females Conners (2001, p. 126). The wide range of scores may also be explained by the fact that teachers see the child in only one setting, whereas parents see the child in many different settings. ADHD rating scales are integral to the diagnosis and treatment of $\mathrm{ADHD}$.

\section{Stimulant Medication}

Stimulant medication has been used for decades for ADHD and other mental health problems (Santosh \& Taylor, 2000). In general, when medication is indicated for the treatment of ADHD, a stimulant is usually the first choice (Santosh \& Taylor, 2000). The stimulants are particularly effective in treating the core symptoms of the disorder (NIH, 2000) - inattention, hyperactivity and impulsivity. Stimulants reduce fidgeting and interrupting in class and improve a child's ability to stay on task at school. At home, 
parents can expect similar changes with respect to on task behavior. McLellan and Werry (2003, p. 1389) report that some studies have found that children are better able to follow instructions and show less aggression when taking stimulant medication. The Food and Drug Administration (FDA) does not recommend methylphenidate (MPH) for children under six years of age, although dextroamphetamine may be used in children as young as three (McLellan, \& Werry, 2003).

Currently there are three types of stimulant preparations on the market: short, intermediate, and long acting. Short acting, or immediate release medications take effect in 20 minutes to an hour (Biederman, 2002), are effective for approximately three to seven hours and include Focalin, Adderall, Methylin, Metadate, Dexedrine and Dextrostat. Ritalin and Methylin are shorter acting than are the dextroamphetamines (Dexedrine and Dextrostat) and mixed amphetamine salt (Adderall) preparations (Dopheide, 2005). When short acting medications are used, multiple day dosing is usually required to cover the child through the school day and homework periods, and it is often necessary for children to take medication at home and at school.

The older intermediate acting medications take effect in an hour to an hour and a half, last approximately five to eight hours and include Ritalin-SR, Metadate-ER, and Methylin-ER and Dexedrine Spansules (Biederman, 2002). Newer intermediate acting stimulants including Metadate CD, and Ritalin-LA have different drug release systems. The newer preparations have a bimodal pattern of release and are effective for a five to eight hour period of time (Biederman, 2002). The intermediate release preparations ensure that the child receives medication throughout the school day. 
Concerta, one of the three long acting medications, is a long acting form of Ritalin with an osmotic type drug release system. Twenty-two percent of the initial dose is released immediately followed by a continuous release of the remaining $78 \%$ of the drug throughout the rest of the day (Elia, 2005). The first peak plasma concentration occurs in one to two hours and a second peak occurs between six to eight hours post administration. Subsequent to the second peak the blood levels of the drug gradually decrease, producing an overall effect that lasts approximately 12 hours (McNeil, 2002). Some authors report some variability with the duration of effect of the drug, and estimate effectiveness that lasts from 8 and 12 hours (Dophide, 2005).

Adderall XR also has a bimodal pattern of drug release, with an onset of the first dose much like that of the immediate release preparations. Half of the total dose of the drug is released immediately in the form of immediate release beads and the second half, in the form of delayed release beads, is released four hours later. The first peak plasma concentration of the immediate release portion of Adderall XR occurs approximately three hours post administration, and a second occurs at approximately seven hours post administration (Shire, 2005). The overall effect of the drug lasts approximately 10 to 12 hours (Biederman, 2002).

Focalin $\mathrm{XR}$ is the third type of long acting stimulant preparation, and this preparation also has a bimodal release profile. Focalin XR is made up of both immediate and delayed released beads. The average peak plasma concentration of an initial dose occurs approximately 1.5 hours post administration and the second peak occurs in an average of 6.5 hours (Novartis, 2006). 
Currently, liquid forms of medication are not available (Myers, Eisenhauer, \& Ryan, 2003) for those children unable to swallow tablets or capsules, however some preparations may be opened and the contents sprinkled on food. Sprinkle preparations include Dexedrine Spansules, Metadate CD, Ritalin LA, Adderall XR, and Focalin XR. Most medications given for ADHD are given after breakfast in the morning. Short acting stimulants are usually given in the morning, at lunch time at school and at the end of the school day to cover homework. There is some individual variability with respect to drug metabolism and effectiveness and this variability is both clinically evident and reported in the stimulant literature. The type of drug delivery system of a particular medication may affect parental decisions regarding whether or not to discontinue medication. More detailed information about parental impressions of the effects of medication on their child will be elicited during the course of the interviews.

There are some contraindications to stimulant use, such as hypertension, hyperthyroidism, glaucoma, symptomatic cardiovascular disease and sensitivity to stimulants (AACAP, 2002, p. 28S). In general, stimulants have few side effects and most of the possible minor side effects, including abdominal discomfort and headache, diminish or resolve with reductions in the dose or a change in the time of administration. However, some children experience a rebound effect as the medication wears off, and some have sleep problems if the medication is not taken early in the morning. The package insert for Concerta lists growth suppression with long term use as a possibility and suggests that height and weight be monitored, however there is also acknowledgment that current data is insufficient to support a causal relationship (McNeil, 2002). Since many parents often do not administer medication on weekends or holidays, children are 
medication free frequently, and on the days medication is not administered, the issue of side effects becomes irrelevant.

\section{Other Medications Used to Treat ADHD}

Other medications are also used in the treatment of children with ADHD, particularly when treatment with stimulant medication has failed, when side effects of the stimulants are not well tolerated or when a significant tic disorder has been exacerbated. Several studies have shown a tricyclic antidepressant, Desipramine (Norpramin), to be effective in the treatment of $\mathrm{ADHD}$, however, experience with another tricyclic, Imipramine (Tofranil), has shown mixed results (Jadad, Boyle, Cunningham, Kim, \& Schachar, 1999). Two newer antidepressants, Buproprion (Wellbutrin) and Atomoxetine (Strattera) are also used in the treatment of $\mathrm{ADHD}$, however two reports of severe liver injury with Strattera have led to the addition of a warning to the product label (FDA, 2004).

In 2005, a black box warning was added to the Strattera labeling to alert parents to the increased risk of suicidal ideation or worsening of condition in children and adolescents taking this medication (FDA, 2005b). The black box warning is described in the Code of Federal Regulations as the method by which the FDA identifies drugs that have associated with them serious adverse reactions or potential safety hazards. The limitations in the use of the drug and the necessary actions indicated should an adverse reaction occur must be spelled out in a boxed statement whose location in the drug information is determined by the FDA. The establishment of a causal relationship is not necessary for a black box warning to be added (personal communication, L. Lockwood, March 14, 2006). 
Two antihypertensive medications, Tenex and Clonidine, are occasionally used in small doses for the treatment of ADHD. Modafinil, a medication currently used to improve daytime wakefulness, has been expected to be the next addition to the armamentarium of medications used for ADHD, however it was reported on March 23, 2006 that the FDA Psychopharmalogic Drugs Advisory Committee voted not to recommend the approval of the investigational formulation of Modafinil (SPARLON) for use in ADHD until more safety research in the child and adolescent populations has been conducted (Cephalon, 2006). Current indications for the use of the approved version of modafinil, Provigil, include narcolepsy, obstructive sleep apnea and shift work sleep disorder. There are a number of approved medication treatments for children with ADHD. In a recent position statement, the American Society of Health System Pharmacists (Dopheide, 2005) supports stimulants as the first choice for medication treatment (due to their efficacy), followed by Wellbutrin or Strattera as second line medications, tricyclic antidepressants as second or third-line agents and Clonidine or Tenex as fourth line medications or as adjuncts to other medications.

\section{Medication Adherence}

Limited research has been conducted to examine adherence to stimulant medication in the school age population of children with ADHD. This literature review examines ten empirical studies conducted to evaluate adherence with stimulant medication in children with $\mathrm{ADHD}$. Despite the wide use of stimulant drugs for the treatment of ADHD, little research has been conducted with respect to medication in the school age population. A Medline search by Hack and Chow (2001) and the author covering the years 1966 to 2000 resulted in a total of seven articles. A Medline/PubMed 
search by the author covering 2000 to 2005 elicited three additional articles. Five studies were conducted in the U.S., four in Canada, and one in Saudi Arabia, and of the ten, nine were quantitative and one was qualitative. Two were parts of larger studies, two followed up an original study at three and five year time points and all ten appeared in refereed journals between the years 1981 and 2005. Several studies specific to adolescents, those utilizing a child and adolescent sample where findings were not reported out by age and those examining adherence solely with Pemoline were excluded from the review of the literature presented here. Studies where children received the stimulant medication Pemoline were excluded as it was removed from the market in Canada due to reports of hepatotoxicity and is currently being voluntarily, and gradually withdrawn from the market by the manufacturer in the United States (FDA, 2005c).

The starting point of nine of the ten studies predated the MTA study and widespread use of intermediate and long acting stimulant preparations. Each study, however contributed to a growing body of knowledge about medication adherence. The most recent study, conducted by Ibrahim (2002), differed from the others from the perspectives of setting, design, sample and exclusion criteria. It was not surprising that the findings were quite different than were those of the other studies. Three of the studies were completed after the MTA study, but they departed from the use of short acting methylphenidate (Charach, Ickowicz, \& Schachar, 2004; Ibrahim, 2002; Thiruchelvam, Charach, \& Schachar, 2001). Participants in the Thiruchelvam, et al (2001) study and in their later study (Charach, et al., 2004) may have been prescribed a slow release preparation, while participants in Ibrahim's study took medications from several classes, although the primary medication used was MPH. In addition, Ibrahim (2002) found a 
high rate of adherence in a large portion of the sample unlike any other study to date. Salient details of this study are assumed to have been lost in conversion to article format such as the criteria for qualification of sample subjects being of low socioeconomic status. Additionally, the descriptors "low" and "high" have no referents, and it is therefore difficult to ascertain exactly how much medication was taken for the children to be included in one of the two groups.

Studies differed in the discussions of adherence. Kauffman, Smith-Wright, Reese, Simpson, and Jones (1981) examined the incidence of medication nonadherence, or not taking the medication as prescribed, in a sub sample of 12 hyperactive six to 12 year old males, who participated in a related study designed to compare the effectiveness of MPH and Dextroamphetamine in improving school behavior and academic performance (Simpson, Reece, Kauffman and Jones, 1980). Each of the original group of twelve children were randomized to all three treatments - placebo, MPH or Dextroamphetamine for a period of six weeks. The order in which the children received each type of treatment was also randomized. Children did not need to be naïve to medications to be included in the study. Parents, children, teachers and physicians were blinded to the protocol.

Kauffman and colleagues (1981) definition of nonadherence included taking medications not prescribed (positive nonadherence) and omitting doses (negative nonadherence). Objective measures, including urine testing and pill counts were used to monitor adherence. Adherence was reported out as percent of individuals or the mean of patients with positive urines. While there was a wide variation in adherence in patients from week to week, the mean rate of adherence with both Dextroamphetamine and MPH was almost the same. Two thirds of patients in the study were medication compliant and 
no significant differences were found between adherence with the two medications. Their discussion raises the issue of evaluation of drug efficacy when adherence is poor. The authors question the reliability of data gathered about behavior and academic performance even in the context of randomized clinical trials where situations are designed to be well controlled. They cite difficulties with adherence as a possible factor in contradictory findings of studies that have examined drug efficacy (Kauffman, et al., 1981).

Limitations of the study include the small size of the sample and the choice of a solely male, Caucasian group of children. The boys were part of a group of children who had been referred to a university medical center clinic because of hyperactivity (Simpson et al., 1980). The diagnosis of "hyperactivity" was assigned according to visible behavioral cues recorded on a 71 item scale (Werry \& Quay, 1969). Other psychological and educational measures were used for diagnostic purposes; however, the researchers ensured that the participants had demonstrated longstanding behavioral problems clearly evident at home and at school.

In the early $1980 \mathrm{~s}$, little was known about medication adherence in the pediatric ADHD population. Firestone's (1982) study was an attempt to determine what normal drug usage patterns were in a child outpatient population. This was prompted as the findings of many short term studies indicated that classroom behavior and attention improved with medication; however these results were not supported in the few existing long term studies. Participating children had been hyperactive from an early age and must have scored higher than 15 on the hyperactivity index of the Conners to be included in the sample (Firestone, 1982). Parents were also asked to fill out Conners parent scales, 
and measures were taken to exclude children with hyperactivity due to psychosis or neurological problems.

Firestone defined "adherents" and "nonadherents" - those who complied with treatment for nine months or more, and those who declined medication treatment or who discontinued medication prior to the four month point in the year long study. Not all of the seventy six children, 68 boys and 8 girls $(n=76)$, between five and nine years of age who met criteria for the study were included in the randomization to a medication only (Ritalin) group or a group where the child received medication (Ritalin) and parents received training in behavior modification. In instances where parents rejected medication treatment, for the purposes of the study those families were categorized as nonadherent. In other words, all of the eligible children were included in the analysis whether or not randomization to medication took place. Medication was intended to be used for a total of ten months with time off for drug holidays and the medications were titrated according to the response of each individual child.

Nine families declined any type of treatment, another eleven declined treatment that included medication, and three families had children whose symptoms improved so much prior to the study that interventions were not deemed necessary (Firestone, 1982). It is not known how many families participated in each of the two treatment groups, and the authors found that the differences in attrition rates between the two treatment groups were not significant. Of the families who began the study, eight had children who were withdrawn due to adverse effects of the medication. The percentage of patients who failed to start, and who did and did not remain in treatment were calculated. 
The adherent and nonadherent groups were compared on a number of factors including parents' age, IQ, education, marital satisfaction, income and number of siblings. Findings indicated there was no parental personality profile that could predict nonadherence, however, parents of children in the nonadherent group were younger and had lower scores on intelligence tests than did parents in the adherent group. The investigators concluded that many parents do not accept medication treatment, nonadherence increases with time from the date the prescription was written, and that parents do not inform the physician about nonadherence. Two other interesting findings were that less than ten percent of the families contacted the provider prior to discontinuing the medication and that neither medication side effects nor the disappearance of symptoms appeared to be important reasons for lack of adherence.

The results of Sleator, Ullman, and vonNeuman's (1982) qualitative study where children were interviewed to determine their attitudes toward taking medication indicated that children generally dislike taking medication. Fifty two children who were followed for a period of eight years and who were all over the age of eight were interviewed by a physician, a trained researcher or both. Interviews were assessed for internal and external inconsistencies. Multiple additional sources of information, including teacher and parent reports were obtained to corroborate or show inconsistencies in statements made by the children. Sleator et al. reported that children dislike taking medication, yet this research group discovered through analysis of multiple information sources that children reported inaccurate and often conflicting information.

Brown, Borden, and Clingerman's study (1985) of 30 , six to twelve year olds was conducted to further efforts to accurately measure adherence and describe related child 
and parent demographic and psychological factors in a three month placebo controlled MPH study. Adherence was measured by pill counts and were classified as 1) "adherents" (those who returned less than 24 capsules), 2) "partial adherents" (those returning more than 24 capsules), and 3) "dropouts" (prematurely dropped from the study). "Dropouts" included not only children who were withdrawn from the study by parents, but those who were withdrawn by investigators due to persistent side effects.

Brown and associates found that $25 \%$ of the children did not take medication as prescribed and $50 \%$ of the children left the study prematurely. Children who left the study prematurely were more impulsive and inattentive. On the other hand, adherent children were more depressed than were partial adherents. Partially adherent families had a more moral/religious emphasis in the home than did dropouts, and adherent families assessed themselves as more conflictual than either partial adherents or dropouts.

Families were assessed as having intact marriages or those where parents were separated or divorced. Interestingly a greater proportion of dropouts were from families with intact marriages, whereas a statistically significant larger proportion of the adherents were from families of divorce. Of those families with intact marriages, four of 29 were adherent, five were partially adherent, and 13 dropped out. Of the families whose parents were divorced, there were four adherent families, one partially adherent family, and only one that dropped out.

Brown, Borden, Wynne, Spunt, and Clingerman's (1987) study of 58 predominantly male six to 13 year olds was designed to look at the relationship of demographic variables and degree of adherence in randomly assigned medication and psychotherapy treatments. It also examined the relationship between adherence and 
outcome. Brown, et al. (1987) utilized different terminology to describe different levels of adherence in the study sample. The "nonengaged" were those families who declined participation, the "dropouts" were those who terminated prematurely, and "completers" were the children who completed the three month study. Adherence was measured by pill counts and parental reports of missed doses. One quarter of the tablets dispensed were returned to the pharmacy in the completer group. The authors do not describe the pattern of return in terms of whether many patients missed a few doses or a few patients missed many doses although it is evident from the report that this was calculated. In addition, the authors explained that due to the small sample size, dropouts were combined with the nonengaged. Although the completer group finished the study, it was found that adherence in general with medication was poor.

Brown, Borden, Wynne, Spunt, and Clingerman's third study (1988) examined adherence in a sample of 71 predominantly male children randomized to attention control or cognitive therapy treatments with MPH and placebo controls. Adherence in the three month study was measured by pill counts and parent reports of the number of tablets taken. No clear explanations for medication nonadherence were found. The authors do suggest, however, that problems with adherence are associated with a "more severe form of ADD” (Brown, et al., 1988, p. 34). However, if symptoms of ADHD are ameliorated with the administration of medication, it seems to defy logic that this patient population would be less adherent than a less symptomatic population. Perhaps an alternative explanation might include the need to change medication due to lack of efficacy and the inability to do so due to restrictions of the study protocol. The dosing in this study was weight based as opposed to titration according to response. Perhaps the behavior noted at 
school by teachers but not by parents might be related to the noon dosing at school (late or omitted).

Brown and associates (1988, p. 36) point out that drawing conclusions about stimulant adherence in children participating in research studies is misleading as these children represent a "unique sample" and the data may be biased as a result. Their argument presents a strong case for further research with study eligible children whose parents decline treatment with medication. The authors also concluded that intellectual, behavioral and cognitive assessment can help predict adherence risk and this information may be used to plan treatment. Finally, the authors asserted that "satisfactory compliance is a prerequisite to the assessment of treatment efficacy".

To gain more information about what parents think about treatment with medication, Johnson and Fine (1993) examined adherence in yet another blinded, placebo controlled medication trial. The researchers randomly assigned 24, six to ten year olds who had been matched in pairs on sex and age (within six months) to two treatment conditions for ADHD, a placebo controlled MPH condition and a typical clinical procedures (TCP) condition. Participants in the two treatment conditions were to be compared on the basis of parental satisfaction, parental acceptance and on adherence with treatment. Prior research findings have suggested that parents may have been hesitant to place their children on medication, and it was thought by the authors that a closely controlled, blinded study may have methodological advantages over community care by facilitating an objective way of evaluating the effectiveness of the medication, providing close monitoring of patients and obtaining information from collateral sources. The authors also thought that perhaps the method by which a randomized clinical trial (RCT) 
is conducted may positively influence the three measures previously mentioned, parental acceptance, parental satisfaction, and treatment adherence. Data regarding socioeconomic status and a measure of mothers' intellectual functioning was collected. Medication dose was titrated according to clinical response.

Although no formal definition of adherence was offered, pill counts and urine analysis were two measures of adherence used in the study. Adherence with treatment was indicated when the urine of patients on MPH was positive for the drug and negative when patients were not medicated. Parent reports of adherence were also part of the evaluation. The authors concluded that parents accepted both treatments but were more satisfied with the medication trial. Neither satisfaction nor acceptability predicted adherence. In addition, the authors did not find a correlation between adherence and dosage or treatment effectiveness, nor did they find relationships between adherence and socioeconomic status, child age or parent attitudes.

Thiruchelvam, et al. (2001) conducted a three year longitudinal study to examine mediators and moderators of adherence to stimulant medication among six to twelve year old medication naïve children $(n=71)$ with $A D H D$. Mediators refer to the baseline characteristics of the child that influence whether or not the child continues to take medication whereas moderators are those factors arising after the initiation of treatment that influence whether or not the child remains adherent. Although two children took Pemoline, this study is included in the review as the other medications used included MPH, Dextroamphetamine and slow release stimulant preparations. None of the children had been prescribed MPH in the past. Adherence was defined as taking medication for five or more days per week over a three year period with the exception of summers and 
holidays. It was assessed with the use of two unpublished instruments, the Treatment Monitoring Questionnaire (Corkum, Rimer, \& Schachar, 1997) and the Child Satisfaction Survey (Corkum, Schachar, Tannock, \& Cunningham, 1997).

Each of the children was randomly assigned to one of four treatment combinations which included placebo and parent training or placebo and parent support or MPH and parent training or MPH and parent support. Parents were permitted to request a change from one to the other medication condition. The blind was maintained for 12 months, after which care was transferred to physicians in the community with monitoring by the research staff.

Six child factors - severity of ADHD, presence of conduct disorder (CD), a learning disorder (LD), oppositional defiant disorder (ODD), anxiety and age and two family related factors - socioeconomic adversity and family dysfunction were examined to determine whether the authors were able to predict adherence over the duration of the study. Rates of adherence were measured with data obtained from the two instruments (that included an interview with the child), a semi structured interview with parents and teachers, pill counts and prescribing records. The rates were fairly high with $81 \%$ of children adherent over 12 months, $67 \%$ at two years and $52 \%$ at three years. At year three, $88.7 \%$ of the original 71 children remained in the study. The reasons for attrition of the remainder of the study sample were attributed to lack of cooperation, lack of interest and lost to contact (Thiruchelvam et al., 2001).

The possible moderator variables were identified as age, ADHD symptoms at school, presence of ODD at school, anxiety and family dysfunction. Adherents were more likely to be younger, to have more teacher-rated ADHD symptoms and less likely 
to have ODD at school. The logistic regression model was able to predict adherence in $84 \%$ of subjects whereas only $50 \%$ would have been predicted by chance (Thiruchelvam et al., 2001, p. 925). Limitations of the study include the small sample size, a reduction in power of the study that the authors identify as a result of the complexity of measuring patterns of adherence, an inability to the placebo controlled portion of the study as parents requested crossover to a medication arm of the study, less contact between the research team and patients as time went on, lack of measures of adherence and use of self reports of the parents and children (Thiruchelvam, 2001).

Recently, Charach et al., (2004) conducted a follow-up study that had originated with a RCT $(n=91)$ conducted between the years 1993 and 1995 (Shachar, Tannock, Cunningham, \& Corkum, 1997) designed to document the effectiveness of stimulant medication. Children were randomly assigned to a placebo or medication treatment for ADHD. In another study with the same cohort of children, Thiruchelvam et al., (2001) examined the mediators and moderators of adherence to stimulant medication after three years. Charach et al., (2004) elaborated upon the study to obtain an evaluation of adherence with stimulants that spanned a five year period. Very few studies have examined adherence over the long term.

Attrition over the study period resulted in a total of 69 participants at the five year point. Although the study was underpowered, the authors found that a positive treatment response continued over the duration of the study. Side effects, the most common of which was loss of appetite, were predominantly mild and fairly well tolerated, however they continued to occur regardless of the duration of stimulant treatment. Differences in side effects between adherents and non adherents became significant in the third year. 
The number of patients adherent to medication treatment declined over time with percentages in year two of $42(n=53)$, year three $34(n=44)$, year four $28(n=38)$ and year five $25(n=36)$. Treatment with medications other than stimulants was exclusionary criteria for the purposes of the study, however adjunctive medication as Clonidine was not exclusionary. To summarize, side effects appeared and continued to occur regardless of the length of treatment with stimulants, those adherent to medication continued to benefit from treatment over time, yet adherence with medication continued to decline over time. Interestingly, children adherent to medication were those whose ADHD symptoms were more severe at the outset (Charach et al., 2004).

Finally, Ibrahim (2002) conducted a study with 51 children aged 6 to 17 to evaluate the rate and stability of reports of adherence with a variety of medications for ADHD over a three month period. In contrast to several other studies, exclusionary criteria included the presence of oppositional defiant disorder. The majority of the youth in the sample were taking MPH (84\%). In addition to medication treatment, children received weekly lessons in behavior modification and parents received weekly parent training. Treatment response at the end of 12 months, as measured by teachers in terms of reduction of symptoms was not found to be related to medication adherence at a significant level.

Adherence was measured according to information provided on forms that tabulated the number of tablets taken the previous week and were filled out at each weekly visit. Pill counts were also completed by the researcher. "High" (70\%-100\%) and "low" (less than 20\%) adherence groups were identified. The Compliance with Treatment Opinion and Attitude Scale (CTOS), a 30 item questionnaire designed by the author, was 
used to evaluate parental opinion about treatment of ADHD and noncompliant and compliant attitudes toward taking medication. The majority of the 51 , predominantly male patients showed high adherence and there was a high level of agreement in reports of medication adherence between patients and parents.

The findings of high rates of adherence and stability of reports between parents and children ( $94 \%$ of children were of elementary school age) were unexpected. Factors associated with the high level of adherence included family characteristics and parents' attitude and perception of the role of medication in treatment.

For years researchers have been challenged with questions related to pediatric medication adherence. Over the short term, stimulants have been found to be highly effective, however longitudinally overall medication adherence wanes over time. Brown et al. (1988) note that treatment efficacy cannot, be assessed unless adherence is clearly established. Issues related to the concepts adherence and compliance were identified earlier. The concepts adherence and nonadherence may not be the inverse of one another. Certainly discovery of the factors that contribute to higher rates of adherence is important, however examining the factors that account for declining participation in a medication study, premature discontinuation or not taking the medication as prescribed may be due to a completely different set of factors.

Extant research has included the study of normal patterns of medication use in the outpatient pediatric population (Firestone, 1982), patients' attitudes toward taking medication (Sleator, 1982) demographic characteristics, and psychological and other factors (parent and child related) that might help explain lack of adherence (Brown et al., 1985, 1987, 1988; Firestone, 1982; Ibrahim, 2002; Kauffman et al., 1981; Thiruchelvam, 
2001). Johnson and Fine (1993) evaluated parents' attitudes toward, satisfaction with and adherence with medication.

This selected group of studies extends over a twenty four year period. There have been many social changes during this period of time. Many children are part of one parent households and even when living in a two parent household, it is common for both parents to be employed, therefore fathers, rather than mothers may administer medication. Some children are given the responsibility for taking their own medication. In the studies included, children had at least one parent living in the home. Children with other living arrangements were excluded, although some children today may reside with grandparents or other extended family members. While it was easier to obtain informed consent from the parents to participate in the studies, this requirement may have limited the economic and cultural diversity of the samples.

Intermediate and long acting forms of medication permit administration once daily, therefore it is not usually necessary for children to be medicated at school. Since twice daily dosing required adherence by both the family and school, the change to single daily dosing with the introduction of new medicines may have changed adherence. Stimulant medications are controlled substances, and in the past prescriptions had to be written on special prescription forms called "triplicates". Until January 1, 2004 these prescriptions were only good for 13 days from the date written, and many of them expired without being filled. The law has been changed and although special prescription forms are used, they are now valid for six months; they still however, cannot be refilled.

The issues involved in studying stimulant medication adherence are numerous. Many stem from the lack of consistent definitions of adherence and compliance. The 
notion of adherence has evolved from a change in the nature of the provider/patient relationship. At one time a patient was "compliant" if the directives of the provider were followed. In recent years the notion of "adherence", a concept indicative of a more consensual relationship between patient and provider, has replaced compliance. Many different kinds of objective and subjective measurements of adherence were used in the studies. The use of multiple methods of measurement has been recommended. "Acceptable" levels of adherence are also problematic, and are often set in an arbitrary manner.

The samples in the studies were small, with a range of 12 to 76 children. Participants were overwhelmingly male, predominantly latency age children. Almost all studies were double or triple blind and involved random assignment to a medication/placebo treatment or medication/placebo/group or typical procedure treatment. Some studies compared adherence with stimulant medication to adherence with other treatments.

Almost all children in the studies were given short acting MPH or Dextroamphetamine, twice daily. Some children were naive to medication while others had some previous experience with medication. In some cases, children had their regular medication changed to that designated by the study protocol. Dosages varied. Some children were on fixed doses of medication while others received doses based on weight. In some trials, the medication was titrated according to response. The implications of twice daily dosing with short term preparations meant that children had no medication coverage for homework that was to be completed after the school day had ended. Methods differed across studies. The longest study was a year in length, however one 
study (Thiruchelvam et al., 2001) followed participants over a five year period to determine whether or not children continued the medication.

DSM criteria were used for diagnostic purposes with the exception of two studies, one of which used a "predetermined set of criteria" (Kauffman et al., 1981). The other study utilized both DSM and ICD-10 (Ibrahim, 2002) criteria. Conners scales were used in two thirds of the studies, while a variety of measures were used to assess family functioning, to screen for intelligence and to exclude comorbid disorders.

To summarize, the studies were a-theoretical, samples were small and had an overrepresentation of males, all of which limit generalizability of the findings. In most studies, almost all of which were conducted prior to the year 2000, commonly accepted DSM criteria were used for diagnosis. The quantitative studies with the exception of Ibrahim (2002) were fully or partially blinded and randomized. In all but the most recent study, there is no mention of Conduct Disorder (CD) or Oppositional Defiant Disorder (ODD) being exclusionary. As noted in Thiruchelvam et al. (2001, p. 926), children with ODD were eleven times more likely to discontinue medication than were children without ODD. This may account for the findings of high adherence in Ibrahim's (2002) study. Perhaps ADHD patients without significant externalizing symptoms have higher rates of adherence.

Adherence was rarely explicitly defined, but indicators were both subjective and objective. Levels of adherence were assigned by individual researchers, and expressed as percents, estimates of high or low levels, or even personalized, using the terms "adherents" or "nonadherents". Researchers investigated a number of factors that might predict adherence including attitudes of parents and children toward taking stimulants, 
age, socioeconomic status, presence of comorbid disorders, maternal intelligence, presence of depression or anxiety, satisfaction with treatment, and treatment acceptability. The only significant factor found was maternal level of intelligence.

In general, adherence remains problematic and time threats complicate matters. For example, maturation is an endemic threat as externalizing symptoms wane over time. History is a problem as changes in family structure, working situations, and drug development may affect the independent variable. While all research respects the importance of the control group, there are ethical questions associated with a placebo control in medication studies where research has consistently found medication to be an effective treatment for the disorder.

The findings of these studies have not identified significant ways in which to impact medication adherence. Current knowledge suggests that adherence to medication decreases over time (Brown et al., 1985, p. 29; Firestone, 1982, p. 453; Thiruchelvam et al., 2001, p. 925; Charach et al., 2004, p. 563) and "available studies provide little information about long-term adherence to stimulant medication" (Thiruchelvam et al., 2001, p. 922). The conclusions drawn in a meta-analysis of fourteen extended treatment studies of ADHD, suggest that there is little information as to why children discontinue medication (Schachar et al., 2002, p. 346). Firestone's study (1982, p. 453) indicated that less than $10 \%$ of the families contacted the provider before stopping medication. Cohen and Thompson's (1982) investigation of children's perceptions and attitudes toward medication treatment concluded that the children were more concerned with the consequences of discontinuing medication than were their mothers. It is perhaps as Thiruchelvam posited, that adherence to stimulant medication must be viewed as a 
process over time during which children start and stop medication. Further research is indicated to better understand the decision making process of parents in determining whether or not to continue treatment with stimulant medication.

\section{Parental Discontinuation of Prescribed Treatment}

Winnick, Lucas, Hartman, and Toll (2005) describe three areas where adherence to a prescribed medication regimen for children is integral to good outcomes, in health promotion, disease prevention and in the treatment of disease. In an Australian study illustrative of an example of adherence difficulties in the area of disease prevention, Lawrence, Hull, MacIntyre, and McIntyre (2004) interviewed parents to discover the reasons for incomplete immunization of children. The authors framed discontinuation of treatment not necessarily as being a permanent state of affairs, but presented it in the context of either discontinuation or postponement. While concerns about vaccine safety and delays due to illness of the child were included in the findings, the authors do not discount the possibility that since a series of immunizations are administered over a lengthy period of time, they may be interrupted only to be resumed at a later date. This notion is quite similar to that expressed by Thiruchelvam et al. (2001).

Parental decision making regarding whether or not to continue medication treatment can be assessed within the context of any of three areas: health promotion, disease prevention and treatment of disease. Should future research be conducted about this patient population, it would be done within the context of children being treated for a disease. The area can be narrowed further to treatment of the child being treated for a chronic disease. The international literature describing the success or lack of success with adherence to treatment regimens for children with chronic illness is extensive. Research 
has been conducted in school age populations with varying diagnoses such as asthma (Burkhart \& Rayens, 2005; Milgrom et al., 1996; McQuaid, Kopel, Klein, \& Fritz, 2003), seizure disorder (Pooya, 2005), cystic fibrosis (Slatter, Francis, Smith, \& Bush, 2004), liver and kidney organ transplantation (Falkenstein, Flynn, Kirkpatrick, Casa-Melley, \& Dunn, 2004; Shemesh, 2004; Sudan, Shaw, \& Langnas, 1997), human immunodeficiency virus (HIV) (Arrive et al., 2005; Mellins, Brackis-Cott, Dolezal, \& Abrams, 2004) and other diseases. However limited research specific to parental decision making with respect to adherence to a medication treatment regimen has been conducted. The reasons for discontinuation of medication treatment in pediatric chronic illness, and specifically in school age children with $\mathrm{ADHD}$ remain a mystery.

There has been no published research specific to the decisions parents make to discontinue stimulant medication in cases where treatment with stimulant medication was initially acceptable. Three closely related articles are presented and reviewed.

The first study examines parental attitudes and beliefs toward treatment of the medical condition and describes parental experiences with different treatments (Johnston, Seipp, Hommersen, Hoza, \& Fine, 2005). The second examines parental perceptions of the diagnosis (manner in which the diagnosis was made) and overall treatment of the condition (Concannon \& Tang, 2005). The last article evaluates the attitudes of both parents and children toward taking stimulant medication (McElearney, Fitzpatrick, Farrell, King, \& Lynch, 2004). The first two studies were Canadian and Australian respectively and had community based samples, and the third, an Irish study, had a hospital based outpatient sample of children. 
Johnston, Seipp, Hommersen, Hoza, \& Fine's (2005) quantitative study was designed to study the relationships between parental beliefs and attitudes toward and experiences with a variety of treatments for ADHD. The investigators utilized a convenience sample of the parents of 73 boys aged from 3 to 13 years. Since there was an insufficient number of girls in the sample for the purposes of comparison, they were excluded from the sample. Demographic data and parent ratings of the child's behavior were obtained in telephone interviews, and participants were sent ADHD rating scales for the teachers to complete. In addition, parents were asked to respond to three questionnaires about treatment history and beliefs about the causes of and treatments used in ADHD, and about treatment effectiveness.

The Treatment History Questionnaire (Holroyd, Holm, Penzien, Cordingley, Hursey, Martin et al., 1989) was used to obtain information about the history of treatments used and asks for an evaluation of their effectiveness. The ADHD Beliefs Scale (Johnston \& Freeman, 2002), which assesses information about the beliefs about the causes of and treatments for ADHD was also sent to the parents. In the Written Analogue Questionnaire (Johnston \& Patenaude, 1994) that describes several scenarios involving parent and child interactions, parents are asked to identify causes of the child's behavior. In several cases more than one parent report was received for a particular child. In cases where two parents reported about the same child, the scores were averaged.

Although many parents utilized more than one treatment for $\mathrm{ADHD}$ at various times, $81 \%$ of the children were taking medication, and of the $81 \%, 85 \%$ were taking stimulant medication. More than half of the 16 children not taking medication had taken it in the past. Of the 32 parents who had discontinued medication previously, $59 \%$ 
discontinued medication due to side effects and the other $31 \%$ discontinued medication due to lack of efficacy (Johnston et al., 2005). Parents of children receiving medication had higher Belief in Medication scores and lower scores on the other treatment scales.

Limitations of the study include a small sample size, lack of a female comparison group, and use of a predominantly Caucasian sample. The researchers relied on parental reports of the child being diagnosed by a pediatrician or psychiatrist and by parent and teacher reports on an $\mathrm{ADHD}$ rating scale. The authors mention that impairment in one setting was sufficient to be diagnostic, however according to the DSM-IV-TR, impairment is required in two settings to meet criteria for the disorder.

In an Australian school based community sample of 278 children aged 10-12 diagnosed with $\mathrm{ADHD}$ investigators examined parental perceptions of the diagnosis and overall treatment of their children (Concannon \& Yang, 2005). Data collection included how the diagnosis of $\mathrm{ADHD}$ was made, whether by interview, rating scales, academic evaluation, multiple reporters and by the exclusion of medical problems through examination of the child. In addition, the professional designation of the diagnosing clinician was noted. Parents were asked about treatment options they had chosen, including conventional and complementary or alternative treatments. "Conventional" treatments were designated as such in instances where there was a history of documented evidence in the literature with respect to their efficacy, whereas those referred to as "nonconventional" treatments did not have a well established history of efficacy. Parents were asked about their level of satisfaction with the treatments and their perceptions of their usefulness. Satisfaction with treatment was measured with the use of a five point Likert scale with a range of choices from very dissatisfied to very satisfied. Finally, the 
study addressed parental opinions of unmet needs, potentially useful information for the future treatment of children with ADHD.

Of the 278 participants in the study, $82 \%$ had tried stimulant medication and at the time of the study $66 \%$ were still taking the medication. Fifty-five percent of all parents were satisfied with treatment, and of the group whose children were treated with medication $73 \%$ expressed satisfaction with overall treatment whereas only $36 \%$ of the parents whose children were not on medication were satisfied with treatment. Parents whose children were seen for appointments more frequently than once every six months (66\%) were more satisfied than were those whose appointments were less frequent than once every six months (34\%). Although parents whose children were treated with medication indicated they were satisfied with treatment, $16 \%$ of the children were no longer receiving medication treatment. The purpose of this study was not to examine the reasons for discontinuation of treatment with medication and no reasons to account for this apparent incongruence were offered.

The limitations of the study include lack of consideration of comorbid disorders in the children and their possible influence on parental perception of diagnosis and treatment, the fact that the study was retrospective and as such depended on parental recall, and the inability of the investigators to compare the parents who responded to the study with those who declined participation (Concannon \& Tang, 2004).

A comparative analysis of parent and child views toward taking stimulant medication for the treatment of ADHD and a variety of medications for seizure disorder was conducted with an outpatient clinic sample of children in Ireland. The sample was split into two groups with $\mathbf{4 0}$ children in each group. The participants ranged in age from 
8 to 18 years, with mean age in the ADHD group of 10.5 years and in the seizure disorder group of 12.2 years (McElearney, Fitzpatrick, Farrell, King, \& Lynch, 2004). Both the child and parent in each dyad participated in semi-structured interviews at which time demographic information was gathered, the child completed the Attitude to Medication Questionnaire (Efron, Jarman, \& Barker, 1998) and the parent completed both the Parent Attitude to Medication Questionnaire (Efron, Jarmon \& Barker, 1998) and the Dosage Side Effects Questionnaire (Barkley, McMurray, Edelbrock, \& Robins, 1990). The authors acknowledge the burden of continuing to adhere to a medication regimen as accruing to both the child and parent.

Sixty percent of the children in both groups had positive things to say about medication treatment however $15 \%$ of the ADHD group had negative reports about medication including side effects, a dislike of taking medication daily, or of having to take medication at all. Adherence to treatment (defined in the study as taking medication as prescribed by the physician) was reported at $60 \%$, a figure reported by the authors as higher than that found in other studies. In the parent group whose children had ADHD, $90 \%$ of parents reported positive changes when their child was on medication. Parents were more likely to report both positive and negative things about medication treatment than were their children (McElearney et al., 2004).

Two findings of interest in this study were that parents have a more favorable view toward stimulants than do their children, and also that parents who reported poor adherence with medication also reported more side effects (McElearney et al., 2004). Limitations of the study include a small sample size, use of a two group sample where the 
groups were not matched, an ADHD sample group that included children with comorbid disorders and the use of two different sites for the study.

To summarize, it is evident that parents assess medication treatment as being beneficial for their children and are satisfied with this choice of treatment. Child and parent views about stimulant medication differ somewhat in terms of assessment of efficacy of the medication with children at least acknowledging the medication is helpful both at home and at school. Despite the positive views of both parents and children toward stimulant treatment for $\mathrm{ADHD}$, apart from some mention of side effects, the poor rates of adherence are unexplained yet many of the side effects of stimulants are transient and amenable to treatment. Further research is needed to determine the decision making process used by parents in the administration of medication.

\section{Qualitative Literature Review}

A literature review of Cinahl, Medline and Academic Search for the years 1980 to 2006 was conducted to obtain qualitatively oriented studies related to parental decision making and the use of stimulant medication in children. A total of four articles written between the years 2003 and 2006 were found, three of which had the same author.

Taylor, O'Donoghue, and Houghton (2006), describe the process parents use to make the initial decision whether or not to medicate their ADHD children. The authors used a grounded theory approach with a perspective consistent with symbolic interactionism for the study. A total of $33(n=33)$ parents, including 5 fathers and 28 mothers were recruited from a University based center for attention and related disorders and from the Learning and Attentional Disorders Society Support Group in Western Australia. This parent sample, from the metropolitan area of Perth, in Western Australia, 
had broad representation socioeconomically. Interestingly, almost half of the parent sample were "sole" parents $(n=15)$ and the rest $(n=17)$ were in a "shared" parenting relationship (Taylor, et al, 2006, p. 114). One parent in the sample was excluded from both of the two categories. The marital status of parents in "shared" parenting relationships is not made explicit in the article. Twenty two of the adults were parents of young children ( 16 boys and 6 girls) and 11 of the parents had adolescent boys.

Prior to the interviews, participants received a mailing with six broad interview questions upon which the actual interview questions would be based. Parents were given the option of a face to face or telephone interview, and eight chose the face to face interviews. The authors indicate that telephone interviews were conducted to accommodate parental work schedules. The interviews lasted between 45 minutes and an hour, and no upper limit was placed on the maximum allotted time. Interviews were taped and transcribed verbatim.

Analysis of the interview content yielded a theory of parental response to diagnosis consisting of three stages, grieving, cynicism and proactive parenting. The first stage, grieving consisted of seven substages, and the way in which parents progressed through the first six of those depended upon the support they received (Taylor, et al., 2006). The grounded theory that emerged was "doing right by my child". The authors found that where parents' acquired and experiential knowledge of ADHD is consistent, parents generally accepted the pediatrician's diagnosis, whereas in instances where there was incongruency between experiential and acquired knowledge about ADHD, parents experienced a grieving process. The authors stated that parents thought the ways in which positive outcomes for their children could be achieved was by working with the 
medication regimen and through educating others. Taylor et al. (2006) go on to say that parents "came to the realization" (Taylor, et al., 2006, p. 126), that they alone have the lifelong responsibility to protect their children and as a result, need to do that which is necessary for them.

Limitations of the study include lack of generalizability, inherent in all qualitative research. Parents were predominantly female, in the sample of 28 mothers and 5 fathers. The authors identify contextually significant factors relevant to the Australian health care system including the fact that dextroamphetamine is formulary and the least costly intervention available for the treatment of $\mathrm{ADHD}$, and that limited funding prevents pediatricians from offering other kinds of treatments. Children were diagnosed and treated by pediatricians, rather than psychiatrists or both types of physicians, as in a mixed practice model. The authors did not reveal whether there were differences in the decision making processes of those parents who chose to utilize medication and those who declined treatment with medication.

In a series of three articles (Singh, 2003, 2004, 2005) based on the author's dissertation at Harvard University (2000), the author explores medication treatment qualitatively, from a gender based perspective. These unique, descriptive, informative studies explore new areas in the decision making process of parents specific to the ADHD diagnosis and treatment of their children. These studies have prompted significant commentary from the academic and medical community.

In the first of three articles, Singh (2003) describes fathers' thoughts about diagnosis, symptoms and treatment for ADHD. The point that previous studies have focused on mothers and sons is raised, as is the notion that previous studies described 
families as "parents" and children rather than mothers and children. The centrality of gender to the focus of Singh's study is iterated by the author of the article and it is noteworthy that Singh's thesis advisor at Harvard was Carol Gilligan, author of "In a Different Voice" (1982/1993).

In the first study, two research questions were asked, the first of which was whether fathers "mattered" to the understanding and treatment of ADHD, and the second asked why fathers are absent in ADHD environments. A total of 61 parents $(n=61)$ including 39 mothers and 22 fathers of boys with $\mathrm{ADHD}$ participated in this study. Initial recruitment from a pediatric neurodevelopmental clinic in Rhode Island yielded a sample of 22 mothers and 12 fathers of latency age boys with ADHD. The sample was later extended to include a community based group of parents that added 17 mothers and 10 fathers for a total sample of 63 parents $(n=63)$. Parents were from the low middle to middle socioeconomic class and were Caucasian. Socioeconomic status was established utilizing the Hollingshed index (Hollingshead, as cited in Singh, 2003, p. 311). To be included in the study, parents had to have children who had been on medication for at least three months but not more than one year. Forty two percent of the children had a learning disability and seven percent had Asperger's disorder (Singh, 2003).

The researcher conducted interviews utilizing pictures to stimulate creative thought. The pictures chosen by parents were from a circumscribed set of popular magazines, including People, Self, Sports Illustrated, Women's Day, and Newsweek (Singh, 2003). Picture choice was based on a question related to parents' thoughts and feelings about stimulant treatment for ADHD (Singh, 2003). The length of interviews 
varied, from between one to three hours. Singh described the approach to the study as grounded theory.

Fathers were found to be "reluctant believers" or "tolerant nonbelievers" with respect to diagnosis, symptomatic behavior and drug treatment for ADHD. Reluctant believers (59\%) thought that medication was helpful whereas tolerant nonbelievers (27\%) did not agree with the diagnosis nor the utility of medication. The remainder of the fathers did not fit either of the two categories, but were essentially tolerant of both diagnosis and medication treatment. Separation of these two categories, reluctant believers and tolerant nonbelievers was related to whether or not the father situated the condition in a medical perspective, whether there was personal identification with the child's behavior, and whether fathers were adverse to treatment with medication. Mothers in the study sample subscribed to the medical explanation for ADHD where fathers subscribed to a different etiological explanation (Singh, 2003).

Limitations of the study include lack of generalizability, and the small size and homogeneity of the sample. All of the fathers were Caucasian (Singh, 2003). The author also stated that interviewing parents after treatment had begun may have resulted in different findings had the study utilized more than one time point. The results described by the author clearly identified differences in thinking about the condition by parental gender. While there may indeed be significant differences between mothers and fathers thoughts about the diagnosis of ADHD, many ADHD children live with one parent and many have other kinds of family structures. Therefore, a different type of sample might yield very different results. Single parent households may have one parent doing the mothering and fathering. The terms "mother" and "father", have completely different 
implications when they are used in the biological, rather than the sense of social role. Teasing out the various threads central to gender and role of mothers and fathers in the context of parental relationship with their children is arduous due to the nature of the sample.

The second of three qualitative articles by Singh (2004) examines mothers' perspectives of blame for the diagnosis of ADHD and use of medication. The etiology of ADHD remains unclear to this day and research has taken a number of twists and turns over the last century. The condition has had proponents who pose both biological and social explanations for its presence. Among the social explanations was mother blame. Behavioral explanations for ADHD tended to view the condition as a possible result of parental conditioning that reinforced negative behavior (Willis \& Lovaas, in Millichap, 1977, p. 122). Psychoanalysis, on the other hand, posited causality in a deficit in the relationship between a child and his mother, where negativity of the mother resulted in hyperactive behavior (Bettleheim, as cited in Sandberg, 2002, p. 21).

In this article, the author illustrates the dichotomy of causal attribution for the condition to either organic reasons or mothering metaphorically through the use of the expression "mother-blame-brain-blame" (Singh, 2004, p. 1194). It is assumed that the sample was the same as that in the initial study, where 22 mothers and 12 fathers of boys with $\mathrm{ADHD}$ treated at a clinic in Rhode Island participated in 2 to 3 hour interviews. The researcher described the method as a grounded theory approach utilizing an auto-driven interview technique. This technique involved participant selection of pictures from popular magazines that were seen by parents to be related to how they thought and felt 
about stimulant use. According to the author, this technique was used to minimize the power imbalance between the researcher and participants (Singh, 2004).

Analysis of family problems, behavioral problems, social problems and school problems related to ADHD were interpreted by Singh (2004, p. 1196) in the context of "particular socializing agents that reinforce oppressive and stereotypic notions of mothers and also of young boys". The two areas that impacted mothers' feelings of inadequacy included attitudes of the fathers in dismissal of ADHD behaviors as problematic and public display of ADHD behaviors that precipitated comments from onlookers. Adoption of the "brain-blame" narrative by mothers served to rid them of "mother-blame". Medication administration minimizes the impact of publicly unacceptable behavior and changes "bad-mother" into "good-mother". Mothers, are therefore socially reinforced for giving medication. Father's attitudes of disbelief of ADHD as a medical condition, thinking that medication has more benefits for the mother than the child, and their notable lack of participation in diagnosis and treatment of their children all tend to fuel the mother blame scenario.

A third study (Singh, 2005) sought to find an explanation for the moral dilemmas parents experience in making decisions about use of Ritalin. According to the author this study was designed to examine parent's use of the moral ideal of authenticity to justify the administration of Ritalin. Three concepts are that are central to understanding of Singh's (2005) article include morals, ethical dilemmas and authenticity. First, Davis and Aroskar (1991, p. 2) describe morals as "character, conduct and motives involved in moral acts". These standards of conduct often have value judgments assigned to them. The author states that morality is social in origin and is guided by a number of principles, 
or ideals. Second, Davis and Aroskar (1991) define an ethical dilemma as a problem with no clear cut correct answer or one where there is a choice to be made between two unsatisfactory choices. Authenticity is the third concept important to an understanding of the study. Authenticity has been defined in the Webster's New World Dictionary (1994) as "the quality or state of being authentic; reliability; genuineness" when authentic is defined in one sense as "one that is in fact as represented, genuine, real" (p. 92).

Interpreting the work of Charles Taylor, a contemporary contributor to philosophic thought, Abbey (2000) describes authenticity as a universal value, for every person has the potential for authenticity, but when it comes to being true to oneself, "each individual must decide for himself or herself what being authentic means" (p. 86). The concept of authenticity has been modernized from its initial construction where one's internal moral compass pointed to the correct direction for one's actions. The concept has been further modified over time, and Taylor (1991, p. 29) refers to the more modern notion of authenticity in the sense of self actualization, or an individualistic conception of "doing your own thing". This is not to say that the individual lives as an isolated self, or as a remote island in a sea of others, but as one who is mindful of being unique while at the same time existing as part of a larger social group. The influences of those external to the individual (which Taylor attributes to the work of Jean Jacques Rousseau), however, should not determine the actions of an individual (Taylor, 1991).

The study was qualitative and appeared to use a portion of the same sample as that used in the first article - with 22 mothers $(n=22)$ and 12 fathers $(n=12)$ of boys who had been seen in a pediatric neurodevelopmental clinic affiliated with a university hospital in Rhode Island. This sample was later expanded to include an additional 17 
mothers $(n=17)$ and 10 fathers $(n=10)$ of boys recruited from the community. Again, the parents were Caucasian and from the low middle to middle class socioeconomic groups. Children had been diagnosed with ADHD and had taken medication for between three months and a year. Most of the children in the sample were taking Ritalin, a short acting stimulant. The interviews were again picture driven, and parents were asked to choose up to 10 pictures from a set of magazines that included People, Newsweek, Self, Women's Day and Sports Illustrated. According to the author, pictures were used to help explain parental response to the question, or how parents thought and felt about Ritalin or other stimulant treatment. The interviews were approximately three hours in length and multiple coders were trained for the task of open coding for this project.

Three ethical issues related to the use of Ritalin were explored by the author of the study. The first was the use of Ritalin for the purposes of enhancement. The second had to do with the potential effect on the child's "authentic" self, and the third issue addressed the rights of parents to make decisions for their children when the decisions made could significantly affect the child's future (Singh, 2005). In this article the author examined the contextually and temporally based moral dilemmas of parents related to treatment with Ritalin in terms of both the initial and ongoing decisions made by parents in administering medication to children. The author found that parents' use of the notion of authenticity was a "strategic construction that has practical import: it informs and justifies decisions about medication use" (Singh, 2005, p. 36).

Mothers are seen to have therapeutic narratives surrounding the use of Ritalin, whereas fathers subscribe to an anti-therapeutic view of medication taking. Fathers view drug use as medicating children's behaviors that are ordinary, male oriented, acceptable, 
"boys will be boys" behavior (Singh, 2005). Although the broader categories of the therapeutic and anti-therapeutic narratives are explained further in the research, it is interesting to note that mothers utilized both a therapeutic and anti-therapeutic narrative during the interviews when discussing whether or not to give medication on the weekends.

Unlike many other medications, the effects of Ritalin wear off quickly. Many parents give medication during the week when the child is expected to listen to the teacher and remain seated in a classroom. Some parents do not give medication on the weekends unless the child participates in an activity that demands his full attention. In essence, mothers decisions about giving their children medication during the week for school, but not on weekends, permitting their children to be themselves on the weekend, signifies, according to Singh (2005), contradictory notions of the "ideal" of authenticity. While authenticity may be a universal value, its ascription to the status of "ideal" can be contested by some who seek to perform beyond their natural capabilities or those who, perhaps, are unhappy or otherwise dissatisfied with their current situation and seek a happier, or more fulfilling kind of life.

The dilemma of fathers, rather than mothers, differs contextually, for fathers' involvement with their children and medication often occurs in situations where a child's performance on a sports field is the focus of the decision situation. Singh (2005) found that to fathers, the success of their children on the sports field had more importance than did the success of their children in the classroom. The notion of the authentic child being the unmedicated child became less clear when the child's performance on the sports field reflected symptoms consistent with $\mathrm{ADHD}$. Were the boys unable to focus on the game 
the "real boys", or were the "real boys" those who played well after a dose of Ritalin? Fathers did not use the authenticity argument to ground decision making regarding medication use for sports. Fathers, instead, attributed poor performance on the field to lack of motivation and in instances where fathers thought performance was due to lack of motivation, medication administration was not warranted. It was found that in many cases, the fathers left medication administration decisions to their wives (Singh, 2005).

Singh (2005) raises several ethical issues related to the use of stimulants in children, one of which follows from the question whether the children would decide to take the medication if the decision was theirs to make. Parents have the legal authority to make health care choices for their children while they are minors. The expectations for parents are that they make decisions in the spirit of promoting well-being and preventing harm to their children (Post, 2004, p. 388). The expediency of Ritalin as a "quick fix" to troublesome behaviors in a number of settings can be viewed as an ethical violation of parental responsibility. Whether parents give medication in the interest of the child or to serve their own interests has been raised as an issue.

The author has clearly articulated the complex interplay of factors integral to medication administration, including parenting practices, differences in approach to diagnosis and treatment by mothers and fathers, gender specific self-concepts of parents and derivation of self-concepts, social and temporal aspects of the child's environment, cultural notions of what is and is not acceptable behavior for children, family functioning, separation of the child from the child's behaviors, assignment of the responsibility for medication decisions by one parent to another, and the impact of the health care system on decision making (Singh, 2005). The conclusions of this segment of the original 
research are that parental decisions regarding Ritalin treatment are "inconsistent, contradictory, strategic and incomplete" from a moral standpoint (Singh, 2005, p. 45).

The four articles comprising the qualitative literature review with relevant to parents and medication use in children with ADHD represent several different aspects of decision making. In the first article, Taylor, et al. (2006) describe the decision making process parents go through in making the initial decision about medicating their children. Singh's (2003) first article following publication of her dissertation explores parent's thoughts and feelings about symptoms, diagnosis and medication from a gendered perspective. The author's second article (Singh, 2004) examines contextually significant gender specific psychological implications for mothers' subsequent to the decision to medicate their sons with Ritalin. The last article (Singh, 2005) frames decision making in a moral context where the author explores the use of the moral ideal of authenticity as potential justification for parental decisions to utilize medication treatment for their children.

The following section presents an analysis of the methodology utilized in the latter three studies. Although all four studies were qualitative, Taylor et al. (2006) utilized a traditional grounded theory approach whereas Singh $(2003,2004,2005)$ mixed qualitative approaches, combining grounded theory with a phenomenological approach. The focus of Singh's (2000) dissertation "A crutch a tool" - how mothers and fathers of boys with ADHD experience and understand the work of Ritalin" was to examine the "work" of Ritalin from the perspective of mothers with latency age boys who had been diagnosed with ADHD and who had been on medication, (Ritalin or Dexedrine) for a period of between three and twelve months. The three articles were published after the 
completion of the dissertation and appear to have used the same group of participants, setting and interview structure. Select bits of data obtained in the interviews were used to answer the research questions that were asked in each of the studies.

The complexity of the research considering the salience of gender as perspective, rich social and historical context and focus on decision making facilitated the use of mixed qualitative methods. The three studies represent examples of both interpretive hermeneutic phenomenology as they present views of parents' way of "being in the world" and also of descriptive phenomenology as they seek to describe the "essence" of ADHD. Parents clearly identify a lack of agreement among themselves about exactly what constitutes the phenomenon, and through the use of composite narratives (Crist, \& Tanner, 2003), reveal not only what giving stimulant medication means to them personally but also provide a description of how they process the symptoms, diagnosis and treatment of their ADHD children. The combination of phenomenological methods is somewhat problematic, for Heidiggerian interpretive phenomenology is interpretive and ontologic while Husserlian phenomenology represents a descriptive and epistemic approach (Mackey, 2004).

Both approaches are utilized - the studies are framed in psychoanalytic themes that relate to identity of the individual (one's way of being in the world) and include descriptions how these "identities" exist in a social context when the child with ADHD is superimposed. While interpretation and description are compatible activities in the phenomenologic approach (Mackey, 2004), the position of the researcher in the research process remains an issue. Singh does not separate her perspective from interpretation or description as it is clear that gender takes center stage in this research. 
Where this becomes problematic is when it comes to establishing rigor in Husserlian research as in this type of qualitative research, perspective needs to be bracketed. This is not true in the Heidiggerian tradition where no bracketing is necessary (Lowes \& Prowse, 2001). In utilizing a mix of essentially three qualitative methods, Singh's research may have been attempting a Herculean task. A larger, more diverse sample and additional studies with participants who either agree on what constitutes the phenomenon or who agree that the behavioral symptoms do not constitute the phenomenon may reveal some very interesting findings.

The interview findings were reported in the forms of responses to the specific research questions asked in each study, however can be described in theoretical terms as salient comparisons by gender and role were found in some of the studies. The findings have implications for diagnosis and treatment. For example, fathers' narratives subscribed to a non medical (non biological) basis for ADHD where mothers narrative (although inconsistent) tended to view ADHD from a more biologically oriented perspective. These findings are helpful since an awareness of the thoughts and feelings of fathers related to diagnosis and medication may help nurses better understand fathers' perspectives and suggest interventions that may promote more involvement in treatment and treatment planning (where appropriate). The pieces of the puzzle that could be put together to form theory were present in the explanation of findings, however the author might have provided the linkages to present a coherent theoretical structure to the reader.

Another very interesting feature of Singh's work and one that contributes to its originality is inherent in the interview process. The interviews used a picture based approach with which to elicit the thoughts and feelings of parents toward stimulant 
treatment of ADHD. This technique was described in Singh's dissertation (2000) as a modified Zaltman Metaphor Elicitation Technique (ZMET), and is a qualitative research tool designed to improve advertising research (Zaltman \& Coulter, 1995). This methodology is not specifically articulated in any of the three studies, however one study (Singh, 2004, p. 1195) does identify the interview process as "auto driven". Preparation for the interviews, however, was consistent with the Zaltman technique.

Zaltman developed the ZMET while at Harvard University where he was a professor of Business Administration. The reasons for thoroughly understanding what goes through the mind of the consumer in digesting information about various products and services on the market and discovering how choices are made do not require explanation. While there are several assumptions inherent in this technique, the first of importance to Singh's work is the idea that "mental images people use in daily life are visual" (Zaltman \& Coulter, 1995, p. 37). The second idea is that metaphors "are the key windows/mechanisms for viewing consumer thoughts and feelings and for understanding behavior" (Zaltman \& Coulter, 1995, p. 37). According to Zaltman and Coulter (1995), what follows is that the creation of mental models facilitates the development of stories. It is proposed that the end result is a deeper understanding of the thoughts and feelings of consumers.

Theoretically speaking, the technique has benefits, but there are also some drawbacks to its use. In one study utilizing the technique, participants were asked to comment about advertising in general, without reference to specific printed advertisements. The participants thought that advertising represented idealized images, lacked multiethnic representation, presented stereotypical families, and caused feelings in 
the participants that resulted in the thought that in general, advertising may have negative effects on those with limited means and education (Coulter, Zaltman, \& Coulter, 2001). The authors describe advertising as a form of persuasive communication.

Instructions regarding the type of pictures parents were to choose in preparation for the interviews in Singh's studies were not described in any of the three articles. Although the interviews were informant driven as parents chose the pictures themselves, the restricted choice of magazines had the potential to bias the results of the studies. No stretch of the imagination is required to make the assumption that the portrayal of idealized images is common in People and Sports Illustrated.

There has been considerable support in qualitative research for the use of creative ways to stimulate mental imagery and describe thoughts that are more difficult to access. Other methods include the use of photographs, (Gerace, 1989), transitional objects (Clark, 1998), and even more - as sculpting, art, psychodrama, role playing, the use of timelines, as described by Deacon (2000). Singh's research, with its limitations, has provided a very interesting way of viewing parental decision making and stimulant medication administration for their children with ADHD. Consideration of the social context and thick description adds considerable richness to the research.

Prior to the conduct of any further qualitative studies, some preliminary work in the qualitative area must be done. Substantive theory is needed to explain why children are not taking medication which has, for decades, been shown to be effective for the treatment of ADHD. Just perhaps, in this instance the cart has been placed before the horse and a new perspective is needed to answer an old question. 
Qualitative research may generate theory useful for clinical practice, particularly as the research has not been successful in being able to answer "why" parents discontinue medication. Nurses have the ability to impact parental decision making in a number of ways. Careful, comprehensive and thoughtful patient care can contribute to good patient outcomes. This study has the ability to contribute to the academic literature through middle range theory building. There are a number of potential benefits to continuing a formal, planned program of nursing research specific to this area.

Theoretical Perspectives

Decision Making

Decision making has been defined as "selecting and committing oneself to a course of action" (Hammond, 2000, p. 73) and a process by which one or more individuals make an informed judgment or choice from among more than one available alternatives (Carroll \& Johnson, 1990, p 19). Prescriptive (normative) theories or models emphasize how decisions should be made, whereas descriptive models or theories describe the manner in which decisions are actually made (Baird, 1978). Decision making research has an extensive history and has been conducted by scholars from many disciplines.

There is a large literature that describes and explains multiple aspects of decision making. The foci of interest in decision making have included the decision maker, or who makes the decision, the nature of the problem, the process of decision making, how risky the decision is in terms of the seriousness of its consequences, whether the decision is made under uncertainty (with perfect or imperfect information), examination of factors 
affecting decision choice (personal or contextual) and whether the decision has been made under stressful conditions. Established decision making theories may be helpful in informing future quantitative research regarding parental decision making as to continue or not continue treatment with stimulant medication. Research from a quantitative perspective can assist in finding pertinent factors associated with continuation or discontinuation of treatment, whether related to the family, the child, the provider or the health care system. Qualitatively based research can explore parental perceptions of and decisions related to treatment with stimulant medication. The following literature review includes a description of three established theories, Bayes Theorem (Barnard \& Bayes (1958), the Lens Model (Brunswik, 1952) and the Theory of Reasoned Action (Fishbein \& Azjen, 1975) with examples of clinical applications and a review of qualitative research related to treatment adherence in the school aged child with chronic illness. Quantitative Theoretical Approaches

Hammond, McClelland, \& Mumpower (1980) describe six approaches to decision theory, three of which have economic derivations and three with origins in the field of psychology. These six approaches have been evaluated and mapped on a continuum, from the predominantly psychological (Group II) to the most economic (Group I) in the following order: attribution theory (AT), information integration theory (IIT), social (subjective) judgment theory (SJT), psychological decision theory (PDT), behavioral decision theory (BDT) and decision theory (DT). The Group I theories, PDT, BT and DT have an action orientation where as the Group II theories, AT, ITT and SJT have a more cognitive orientation (Hammond, McClelland, \& Mumpower, 1980). Three theories or models, with applications from the health care literature will be described, followed by a 
discussion of their relevance to informing the decisions of parents or caretakers to continue or not to continue giving stimulant medication to their children. The following three theories represent quantitatively based approaches to decision making about treatment and provide a historical background of research in decision making with medical applications.

\section{Bayes Theorem}

Bayes theorem was developed by the Reverend Thomas Bayes (1702-1761), an eighteenth century theorist and an ordained minister in the Presbyterian Church. Although little is known about Bayes, according to Barnard (1958), it is thought that Bayes learned mathematics from a founder of the theory of probability and was well known and respected for his talent in the field. Bayes theorem $(1763 / 1958)$ is a mathematical theorem (method) utilized as a rule in the context of revision of beliefs or opinions, based on evidence (Anderson, Deane, Hammond, \& McClellan, 1981, p.22). It is classified as a prescriptive (normative) type of decision model (Hammond, 2000; Wright, 1984) and belongs with the group of theories associated with decision, choice or preference (Anderson et al., 1981). Bayes theorem employs the concept of subjective probability and provides information about how rational decision makers should behave with respect to the addition of new information. If researchers were to describe how decisions are actually made and compared real decision making with the ideal, it is reasonable to think that interventions could be designed to narrow the gap between the two (Hammond, 2000).

An understanding of the mathematical concept of probability is integral to the description of Bayes theorem. Probability is expressed by a number that falls between 
(almost) zero and (almost) one where zero represents an event that will not occur and one represents an event that is certain to occur. Second, the sum of the probabilities of all mutually exclusive events is equal to one. Third, the probability of either one of two mutually exclusive events occurring is equal to the sum of their probabilities. Finally, the probability of two events occurring is equal to the probability of one event multiplied by the probability of the other provided that one event has occurred prior to the occurrence of the second event (Wright, 1984, p.82).

The first of four kinds of probability to be described, necessary (objective) probability, refers to the probability of the occurrence of an event based on the physical structure of the object of the calculation. For example, since the structure of dice is universal and consistent, we assume that in the case of dice, a fair roll of a standard pair in obtaining a specific number would have a given probability (Beach \& Connolly, 2005, p. 64). Frequentistic probability refers to the prediction of future events based on what has occurred in the past. Inherent in this definition is the assumption that past events are applicable to future events and that events continue to occur in the same manner as they have in the past. Subjective probability refers to the belief in the likelihood of the occurrence of an event and as previously described has a mathematical range from (almost) zero where an event is not likely to happen to (almost) one where an event is certain to occur. Individuals often describe subjective probabilities as proportions or percentages (Beach and Connolly, 2005). For example, an individual thinking that there is a $90 \%$ chance of a public transportation strike, may decide to drive to work. The difference between necessary, or objective probability and subjective probability is attributable to the judgment of an individual. Finally, conditional probability refers to the 
probability of the occurrence of an event when another, previously occurring event has taken place. Each of the four types of probability can be represented mathematically. Interestingly, Hammond et al., (1980, p. 195) compare the concept of conditional probability in Bayes theorem to the concept of ecological validity in SJT.

In the description of Bayes theorem that follows, $\mathrm{P}$ represents probability, $\mathrm{H}$ represents hypothesis and D represents data. An individual makes an initial hypothesis with prior probability $\mathrm{P}(\mathrm{H})$, or a priori, where little or no data is known. There is a belief at the outset that the a priori probability is true. The likelihood of a given event occurring is calculated after gathering data and is computed as the probability that these data would have been obtained if the hypothesis is true $\mathrm{P}(\mathrm{D} / \mathrm{H})$ as the numerator, divided by the possibility that these data would have been obtained whether or not the hypothesis is true P(D) as the denominator. The result of this calculation, or "likelihood" is multiplied by the prior probability to obtain the posterior probability, or the probability that the hypothesis is true utilizing the data obtained $\mathrm{P}(\mathrm{H} / \mathrm{D})$. $\mathrm{P}(\mathrm{H} / \mathrm{D})$ can be expressed as the probability of the hypothesis being true given the data (Beach and Connolly, 2005).

$$
\mathrm{P}(\mathrm{H} / \mathrm{D})=\frac{\mathrm{P}(\mathrm{D} / \mathrm{H}) \mathrm{P}(\mathrm{H})}{\mathrm{P}(\mathrm{D})}
$$

Bayes theorem is a mathematical way of looking at the effect of obtained data on the initial hypothesis, or the difference between the a priori and a posteriori probabilities. Prior research has shown evidence of conservatism, or the revision of decisions that is less than that prescribed by the theorem (Edwards \& Tversky, 1967). To summarize, Bayes theorem involves decision making under uncertainty and longitudinally over time 
and facilitates improvement of the probability of making a correct decision as decisions are revised with the acquisition of new information. Even though the objective of Bayes theorem is to improve decision making, it does not preclude the ability to evaluate real decisions that are measured against an ideal, or correct decision.

Wright (1984) illustrates a classic, medical application of Bayes theorem, where a physician must decide whether a patient has a brain disorder or functional illness. The physician has some preliminary information likely based on symptom presentation and past experience with this patient population. The physician decides that the probability of the patient being brain disordered as opposed to functionally ill is 50/50. An opportunity for decision revision is made possible after new information is obtained from the results of the Memory-for-Designs test (Wright, 1984, p. 93).

The Memory-for-Designs test is an instrument constructed by Graham and Kendall (1960) to aid in the study of patients with possible brain damage. The test involves reproducing a number of geometric designs from memory, and is scored according to the number of errors made in the reproduction of the figure. Errors that are more commonly found in brain disordered patients are penalized more heavily than are others. Orientation errors are one of those more costly kinds of errors (Graham \& Kendall, 1960).

There are a total of 15 designs to reproduce. The tester informs the patient that he will be shown several designs, each of which is viewed for five seconds. At the end of this time the card on which the design is presented is removed. The participant is then asked to draw the figure exactly like the design on the card. The interpretation and scoring of the drawn figures is somewhat arbitrary. In the review of the psychometrics of 
the instrument, Graham and Kendall (1960) reported that earlier testing with a different sample produced a critical cut off score above which $50 \%$ of individuals were considered to be brain disordered. Only $4 \%$ of patients, (false positives), who had a functional illness scored above this cut point, and these results were fairly consistent across samples.

Wright (1984) provides an application of Bayes theorem to the clinical setting. In this decision problem where a distinction must be made between a functionally ill or brain damaged individual, the initial or a priori probability regarding diagnosis can be revised with the addition of new information, or the test results. The a priori probability of the patient having a brain disorder is $50 / 50$. This probability $(0.5)$ is multiplied by the likelihood $(0.5)$ to establish the posterior probability $(0.5 \times 0.5=0.25) / 0.27$, or 0.93 . The a priori probability of functional illness $(0.5)$ is multiplied by the likelihood $(0.04)$ to establish the posterior probability $(0.5 \times 0.04=0.02) / 0.27$, or 0.07 . Knowledge of the test result means that the physician is now $93 \%$ sure that the patient has a brain disorder and only $7 \%$ sure that the patient has a functional illness. 
Table 1

Revision of Diagnostic Decision Making Utilizing Bayes Theorem

\begin{tabular}{|c|c|c|c|c|}
\hline Hypotheses & Priors & Likelihoods & $\begin{array}{l}\text { Priors X } \\
\text { Likelihoods }\end{array}$ & Posteriors \\
\hline Functional & 0.5 & 0.04 & 0.02 & $\underline{0.02}$ \\
\hline Illness & & & & $\overline{0.27}=0.07$ \\
\hline Brain Damage & 0.5 & 0.50 & 0.25 & $\frac{0.25}{0.27}=0.93$ \\
\hline & & & Sum $=0.27$ & Sum $=1.00$ \\
\hline
\end{tabular}

Note. From Behavioral Decision Theory: an introduction (p. 93), by G. Wright, 1984, Beverly Hills: Sage Publications. Copyright 1984 by Sage Publications. Reprinted with permission.

* copyright permission letter, see Appendix G

There are several implications for Bayes theorem for the science of nursing. The preceding example showed the utility of the theorem for improving diagnostic decisions. Decisions about capital investment in new medical equipment to be used for testing can be made based on calculations of the increase in probability of correctly diagnosing a patient given the results of a specific test. The increase in probability can be compared to the cost of the test and as a result, a more rational decision can be made regarding the purchase of the equipment. This example can be extended to assist in decision making when a choice must be made between two different kinds of equipment. These scenarios raise the question, however, as to whether the treatment ordered would differ whether or not the test was available. Finally, the theory can be used to establish a point at which no further testing is needed (Wright, 1984). 
Medical information is never perfect. Physicians, parents and caretakers are going to make decisions about whether or not to continue stimulant medication treatment in children based on information that has some uncertainty. Do health care providers such as nurse practitioners and parents make treatment decisions based on the same information? This is a question that merits some attention. An optimal decision case must be created so that certain information can be used as the gold standard, or correct decision. This could be accomplished by convening an expert, interdisciplinary panel of medical providers familiar with ADHD, stimulant medications and family dynamics. This group could design a list of indications for discontinuing stimulant medication. The reasons, like the cues in the Memory-for-Designs test, could be weighted to make a distinction between minor problems that might not be a cause for discontinuation but may require an intervention and major factors, which undoubtedly would require discontinuation of treatment. The panel could also examine combinations of factors that alone may not be problematic, however in conjunction with another factor may require termination of stimulants. Based upon the foregoing theoretical perspective, a decision guide that has the potential to identify significant factors associated with continuation and/or discontinuation with treatment could be developed.

\section{The Lens Model}

The lens model, the precursor to social judgment theory, can be attributed to the work of an early twentieth century psychologist and theorist, Egon Brunswik (19031955). Brunswik advocated conducting research in a natural environment (representative design) rather than in settings where conditions were too tightly controlled (Tolman, in Hammond, 1966, pp. 1-12), and thought that the object of psychology, a natural science, 
was to examine the relationship of "causal couplings" of environmental events and reactions to these events (Brunswik, 1937, p. 236). The theorist's approach to research in psychology, known as probabilistic functionalism, demonstrated his interest in the area of perception and perceptual constancy. Brunswik's early research contributed to the development of a model representative of the way in which individuals use cues to interpret their environment.

According to Hammond et al. (1980), Brunswik had been in the process of shifting the focus of his work from perception to judgment at the time of his death, and it was from this perspective that Hammond elaborated upon and named the perspective "the lens model". Perception and judgment are integral to the lens model as a stimulus is presented and perceived by an individual in the form of cues. The cues are then utilized by an individual to formulate a judgment in the form of a decision or goal. The lens model is based on systems theory, where the contribution of the environment is analogous to input, where perception or cognition are analogous to the processor and where a decision or judgment is analogous to output (Gibson, Ivancevich \& Donnelly, 1976; Miller \& Rice, 1967).

Brunswik's lens model (Brunswik, 1952) was introduced to describe the interaction between organismic and environmental systems as they relate to human judgment. The model is constructed to resemble a lens, with a left and right side that are mirror images of each other. The left, or perceptual side of the lens, depicts the distal stimulus object and the proximal cues, or representations of the distal stimulus as they are perceived by the individual. The context or environment is an integral part of the model and is always considered to be a part of the total stimulus pattern (Brunswik, 1937). 
Numerical values can be assigned to the stimulus and cues. Cues are weighted in importance according to the amount of variability in the stimulus they are able to explain. The left side of the lens represents an optimal model where there is good correspondence between the cues and the distal stimulus. This correspondence between cues and the stimulus is referred to as the ecological validity of the cue (Brunswik, in Hammond, 1966, pp. 15-80). A good optimal model has a high level of ecological validity. The left side of the lens can be represented mathematically utilizing a regression equation.

The right side, or judgment side of the lens is where the individual attributes meaning to the cues and assigns weights to them to arrive at a decision or judgment. The individual may utilize the cues in a different manner than they were used to construct the optimal model. The mathematical calculation of cue utilization in the judgment process provides an estimate as to how closely the individual's assessment resembles the "real" situation. In most cases it is not possible to ascertain the "real" situation, unless it is revealed by chance. This is due to the acknowledgement of a certain amount of uncertainty in the model.

The first of the two areas of uncertainty associated with the environment is related to the concept environmental probability. Environmental probability refers to the ambiguity of the environment or uncertainty inherent in the environment. In order for there to be no uncertainty, researchers would have to control for all of the conditions in the environment (Brunswik, 1943, p. 258). The second area is related to the concept of ecological validity. The uncertainty here has to do with the extent to which the proximal cues represent the actual stimulus (Brunswik, 1943, p. 260). If there is uncertainty in the environment, it is not likely the correlations will be perfect even in the most optimal 
model. Uncertainty is also evident in the concept "probabilistic" functionalism, or that uncertainty resulting from imperfect relationships between the environmental event or object, the cues and the end point of the cognitive processing of cues, goal achievement, or means (Hammond, 1966).

The model exemplifies the idea of symmetry, and in doing so utilizes a number of parallel concepts which correspond to one another on each side of the lens. For example, ecological validity and cue utilization are related in the sense that there is variability associated with each concept (Hammond et al., 1980). The model has been updated and refined over the years and has proven useful in studying judgment situations from weather forecasting to prescribing medication. Hammond's two contributions to the lens model include a description of the functional relationships between the distal stimulus and cues and on the other side of the lens, a description of the relationship between the cues and judgment and principles of organization, or the method by which an individual utilizes cues to form judgments (Cooksey, 1996).

One of Brunswik's (1937) early studies in perceptual constancy not only provided a good illustration of the early development of the lens model, but introduced the utility of correlation statistics in quantifying relationships between the distal object, proximal cues and perceptual response. Fifteen wooden cubes of different sizes were set on tables at varying distances from student observers. At the back of the room were another thirteen cubes of similar sizes. The task of the observer, seated so that all of the cubes were clearly visible, was to match the size of the cubes on the tables with those at the back of the room. Each of the eight students completed the experiment once, and their perceptions were recorded as the values of $e$, or the average estimates of the sizes of the 
boxes in comparison to those at the back of the room. The distal stimuli, the boxes at the back of the room, were represented by the expression $b$. The proximal stimuli, or the boxes on the tables were represented by the expression $p$.

The results indicated that e represented an intermediate position with a value between that of the distal and proximal stimuli. The perception of the participants of the true size of the boxes was closer to the actual value of the distal stimuli rather than that of the proximal stimuli. In fact, the correlation coefficient between the distal stimulus and proximal stimulus $\left(r_{b p}\right)$ was .10 , between the proximal stimulus and perceptual response $\left(\mathrm{r}_{\mathrm{ep}}\right)$, was .26 and between the distal stimulus and perceptual response $\left(\mathrm{r}_{\mathrm{eb}}\right)$ was .97 . This interesting finding led to the conclusion that the proximal cues, or the appearance of the boxes in terms of retinal perception were not helpful as cues to the true size of the boxes at the back of the room. It also led to the conclusion that there are likely other, better proximal clues utilized by the individual that led to better agreement of the perceptual response with the distal stimulus. The relationships within the model were effectively illustrated with the use of regression and correlation coefficients. Brunswik, (1937, p. 240; Brunswik, 1940). Brunswik used the term "thing constancy" to depict good correspondence between the distal stimulus and judgment, and developed a constancy ratio $(c=e-p / b-p)$ that was able to demonstrate that there was a higher degree of constancy for cubes located closer, rather than farther from the observer. The constancy ratio can be used to express the level of agreement between the distal stimuli and judgment or decision.

There are three different research designs associated with the lens model, the single, double and the triple system designs. The single system design refers to one where 
there is no optimal model available for comparison and where judgment of the individual is the objective of the study (Hammond, 1980). The double system design is consistent with the general explanation of the model previously described in this paper, where the accuracy of judgment of an individual can be measured and compared to a more objective assessment of the distal stimulus. This design facilitates an analysis of the performance of two or more individuals to examine similarities in cue utilization and judgmental agreement. The triple system is more complex and permits examination of both judgmental agreement and achievement across judges (Cooksey, 1996).

The lens regression equation provides the methodology for the model. The idiographic method, or that which begins with the assumption that each decision maker may have a unique judgment model is associated with SJT. The differences in judgments or decisions are not necessarily due to error (Hammond et al., 1980), but may be due to differences in the choice of cues and their utilization. In any case, many researchers calculate the model for each member of a specific group for the purposes of comparative analysis. This is a common occurrence in the development of a policy.

The double system equation is expressed by the formula: $r_{a}=G R_{1} R_{2}$, where $r_{a}$ represents the correlation between judgments of two judges; $G$ represents the similarity of the two judges judgments in systematic aspects of the model and the value of $R_{1}$ and $R_{2}$ represent the consistency of cue utilization, or the two judgments (Hammond, Brehmer and Steinmann, in Kaplan and Schwartz, 1975, pp. 297). The development of policies in different areas relies on the analysis of two different lens equations, one representing the optimal decision making model and another representing the decision making model of an individual. Once the analysis is complete, the two models can be compared to evaluate 
the performance of the individual. The lens model can be used to develop policies, or models based on historical decision making behavior that is applied to new situations (Beach, \& Connolly, 2005). The correlation coefficient obtained for the linear model on the right side of the lens and is compared to that obtained in the first model. The result obtained is known as the achievement coefficient, or a measure of performance of the judge (Beach \& Connolly, 2005).

Although the methodology involving the description of judgment and decision making is fairly complex, it is almost entirely based in regression. Good descriptions of the methodology are provided by Ullman and Doherty (1984) and Cooksey (1996). The achievement of an individual may be measured against the optimal model or in terms of consistency over a number of objects or subjects. The relationship between the stimulus and the cues on the left side or perception side of the lens can be represented by the correlation coefficient $R_{e}$ and the relationship between the cues and the judgment on the right side of the lens can be represented by the multiple correlation coefficient $R_{s}$. The calculations conducted to assess each side of the lens in this linear model facilitate comparison.

On the right side of the lens $Y_{s}$ represents the dependent variable or actual judgments of the individual. If there were 40 cases and six cues then a regression equation could be set up where the 40 obtained values were regressed on the 40 sets of 10 cues. This yields a correlation coefficient representative of the consistency of the judge. Next, the $\mathbf{4 0}$ sets of 10 cues are placed into the individual's policy equation, and the calculation results in 100 predicted values, or Y's. The correlation between the predicted $Y^{\prime}$ values and the $Y_{s}$ values result in $R_{s}$ or the multiple correlation between the cues and 
individual's judgment. The residual in the relationship between the cues and judgment that has not been explained is the quantity $Y_{s}-Y^{\prime}$. A similar process can be conducted on the left side of the lens, where there may also be slight variations in the optimal model. The multiple correlation between the cues and the distal stimulus on the left side of the lens is represented by the expression $R_{e}$. The residual can be expressed as $Y_{e}-Y^{\prime}$. The direct correlation between the cues and object and cues and subject are represented by $\mathbf{r}_{\mathbf{a}}$. Conceptually this refers to the correlation between the distal stimulus and subject's judgment.

A comparison of the set of $Y_{s}$ and $Y^{\prime}$ can be made, the result designated by the letter G. This index is an evaluation of how well the subject's judgment corresponds to the actual situation, provided that the relationship is linear and additive (Ullman, \& Doherty, 1984, p. 179). Finally, the $\mathrm{C}$ index represents the correlation between the differences of the actual and predicted $Y_{e} s\left(Y_{e}-Y_{e}\right)$ and the actual and predicted $Y_{s} s\left(Y_{s}\right.$

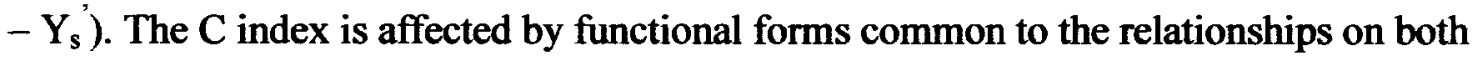
sides of the lens that are neither linear nor curvilinear and also by use of an appropriate cue on the part of the subject that has not been recognized by the optimal model (Ullman, \& Doherty, 1984, p. 180). In the following example, Hammond, Hursch, and Todd, (1964) include a calculation with the beta weights of the cues related to the object on the left side of the lens and the beta weights of the cues related to the individual's response on the right side of the lens. The equation for the entire model follows: $r_{a}=R_{e}{ }^{2}+R_{s}{ }^{2}$ sum $d / 2+C\left(1-R_{e}{ }^{2}\right)\left(1-R_{s}{ }^{2}\right)$. Sum $d$ refers to the sum of the products: $\left(r_{e i}-r_{s i}\right)\left(B_{e i}-B_{s i}\right)$ where $r_{e i}$ is the correlation between the proximal cue $e_{i}$ and the distal stimulus $r_{e i}$ and $r_{s i}$ represents the correlation between the cue $\mathrm{e}_{\mathrm{i}}$ and judgment; and where $\mathrm{B}_{\mathrm{ei}}$ is equal to the 
beta weight for the correlation between proximal cue and the distal stimulus and $\mathrm{B}_{\mathrm{si}}$ is equal to the beta weight of the correlation between the cue $\mathrm{i}_{\mathrm{i}}$ and the judgment (Hammond, Hursch, \& Todd, 1964, p. 440).

The lens model has been used to quantify medical decision making in a number of areas including diagnosis, treatment and prognosis. In medical decision making the left side of the lens captures the relationship of the cues to outcome, and the right side of the lens demonstrates use of the cues by the clinician to make decisions (Wigton, 1996). The model permits comparison among clinicians to examine variations in practice (Gillis, Lipkin, \& Moran, 1981). The method holds promise for improving decision making in situations where information is imperfect, to offer guidance in the correct weighting of cues (Wigton, 1996), to improve predictive ability to achieve specific outcomes and to maximize the utility of financial investment in medical care and testing (Diamond \& Forrester, 1979).

Gillis and Moran's (1981) study of psychotropic medication prescribing by sixteen physicians at a Veterans Administration Hospital for $\mathbf{4 0}$ hypothetical patients was conducted to look at exactly how physicians make drug choices and dosing decisions for their patients. The study, a triple system design, examined decisions about cue weighting, evaluated each patient profile and assessed agreement across the physician judges. Between the physician group and the prescribing literature available at the time of the study, a list of symptoms and factors commonly utilized for the purposes of prescribing treatment was compiled. The list included approximately 25 symptoms and additional factors as age, severity of symptoms, and symptoms of other psychiatric disorders. Each physician identified what appeared to be the most useful items and each was provided the 
opportunity of adding to the list. The eight most frequently appearing items were chosen by the investigators as the cues to be used in the study.

Each of the 16 judges was given 40 patient profiles that described the patients in terms of these eight symptoms. The judges were asked to prescribe primary medication at a recommended dose, or primary medication and supplementary medication(s) with recommended doses, no medication or electroconvulsive therapy (ECT). The profiles provided information about the presence or absence of a symptom and its severity. Symptom severity was presented on a 10 point scale, with higher numbers representative of greater severity of symptoms (Gillis \& Moran, 1981).

The analysis focused on the cues utilized by the physicians and an estimation of which of them were considered to be the most important. In addition, the authors evaluated the types of medications prescribed and examined the similarities and differences in decisions across judges. Once agreement or lack of agreement was determined, the reasons for agreement or lack of it were investigated. Most of the physicians prescribed drugs from the major tranquilizer class, although there were responses that supported the choices of ECT and no medication. The conclusion drawn after conducting pairwise comparisons among judges with results that ranged from .30 to .90 was that there was general agreement about prescribing drugs from the major tranquilizer class of drugs. The mean level of agreement across pairs of physicians with respect to drug class was .62 or $62 \%$. When it came to the prescription of specific medications for a patient, again, through examination of pairwise agreement it was found that the average obtained probability that any two judges would prescribe the same medication for a patient was .20. This finding was indicative of a low level of agreement, 
however it was significant. Doses expressed in milligrams were collapsed to three categories - low, medium and high doses. The average agreement with respect to specific medication and dose on pairwise comparison among judges was found to be significant at .12. When physicians agreed on a specific medication the mean probability that they agreed on dose level was .63, which was not significant (Gillis \& Moran, 1981).

The reasons why the judges did or did not agree with one another was traced to the proximal cues, or eight symptoms. The symptom severity corresponded to cue weighting in the lens model terminology. A regression analysis facilitated an assessment of the correlation between symptom severity or cue weights and the decision whether or not to prescribe medication. The presence of specific symptoms accounted for the variance in the decision to prescribe or not prescribe each medication. The authors cite the example of the positive association of Prolixin with the symptom of paranoia and chronicity. The researchers found that physicians prescribed specific medications based on specific symptoms, however the $\mathrm{R}^{2} \mathrm{~s}$ were low in terms of the variance explained by severity levels of symptoms (with the exception of the case of Lithium Carbonate). A great deal of variability was found with respect to the cue weighting decisions of individual judges. The salience of this finding is that high variability amongst judges is not sufficient to support the development of policies or guidelines to support decision making in clinical practice. The authors caution that this study is representative of work at an early stage in this kind of research (Gillis \& Moran, 1981).

Unlike Bayes theorem, the lens model belongs to the group II, or psychological theories. Since the lens model describes the actual decision making behavior of an individual, it is considered to be a descriptive, rather than a prescriptive theory. Bayes 
theorem has within it the implicit assumption that there is one correct decision to a question or problem, whereas the assumption inherent in SJT is that a decision is only as good as is the correlation between the distal stimulus and proximal cues in an optimal model. The distinction between the two approaches is clearly made by Hammond (cited in Doherty \& Kurz, 1996, pp. 122), where the author explains that the standard of success for researchers in heuristics or biases, or the prescriptive area of decision research where real performance is measured against an ideal, is coherence, whereas the standard of success for researchers in the area of logical reasoning, or the descriptive arena, is to determine how well an individual performs relative to actual environmental events, or correspondence.

Both Bayes theorem and the lens model support the presence of uncertainty and in the lens model it is inherent in the environment, in the relationship between the cues and distal stimulus and in the imperfect relationship between the cues, stimulus and judgment. Conditional probability is evident in both Bayes theorem and the lens model. In Bayes theorem it is related to the acquisition of new information whereas in the lens model it is related to the sequential nature of events that end in the judgment task. To summarize, the lens model provides researchers with a method of analyzing individual decisions.

Brunswik's model can be used to assess achievement of the individual, and the decision quality will be affected if the cues are not appropriate, if they are not weighted correctly, if the distal stimulus is not amenable to the measures used or if the cues are not relevant to the stimulus.

Brunswik was an advocate of research conducted under natural conditions and this would be consistent with studies of stimulant medication in children that are not 
conducted within randomized medication controlled trials (RCTs). RCTs are subject to the Hawthorne effect, as parents have an awareness that medication giving behavior is being monitored. The lens model involves regression analysis and is therefore suitable for examining a number of variables or cues (independent variables) that may result in parental decisions to continue or not to continue with medication treatment (dependent variable). Further research from a quantitatively oriented perspective might include medical record review and abstraction that would be amenable to the examination of decision making of individual parents or of decisions among a group of parents. Data analysis could explain whether the cues examined in the review are useful. Once this was accomplished an optimal model could be created utilizing an expert panel (or standard of care). The parental decisions with respect to continuing or not continuing medication could be examined and the two models compared. An overall assessment of the judgment of the parents could be calculated in terms of how close their judgment came to that of the physicians in discontinuing medication. Utilizing this model would permit researchers to gain more information about the manner in which parents weighted the cues.

\section{The Theory of Reasoned Action}

The theory of reasoned action (TRA) (1975) originated from Ajzen and Fishbein's interest in attitudes and their relationship to behavior (Ajzen \& Fishbein, 1980). The authors were interested in both understanding and predicting behavior. Research conducted in the 1950 s led to the development of this approach to decision making. The theory is limited, however, to investigation of the antecedents of intentional behavior only. TRA does not belong to the Group I or Group II theories described by Hammond et al. (1980), but has a context in general attitude theory (Herr, 1995). 
Similar to the way in which Brunswik shifted the focus of his work from perception to judgment, the focus of Fishbein and Azjen shifted from attitude theory and measurement to behavioral prediction. Practical uses of this theory included predicting voting and consumer behavior. Not only has the theory has become a useful tool for market research, it has served an important function in the health field for several purposes, including family planning and use of contraception and for examining the roles of physical activity and dieting in weight loss (Ajzen \& Fishbein, 1980).

Attitude, belief and intent are three concepts essential for an understanding of the theory. Beliefs form the basis of attitudes, and attitudes form the basis for intent to perform a certain behavior. Fishbein and Ajzen $(1975$, p. 12) define belief as the information one has regarding an object and links the object with an attribute. The relative strength of a belief can be measured utilizing subjective probability when the object/attribute linkage has been made (Fishbein \& Ajzen, 1975, p. 58).

Two types of beliefs are explicated in the theory. The first refers to behavioral beliefs, or those about a particular consequence of behavior. A person who believes that engaging in a certain behavior will have a positive outcome will be more inclined to engage in the behavior. The converse also applies where if there is a belief that the behavior is likely to produce a negative outcome, an individual is less likely to perform the behavior. The belief is related to an evaluation of the outcome of the behavior. The second type of belief is a normative belief, or one where a person holds a belief about whether the significant others in his life think he should or should not perform the behavior. To summarize, behavioral and normative beliefs affect attitude toward the behavior and the subjective norm. 
Two factors are determinants of intent. The first factor, attitude, is defined as "a learned predisposition to respond in a consistently favorable or unfavorable manner with respect to a given object" Fishbein and Ajzen $(1975$, p. 6). As can be seen, attitude corresponds to the individual and is evaluative in nature. The second factor is the subjective norm, or social factor. This refers to the individual's perception of the pressure exerted by significant others to either perform, or not perform the behavior. Two areas of "subjective norm" are assessed. The first (normative beliefs) refers to how the individual perceives the significant others support for engaging in the behavior. The second, motivation to comply, permits quantification of the pressure (relative weights) placed on an individual by various referents. This allows investigators to note the identity of significant others to the parent or individual engaging in the behavior. These two factors are the immediate determinants of intent. External variables as demographic factors are thought to have only an indirect influence on intention and behavior (Ajzen \& Fishbein, 1980).

Intent to perform a behavior is viewed as a type of belief of the individual in the role of object and behavior in the role of attribute. A measure of subjective probability will give an estimation of the likelihood that a certain behavior will be carried out. Four other aspects of behavior that are also considered in the theory of reasoned action include action, context, target and time. All four are relevant in that they refer to in individual event or multiple events and measurement is contingent on the specific case being investigated. There must be correspondence between the four for the theory to be able to correctly predict behavior. Finally, the behavior being considered is assumed to be the object of research (Fishbein \& Ajzen, 1975). There is a theoretical assumption that 
people act rationally and use information to make thoughtful decisions about a course of action.

Austin (1989) conducted a study to test TRA to predict pediatric anticonvulsant medication adherence (or the intent to continue giving medication) in a convenience sample of 29 parents whose children had seizure disorders. The children ranged in age from 6 to 14, and $85 \%$ had a history of generalized seizures. Parents had been giving anticonvulsant medication for an average of approximately four years. The author referred to a review (Christensen, cited in Austin, 1989) where it was estimated that approximately $25-50 \%$ of patients do not take medication as prescribed. A number of barriers to continuing treatment with anticonvulsants were described.

Attitude toward the behavior was identified as how much the parent liked or disliked giving the medication. Subjective norm was assessed as the perception of pressure from others to give or not give the medication. The study attempted to answer three questions. The first was whether attitude and subjective norm predicted behavioral intention to give the medication. The second was whether behavioral intent predicted medication giving behavior and the third was whether attitude toward the behavior and subjective norm were better at predicting parental medication giving behavior than was predicting behavior from behavioral intent alone.

The behavior or object of study was medication giving behavior. This was measured with the use of a six item self-report questionnaire designed by the author and assessed for internal consistency reliability and content validity. Internal consistency reliability of the instrument was reported to be 0.70 using Cronbach's alpha and there was support for content validity of the instrument as it had been evaluated by experienced 
clinicians from multiple disciplines. Content validity was established by two doctorally prepared nurses (Austin, 1989).

The questionnaire addressed items that included ensuring that the child actually took the medicine, reference to dose assessment, and attendance at appointments. Behavioral intent was measured by asking whether the parent intended to give the medication on a regular basis and asked the parent to indicate the level of agreement with the statement. Attitude toward the behavior was elicited with a positive statement regarding control of seizures and a related scale that gauged how certain the parent was that the medication was effective (subjective probability). Subjective norm had two measures, the first of which was an acknowledgement that referents thought that it was important to give the medication (agreement with a written statement), and an assessment of the level of influence of the referents on the behavior of the parent (how likely it was that the individual would perform the behavior based on input from family). Austin (1989) reported utilizing Fishbein's Expectancy-Value Model to quantify measures of attitude (multiplying the evaluation of each belief by its weight or subjective probability and then summing the results). A multiple regression and hierarchical regression were conducted.

Study findings indicated parents reported that they "usually" gave their children medication as it was ordered by the physician (behavior). Attitude toward giving medication was slightly positive and strengths associated with the medication on the belief scale (weighting) varied with the highest positive relationship of .86 related to the ability of the medication to control seizures. Even though the participants' subjective 
norm (based on family and physician) was positive, intent to comply with family members was neutral but parents were very likely to comply with the physician's input.

A multiple regression was conducted to examine the relationship between the independent variables attitude and subjective norm and behavioral intent as the dependent variable. The regression yielded an $R$ of $0.62(p<0.01)$, indicative of a significant relationship between the two with subjective norm $($ beta $=0.58)$ accounting for more of the variance on the dependent variable than attitude (beta $=0.37$ ). Attitude and subjective norm are predictive of behavioral intent.

The answer to the third question, or whether attitude and subjective norm were better at predicting behavior than behavioral intent alone, was obtained through the use of hierarchical regression. Behavioral intent was the first variable entered as the theory posited that this is the immediate antecedent to the behavior (Ajzen \& Fishbein, 1980), after which attitude toward the behavior and subjective norm were entered. The relationship between intent and medication giving behavior was $r=.44$, and was significant at the level of $\mathrm{p}=0.016$ and between attitude and subjective norm and the behavior $R=.62$. When attitude and subjective norm were regressed separately with behavior, the relationship between attitude and behavior was 0.44 which was significant at the level of $p=0.016$ and between subjective norm and behavior was 0.36 which was not significant $p=0.57$. Attitude was able to explain a significant amount of variance beyond intent; however subjective norm did not explain more of the variance on the dependent variable.

Theoretically TRA is designed to both understand and predict behavior and Austin (1989) utilized the study to discover areas of misinformation for possible nursing 
interventions. Parental referents can be identified to ensure that linkage between the health care team and parents is strong enough to ensure good patient care and that the referents have the correct information. Overall, the theory was useful in being able to predict medication giving behavior.

Although Fishbein \& Azjen's research interests were in the areas of both understanding and being able to predict behavior, the focus of the TRA is behavioral prediction. The TRA has both descriptive and prescriptive elements but overall can be categorized as a descriptive decision making theory. There is an informational aspect to the theory. Where Bayes theorem considers decision revision based on the addition of new information and correct use of the lens model is contingent upon the ability of one to correctly identify proximal cues to match the distal stimulus, the TRA indirectly assesses information quantity and quality in terms of beliefs that are based on correct and sufficient information and its use in decision making. A correct belief is one where there is good correspondence between the object and attribute (Fishbein and Ajzen, 1975, p. 12).

Since little is known about the trajectory of stimulant medication use in children with ADHD, the TRA approach may be especially helpful to understanding medication giving behavior. Assessment of the subjective norm is of interest due to the extensive involvement of the teacher and school in the life of the latency age child. In addition, it would assist clinicians to better understand the parents weighting of the influence of the physician, the teacher. The results of a study of this kind should there be a program of quantitative research conducted in the future may be useful to the development of appropriate nursing interventions. 
Decision making under uncertainty is common to all three theories. In TRA uncertainty is present in belief strength and also in the realm of attitude and subjective norm. Individuals differ in the manner they assign weights to attitude and subjective norm. Some would consider attitude to be more important in their decision to engage in a behavior while others would consider the opinions of others to be more important to decision making. In conclusion, Bayes theorem is utilized when the goal is to obtain the best decision, the lens model encourages the improvement of decision making through better correspondence between the proximal cues and distal stimulus measured against a good decision making model and the TRA can be utilized to examine the process of decision making with the objective of improving it through education or by other means.

Any one of these models may provide valuable information with which to continue to study the factors related to whether parents continue or do not continue treatment with medication. In addition, should a quantitative approach to future research be utilized, it would be quite possible to integrate Bayes theorem with the lens model by conducting a longitudinal study where an intervention is conducted after the initial lens model calculation. The improvement (or lack of) in judgment could be measured by comparing the initial lens model correlation to the correlation obtained after the intervention. A quantitative study would be integral to the discovery of cues relevant to continuation or discontinuation of medication treatment.

Medical information is never perfect. Health care professionals, parents and caretakers are going to make decisions about whether or not to continue stimulant medication treatment in children with imperfect information. Parents do not make decisions to discontinue medication in the same manner as do physicians and advanced 
practice nurses, and since parental decisions appear to be made for different reasons, their decision making process merits investigation.

\section{Qualitative Theoretical Approaches}

The parental decision making process in the health care of children is multifaceted and can be examined qualitatively from a variety of perspectives. Two such perspectives include feminist theory and critical theory, both of which represent distinct groups of theories that have undergone change over time (Campbell \& Bunting, 1991). These two theoretical approaches are similar in that they share assumptions about the existence of social inequality, however they differ with respect to the sources of inequality. Inequality is due to gender in the feminist perspective but is related to more general social relations in the eyes of the critical theorist. Feminist theory may be subsumed under the rubric of critical theory as "critical feminist theory" since both have a common goal of emancipation from oppression.

Feminist Theory

Kolmar and Bartkowski (2005) describe feminist theory as a "body of writing that attempts to describe, explain, and analyze the condition of women's lives" (p. 2). The authors describe six different historical periods of feminist theory extending from 1792 through 2002. Within that time period several different approaches to feminist thought have emerged, all of which begin with assumptions of inequality due to gender. Examples of these different approaches include liberal feminism, Marxist feminism, cultural feminism, Black feminism, Lesbian feminism, materialist feminism, radical feminism, socialist feminism, poststructural feminism and academic feminism. (Andermahr, Lovell, \& Wolkowitz, 2000). 
Carol Gilligan, a contemporary feminist theorist who's widely read book "In a Different Voice" (1982) presented empirical research illustrating a difference between male and female approaches to moral reasoning, developed a feminist theoretical approach to this topic. Unlike Kohlberg's theory of moral reasoning which was illustrative of the way in which men think and which was based on justice and an appeal to rights, Gilligan's theory was based on a concept of care. Kohlberg's theory offers solutions to a moral dilemma through a rules based approach, whereas Gilligan suggests that solutions can be found with an understanding of the connections that individuals have with one another and with an ethic, or responsibility of care for others (Gilligan, 1982). Gilligan concluded that in the past only a male voice was granted standing, and as a result theoretical knowledge developed consistent with a male perspective (Gilligan, 1982, p. 173).

The findings of Gilligan's study of 29 women from diverse ethnic backgrounds faced with a decision whether or not to have an abortion, showed that gender impacts thoughts about social relations. Men and women seemed to use the same words, but the referents of the words had different subjective and socially contextual meanings (Gilligan, 1982, p. 173). Gilligan's work gave "standing" to women in terms of participation in empirical research. It also gave the impression that women and men think differently about solutions to moral problems. Further empirical studies utilizing Kohlberg's theory failed to find such clear divisions based on gender (Saul, 2003).

According to Gilligan, and based on the psychoanalytic work of Chodorow (1978) gender differences between males and females are established in early connections with others. This notion is based in the assumption that for the first few years, the essential 
human relationship is that between the child and mother. Whereas girls develop a close attachment with mothers and are adverse to separation, boys do not share this kind of attachment with either a mother or father. Instead, boys progress through a separation process from mother (Chodorow, 1978). Mothers “produce daughters with mothering capabilities and the desire to mother" and sons who are prepared for "primary participation in the impersonal extrafamilial world of work and public life" (Chodorow, 1978, p. 7). Men represented the family in the community and society and the class of the family was based on the occupation of the husband (Chodorow, 1978, p. 178). This public/private social distinction resembles that described by both Arent (1958) and Habermas (Pusey, 1987).

Generally speaking, ideas about the roles of women in society, the workplace and family are much the same now as they were in the mid twentieth century despite extensive social change that has taken place. Immigration, rapid, extensive technological change, urbanization, globalization and worldwide political instability have changed family life in the Western world. In some families today, infants make a direct transition from hospital to daycare. Infants may not be cared for by a biological mother in the home setting. International adoptions, many of which have restrictions on the maximum number of years permissible between the age of the infant and adoptive parent, are commonplace. The first few years in the life of a child who has been adopted from a foreign country have likely been spent in an orphanage being cared for by male and female paid caretakers. Infants may not be the natural offspring of one, or perhaps both of its parents as use of surrogates and in vitro fertilization increases. Many children in the contemporary family are cared for by grandparents or other relatives. Some may even 
have parents or step parents who reside in different households. Many children themselves will live in more than one household simultaneously in instances where custody is shared. The "traditional" nuclear family with two biological parents and their natural children living in the home is disappearing. The nuclear family has become the anomaly rather than the norm. As a result, it is questionable whether 'mothering' "stands out in its emotional intensity and meaning, and it's centrality for women's lives and social definition" (Chodorow, 1978, p. 6). Any theory whose assumptions are based in roles that have changed significantly over the years must be reviewed and re-tested and possibly revised. Regardless, Chodorow states that even though women have entered the workforce, when they are home, they still have nearly total responsibility for the children (Chodorow, 1978). This statement may be true today, however the basis for its truth is in question.

A recognized contradiction with respect to the assumptions of various feminist schools of thought exists and has been articulated by White and Klein (2002) in their book, Family Theories. The authors point to the problem of perspective in feminist theory. The assumption that women's experience is a shared experience is in direct conflict with the recognition of each woman's experience as being unique. Unfortunately, there is no easy solution to this problem.

\section{Critical Theory}

Social theory has been concerned with the analysis and explanation of social structures and processes. It differs from sociological theory in that it is interdisciplinary. Critical theory constitutes a comprehensive, intellectual approach to social theory, one in which ideological and cultural issues are researched, analyzed and critiqued with the 
objective of changing them (Miller, Coleman, Connolly, \& Ryan, 1987). Contemporary critical theory developed from the work of scholars as Max Horkheimer, Theodor Adorno and Herbert Marcuse at the Frankfurt Institute for Social Research (the Frankfurt School) during the 1930s and was revised by Jurgen Habermas forty years later (Seidman, 1989). Throughout the twentieth century, the threads of assumptions of the presence of inequality in power relations were woven into social theory.

In Marxist thought inequality is considered to be due to a fixed, structural, exploitative economic situation. Two classes coexist in a capitalist system, a ruling class based on economic superiority derived from ownership of the means of production and a working, or proletariat class. Social change in Marxist thought is produced by a change in economic structure and is described by the term "historic materialism". This term refers to the manner in which the forces of production (tools) and relations of production (labor) are utilized and this, according to Marxist thought, is what determines the prevailing cultural and political climate (Miller, et al., 1987). Revolutionary activity is the way in which the proletariat overcomes class based oppression and achieves emancipation. Marxist analysis infers a structuralist functional view of society where social relations are created externally, in the political economy.

Habermas' contributions to critical theory and the development of knowledge represent a more optimistic view of society and take a broader, more complex approach to the structure of society and social relations. Habermas saw social change as possible with (rational) communication and cooperation toward reaching commonly agreed upon goals (Habermas, 1990). Social change is created though the process of communication (communicative action) and is critical in the sense that social relations are not fixed but 
are subject to change through public, rational discussion (Crossley, 2005). Language and hermeneutics are important to the development of science and are integral components of critical theory in the work of Habermas (1990). Regardless of the type of feminist or critical theory under consideration, inequality has its ultimate roots in power and power relations.

\section{Power in Social Theory}

Multiple attempts to define the term power have been made by scholars from the disciplines of political science, economics and sociology and despite a long history of research, there is no single, generally agreed upon definition of the term. Power is difficult to measure and operationalize. The literature commonly refers to two uses of the concept, "power over" and "power to". Wartenberg (1990) summarizes various schools of thought about the two terms in saying that both are frequently seen in social theory, and that power over is relational and relevant to a discussion of inequality, whereas power to refers to the ability to get things done. Power to is synonymous with transformational power and is positively oriented aspect of power associated with feminist theory (Wartenberg, 1990).

Steven Lukes (1974) describes three dimensions of power over (involving decision making and non decision making) that illustrate the complexity of the term. Dahl's (1957) relational definition of power constitutes the one dimension case, where "A has power over B to the extent that he can get B to do something that B would not otherwise do" (p. 203). This view of power as a causal relation exists in decision making situations where the exercise of power is observable. Although Dahl's definition is consistent with power over, the author recognizes a subset of power that includes the 
distinction between the actual exercise of power and potential power (that which is held by an individual or group but which is not necessarily exercised) (Dahl, in Lukes, 1986). Dahl's ideas about studies of power add complexity to the task as the theorist thinks that every analysis of power should take into consideration information about the magnitude or amount of power, its distribution, scope, domain, resources, skill in use, motivations and costs.

Bachrach and Baratz offer an alternative, two dimensional view of power. Their description incorporates Dahl's one dimension case and adds the case when A exercises power to the extent where A "devotes his energies to creating or reinforcing social and political values and institutional practices that limit the scope of the political process to public consideration of only those issues which are comparatively innocuous to $A$ " (Bachrach \& Baratz, in Bell, Edwards, \& Wagner, 1969, pp. 95). In instances where this situation occurs, B is prevented from raising any issues and as a result, A's interests are maintained, possibly at the expense of the interests of $B$. The one dimensional view of power involves decision making whereas the two dimensional view, includes decision making and non decision making. In the latter case the possible expression of dissent on the part of B can be kept covert by A's purposefully preventing a particular issue from being raised or by not granting a problem "issue" status. In this case no decision needs to be made. (Bachrach \& Baratz, in Bell, et al., 1969, p. 109). According to Lukes (1974, p. 17), Bachrach and Baratz acknowledge the ability of a group with vested interests to gain and maintain control for the purposes of pursuing their own interests at the expense of those of others. 
Lukes' first two dimensions of power describe situations where conflict is present. The author's description of the third dimension of power downplays the predominance of the behavioral aspects of the first two dimensions by extending the definition to a third case, where conflict is absent. In the third case, the power relationship of A to B is one of "shaping their perceptions, cognitions and preferences in such a way that they accept their role in the existing order of things" (Lukes, 1974, p. 24). A's interests are opposed to B's real interests; however B either does not express its interests or is not cognizant of them. Lukes refers to this as "latent conflict" (Lukes, 1974, p. 24), and in this particular view of power it is assumed that there would be conflict if B was aware of their interests or in the event $\mathrm{B}$ was prepared to act upon its interests. This view is a second case of non decision making.

The three dimensional view of power incorporates a variety of meanings and aspects of power that would not necessarily meet definitional criteria of the term for some scholars. Power is an elusive concept. Dahl explicitly recognizes the problems in studying power by saying that in the near future it is not likely that a comprehensive theory of power will be developed. Instead, power research is more apt to produce a number of mid range theories that are more limited in scope but useful to specific research studies (Dahl, 1957, p. 202).

In every discussion of power there are a number of things to consider. Wartenberg $(1990$, p. 5) notes that there is a connection between power to and power over, but does not offer an explanation of this statement. In any case, for the purposes of an analysis of power, some situations are better examples of power to and some of power over. Whether power is legitimate is often a concern, as illegitimate power may, by definition, may 
more closely resemble the coercion or domination. Other considerations and questions that affect discussions of power include who it is that possesses the power, how much power is held, the locus of the power, the location where it will be exercised, whether it is potential or actual power, whether it is contextual or temporal in nature, whether it is held by an individual or group, whether it is overt or covert and whether it is being used in the pursuit of the interests of the power holder(s) or for another person or group. Additional questions about power include whether it is finite or not, and if finite, whether the possession of power means one party has all and the other none, or whether different power holders have some, but not all the power.

Many definitions of power have been articulated. Bertrand Russell's definition of power, "the production of intended effects" (1975, in Lukes, 1986, p. 19) describes power quantitatively in the sense that one is able to achieve the intended effects as one party has more power than does the other. Max Weber ascribes a relational quality to power and describes a special case, “domination", where one individual imposes his will on another (1978, in Lukes, 1986, p. 29). Talcott Parsons has described power as "the means of acquiring control of the factors in effectiveness" (1963, in Lukes, 1986, p. 98). According to Parsons, power is a medium, analogous to money that operates in different subsystems of society to achieve collective goals (Parsons, 1963, in Lukes, 1986).

Hannah Arent took Parson's definition of power one step further by incorporating notions that power is couched in communicative action used to achieve collective goals through a consensus (Arent, 1977, in Lukes, 1986, p. 77). Unlike Parsons description of power, where it was seen a means to an end, Arent viewed power as an end in and of itself. To Arent, power belonged to the group. The social realm was divided up into the 
private and public spheres, where the private sphere is represented by home and labor and the public realm, where work as communicative action and the production of power takes place (Arent, 1958). The author's distinction between public and private realms has led to some discussion, since it follows that if women are participants in the private sphere of things, they are excluded from the political process. A full discussion of the relevance of Arent's work to feminist theory has been summarized by Allen (1999).

Michel Foucault's ideas about power blend historicism and phenomenology. Phenomenology seeks to "heighten critical awareness and deepen reflective thoughtfulness about what is important in the taken-for-granted and seemingly trivial aspects of everyday life" (Powers \& Knapp, 1995, p.123). Foucault has made the not so evident, evident, in a novel, interpretive re-creation of history that seeks to describe and explain power relations in terms of domination and subordination. To Foucault, discourse, or truth produces power and the power that has been created is, in turn, exercised throughout society (Foucault, 1976 in Lukes, 1986, p. 230).

Power is ubiquitious and always present (Foucault, 1978). It is just 'out there'. It is circular, temporal, contextual, historically relativistic, and produced by those who are later subjected to it. It is neither positive nor does it have a pejorative connotation. Instead, power possesses a more neutral quality, since it simply produces truth. It is almost as if the two terms, power and truth are synonymous. Power also produces knowledge (Foucault, 1977, p. 27) and is central to the social system in its exercise (Foucault, 1977, p. 26) rather than in its possession. Power and knowledge "directly imply one another" (Foucault, 1977, p. 27). 
In a Foucauldian analysis an individual is important as a focal point only in certain contexts. The individual who is produced and marginalized or punished as a result of the exercise of power becomes visible or identifiable. Examples of this kind of individual include the prisoner or psychiatric patient. The majority of individuals in society however, just seem to blend into the social system, as if their very existence renders them invisible. Their reality is structured through discourse, culture and history. And to Foucault, history is often not what it seems to be.

According to Foucault, history was once based in sovereignty and the law, but it is now based in discourse that creates power relations of domination. While discourse usually refers to language, in the Foucauldian notion of power it refers to everyday conduct or practices that place certain topics as central to relations of power. We are who we create ourselves to be and we create that which ultimately dominates us.

One area central to Foucault's analysis involved sex. Historically speaking, sex was supposed to be censored, repressed and denied. Legal mechanisms exist for the purposes of sublimating and extinguishing a variety of sexual expressions. Foucault's historical examination of sex in the West has revealed that just the opposite is true. Sex has been the subject of discourse of people from every walk of life. It is discussed in terms of the need for population control, its medicalization and its deployment for pleasure and perversion. There is a multiplicity of discourses or perspectives related to every imaginable aspect of sex. Sex is controlled by power, and is scrutinized, monitored and subjected to intensive analysis and description. It has an extensive vocabulary and language associated with it. Sex is important economically, politically and socially, and assumes the focus of many modern practices and institutions (legitimate or otherwise) as 
psychiatry, prostitution, and pornography. Foucault points out that the entirety of sexual discourse, practices and structures are enmeshed (Foucault, 1978, p. 48).

It is not surprising that feminist theory has looked to Foucault for the grounding of feminist questions. According to Foucault, desexualization of feminist questions has provided the best avenue for the advancement of women (Foucault, 1990, p. 220, in Phelan, 2001). The power relations that currently exist render feminist discourse within a context of sexuality insufficient to be able to shift the existing structures of domination in a significant way. A Foucauldian analysis of feminism in terms of sex or gender is pessimistic at best, as according to Foucault, it is "historical conditions which make various types of quite specific and differentiated subjects possible in the first place" (McHoul, \& Grace, 1993, p. 91).

Studies focusing on a better understanding of decision making about medical treatment will assist in the discovery of information about the existence of health disparities and associated inequalities that have historically led to poor health outcomes. Flaskerud (2002) indicates that few nursing studies have focused on identifying the reasons why some groups experience poorer health than do others. The author posits that variables as income, social and political power, education and access to health care may significantly impact the health status of an individual. These variables may be gender related or related to other social structures or processes.

Perhaps it is time to shift the focus from an emphasis on an analysis of "who" the participants are to a broader, more Foucauldian emphasis on exactly "what" is occurring and "how" certain practices occur. 


\section{Chapter Three \\ Methodology}

The purpose of this study was to describe parental decision making associated with stimulant medication treatment for children with ADHD. This chapter includes a description of the qualitative methodology utilizing a grounded theory approach, a discussion of the issues of bias and rigor in qualitative research, a description of the sample and sampling process and information relevant to data collection, analysis and procedures for the protection of human subjects including informed consent.

Qualitative Research

Glaser and Strauss (1967) suggest that good qualitative research should satisfy four criteria, fit, understanding, generality and control. First, fit refers to the applicability of the categories to the data. When the categories are a good fit to the data, there is a high level of relevance to the phenomenon under study. Second, the ability of the theory to be consistent with the understanding of participants in the research, researchers and clinicians working in the area of concern is essential. Third, the theory must be generalizable to the situations where it will be applied, even though the substantive theory anticipated to be produced will have limited generalizability. Finally, the theory should provide some control over variables that may be modified to produce change in a given situation. 


\section{Use of the Literature}

The differences between quantitative and qualitative approaches to research are substantive. Quantitative research, for example, when used to test existing theory, can be described as a venture into the known, whereas qualitative research is a journey into the unknown. In quantitative research it is common to work with existing theory, however the work of qualitative research involves theory building. It is naïve to think that qualitative researchers are not, at the very least, somewhat familiar with the literature in a particular area. The qualitative researcher does not begin with a "tabula rasa" but in most cases comes to the data with some knowledge of a phenomenon. There are both advantages and disadvantages to the possession of prior knowledge.

Extant research may have sparked an interest in the phenomenon to be studied. In some cases research may be conducted to answer questions that have not been addressed or not adequately addressed in the technical literature. Qualitative research has the ability to add something to existing theory or to use portions of an existing theory to augment a qualitative theory when appropriate (Strauss \& Corbin, 1990), however the ability of a researcher to be successful at this endeavor is contingent upon the development of this knowledge through a rigorous, systematic process of inductive inquiry. Previous research is also useful for developing theoretical sensitivity, or the ability of a researcher to theoretically intuit terms and themes as they emerge from the data (Glaser \& Strauss, 1967; Strauss \& Corbin, 1990). Theoretical sensitivity is developed over time, is related to the personal qualities of the researcher and improves with experience (Glaser \& Strauss, 1967). Strauss and Corbin (1990) indicate that the literature can identify the need to adopt a new approach toward an old problem and since quantitative research has not 
provided very much information about the decisions made by parents, perhaps a qualitative approach is needed. Every phenomenon seems to have a language of its own, and after the completion of a qualitative study the researcher may go back to the technical literature and use it to validate the findings (Strauss \& Corbin, 1990). Prior knowledge is not to be used to frame a study and should be consciously suspended from use, or "bracketed" during the research process. (Meadows \& Morse in Morse, Swanson, \& Kuzel, 2001, p. 192).

The three quantitative theories presented in Chapter Two described different aspects of decision making. In the first example, Bayes theorem, or the process of decision revision according to the acquisition of new information was described. In an example of the application of the theory it was shown that the administration of certain tests has the potential to improve diagnostic decision making. In the second model, Brunswik's lens model, decision makers use certain cues in the process of exercising judgment with respect to a decision problem. The focus of this model is perception and judgment of the decision maker. The third theory, the theory of reasoned action, incorporates a sequential evaluation of attitudinal variables and intent in the decision to perform a particular behavior. Although the three models or theories discuss various aspects of decision making, it is unclear whether or not any of them have something to do with continuing or discontinuing stimulant medication in children with ADHD. The qualitative methodology allows for further elaboration and clarification of why parents continue or discontinue their children's prescribed ADHD medication.

Grounded theory as a qualitative methodology is one way researchers may approach addressing research questions that begin with the question "why". Since this 
approach to research involves actually going to the parents to obtain firsthand information about how they construct their social realities, theory derived from actual experiences can be constructed. Once inductively derived theory has been established, it can be compared with existing theory for the purposes of validation, for extending existing theory (Strauss \& Corbin, 1990).

\section{Controlling for Bias and Establishing Rigor in Qualitative Research}

It is impossible to conduct value free, unbiased research (Denzin \& Lincoln, 1998). It is up to the researcher therefore to clearly identify both the assumptions of the researcher and the contextual or philosophical framework of the study before the study begins (Denzin \& Lincoln, 1998; Gillis \& Jackson, 2002). Despite longstanding and significant problems associated with the assessment of adherence with medication that limit accurate assessment of treatment efficacy, it is generally accepted in the medical community that stimulant treatment of school age children with ADHD is highly effective. In this study the perspective of the nurse researcher is consistent with the prevailing perspective.

The grounded theory method (Glaser \& Strauss, 1967) originated within the discipline of sociology and adopted the perspective of the theory of symbolic interactionism (Blumer, 1969). According to the theory, an individual's relationship with society is developed through the process of symbolic communication, and it is in this manner individuals create their own social reality (Powers \& Knapp, 1995, p. 167). The task of social interactionists is to build process oriented theory about social worlds (Strauss, 1978 in Strauss, 1991). The theory is process oriented and it is the assumption of the researcher that social relations have both process and structural orientations. 
The researcher is inextricably linked with the study and the participants. Reflexivity, defined by Gillis and Jackson (2002, p. 285) is the ability of the researcher to critically examine the effects the researcher may have on the data. This goes a step beyond making explicit the assumptions and perspective of the researcher.

A "biased" sample is potentially problematic in qualitative studies. Random sampling consistent with quantitative studies is not the norm in a qualitative approach where substantive theory is developed to be applicable to a specific population in a particular context. Despite the fact that the study sample is intended to be fairly narrow, the purposive sample should be as wide as possible, to include the broadest representation of children. If the age range at the initiation of treatment is 7 to 12 years, for example, there should be some younger and some older children represented in the sample. Similarly, different ethnic groups should be represented, as should parents of both boys and girls. The parents themselves should be as diverse a group as possible. Powers and Knapp (1995, p. 13) indicate that the deliberate choice of a broad sample of participants offers the advantage of obtaining the "broadest" point of view.

A third way in which bias is controlled is through attempts to gather accurate information from respondents, for example, by tape recording and transcribing interviews verbatim. Accurate information is, on occasion, validated by checking back with a few participants to verify that the researcher has correctly understood and interpreted what has been presented during the interview (Isaac \& Michael, 1995). In addition to controlling for bias, this activity serves as a way of establishing rigor in a study. Some studies assess validation of a respondent's narrative by making follow up telephone calls to the participants. The ability to re contact parents after the study is complete to verify 
the accuracy of information would be addressed in the informed consent. The design of this study did not include a second contact with parents.

Piloting the interview questions with a colleague or a parent is one way in which to discover specific problems with questions or the manner in which they are worded or presented. In addition to potentially identifying sources of bias in a question, piloting the questions is a good way to test them (Denzin \& Lincoln, 1998) or introduce them in a different, more productive sequence. When non directed questions are asked there is less opportunity for the researcher to introduce bias and more opportunity to obtain information that reflects the views of the participants (Hammersley \& Atkinson, 1995). Gillis and Jackson (2002) describe random and systematic errors as sources of bias, but attention to ensuring that a rigorous, systematic approach to data gathering and analysis can ensure rigor in the study as well as control for bias. Random error in a qualitative study might include the odd error in coding whereas a systematic error would be making a coding error that appears consistently throughout the study. Needless to say, the systematic error threatens the integrity of the entire study.

Rigor in a qualitative study is established in several ways. As previously stated, it is important to obtain the broadest possible sample within the population of interest to obtain a rich collection of data. Unlike quantitative research where the sample size is established a priori, in qualitative research the sampling continues until the amount of data collected is sufficient to reach saturation (Denzin \& Lincoln, 1998).

The technique of constant comparison or coding data for a category and comparing it with other data to look at similarities and differences (Glaser \& Strauss, 1967, p. 106) is one method used as a check on validity. Glaser and Strauss (1967) 
advocate concurrent coding and analysis. This technique is just one way in which a study can be checked for validity methodologically. Denzin and Lincoln (2000) raise the issue of the difficulty of assessing validity of interpretation, a much more difficult task to accomplish. Since the researcher approaches the research with various assumptions and a view of the way in which the world works, it is conceivable that the interpretation of a study will differ with the researcher. Unfortunately, there is no simple answer to this problem. While the authors offer some criteria with which to evaluate interpretation in a study depending on the type of approach that has been taken, interpretation merits care even if solely from an ethical standpoint (Denzin \& Lincoln, 2000). The outcome of this research has the potential to impact patients by influencing decisions about medical treatment.

Reliability can be described in two ways. Statistically speaking, reliability refers to consistency with repeated measurements (Powers \& Knapp, 1995). It is difficult to assess reliability in qualitative research due to the contextual nature of this approach (Gillis \& Jackson, 2002). In fact, some sources use more general terms as "methodological rigor" or "credibility" to describe issues related to ensuring a high standard of qualitative research (Glaser \& Strauss, 1967; Maggs-Rapport, 2001).

Creating a clear, concise audit trail is a way of ensuring a rigorous study. Rodgers and Cowles (1993) provide a useful guide that can assist the novice researcher make every step of the process explicit. The guidelines cover the importance of keeping every step in the study explicit, with an audit trail that includes interviews and field notes; the concurrent methodological and analytical documentation (constant comparison) including decisions made by the researcher, strategies used in the approach to the data, any changes 
in interview questions that are made as core variables are obtained; notes relevant to analysis of the data as categories become apparent; and a diary of the personal thoughts and feelings of the researcher during the process of analysis. It is essential to be able to visualize and retrace every step in the construction of the theory. In a qualitative approach the responsibility for minimizing the potential for bias and ensuring rigor in research falls on the investigator. Unlike quantitative research where particular areas are prone to problems with validity, reliability and bias, qualitative research demands constant vigilance for problems from beginning to end.

\section{Dimensional Analysis and Grounded Theory}

Over the years grounded theory has been the subject of debate and scrutiny not only in terms of whether it produces "good science, but also for the difficulty with mastering the techniques of the approach. Since its introduction by Glaser and Strauss (1967), grounded theory has undergone some modifications, one of which will be utilized for the proposed study.

Schatzman's (1991) Dimensional Analysis is an alternative approach to grounding theory in qualitative work. It was developed to make explicit the structural linkage between analysis and interpretation and improve the ability of students to conduct grounded theory research by creating an analytic structure to be used as a guide (Kools, McCarthy, Durham, \& Robrecht, 1996). Schatzman mentored doctoral students in nursing at the University of California at San Francisco (UCSF) and several students whose dissertations were anchored in the methodology of dimensional analysis have documented the process and its ideological and theoretical underpinnings (Kools et al., 1996). 
Dimensional analysis has its origins in both the theory of symbolic interactionism and the theory of natural analysis. The theory of natural analysis draws on the cognitive ability of the individual to be able to "interpret and understand problematic experiences or phenomena" (Kools, et al., 1996, p. 314) and on previous experience with analyzing social phenomena to solve problems by providing a structure to problem solving, or organizing thinking into "dimensions". The capacity for natural analysis develops over time through living a social life, and the structure used by individuals to solve everyday problems can be superimposed on a research problem. Schatzman (1991) assumed that individuals learn analytically, use what they already know, and if what is seen is not recognizable, it is made recognizable by placing it into the realm of that which is already known. Dimensionalizing, or an analytic activity similar to coding (Schatzman, 1991) is sensitive to the interaction of the researcher with the data. It seeks to answer the question posed by Schatzman (1991, p. 310), to describe and explain "What all is involved here?"

Dimensional analysis has the capacity to capture the essence of a phenomenon, but the luxury of increasing methodological structure may come at the expense of some loss of theoretical sensitivity. The benefits of this method include the definitional clarity of concepts comprising the matrix and the ability of the method to identify the overall perspective of the participants. The rather linear process may be seen as either a cost or benefit, depending on the perspective of the researcher.

A synopsis of the technique of dimensional analysis is provided below (Kools et al, 1996: Schatzman, 1991). Data is coded (designated) for identification purposes into dimensions, or attributes, abstract representations of something tangible. Each object possesses a cluster of dimensions. Glaser and Strauss $(1967$, p. 102) advocate concurrent 
coding and theoretical analysis in their discussion of data transformation, however Schatzman's (1991) view on this subject differs. Constant comparison in dimensional analysis takes place initially to identify dimensions and subdimensions; however data is not placed into the explanatory matrix until a sufficient amount has been collected to locate the central dimension. The amount of data needed to reach that particular point will differ according to the researcher and according to the study. At that point all of the data will not have been collected, which means that for all intents and purposes, data collection in dimensional analysis has two stages. The first stage includes data collection sufficient to reach the point of placement of dimensions into the explanatory matrix and identify the central dimension and the second stage, where the explanatory work is done and where the theoretical linkages are validated with additional data to the point of saturation.

The discussion relevant to the second stage of sampling is absent from Schatzman's (1991) article, however is covered in the Kools et al. (1996) publication. There is some discrepancy between the process articulated by Schatzman (1991) and his students regarding the point at which theorizing is to commence. Shatzman's (1991, p. 10) position is as stated previously, whereas Kools et al. $(1996$, p. 317) indicate that theoretical memos are part of the research process commencing in the early phase of analysis.

In the explanatory matrix each dimension is broken down according to its context, conditions, processes and consequences (Schatzman, 1986, as cited in Kools, et al., 1996, p. 318). Context refers to the environment in which the dimension exists; conditions impact the actions or interactions of a given dimension; processes are the actions or 
interactions that result from the conditions of a dimension; and consequences are the results of the actions or interactions (Kools et al., 1996; Schatzman, 1991. Where appropriate, dimensions can be broken down to smaller units by subdimensionalizing. In this manner one is able to reduce a construct to the level of concept. The researcher assesses each dimension for its ability to become the central dimension or the perspective that controls the line of reasoning (Schatzman, 1991) and which offers the best explanation for the relationship among dimensions (Kools, et al., 1996).

Once the central dimension, or perspective, is chosen, the remaining dimensions can be identified as salient, relevant, marginal or irrelevant. The salient, relevant and marginal dimensions are placed back into the explanatory matrix and designated as context, conditions, processes or consequences. Once this organizational matrix has been developed and conceptual linkages made for the purposes of developing theory, additional sampling is conducted until data saturation is achieved (Kools et al., 1996).

Sample

A purposeful convenience sample of parents of children with ADHD was recruited for this study. A purposive sample was chosen because this approach generates valuable information about each child (Isaac \& Michael, 1995) and provides some understanding of the decisions made by parents to discontinue medication. In this manner an appropriate group of parents who gave stimulant medication their children diagnosed with ADHD were identified for inclusion. Parents of children whose treatment with stimulant medication began at some point in time between the ages of 5 and 12 were interviewed. It was expected that 20 parents could be recruited for the study, however 
despite extensive advertising and efforts to recruit participants, only fourteen were interviewed.

Recruitment

Recruitment took place from the Santa Barbara area to the San Diego, California area between November, 2006 and April, 2007. Classified advertisements were placed in local newspapers and distributed to households in several cities in the Los Angeles area. Flyers describing the study were posted on the bulletin boards of local businesses and distributed by hand to passers by in a number of communities in Southern California. The researcher visited several Certified Farmers Markets in Southern California where a poster presentation was set up and information about the study was passed out. A single poster with pertinent information regarding the study was placed in the window of the investigator's vehicle whenever the vehicle was parked, between November 2006 and April 2007.

The investigator received a telephone call from a teenager with ADHD who had seen an ad for the study in a local paper and had a suggestion for recruitment. In response to this contact, the researcher met with the research group from a local, privately owned learning center, and the group agreed to post the study in a bulletin regularly distributed to parents. The learning center did not have a formal Institutional Review Board. Local churches and synagogues were asked to post flyers about the study. Ongoing efforts to recruit participants also involved posting the study on the website for Children and Adults with Attention Deficit/Hyperactivity Disorder (CHADD), the national support organization for individuals with ADHD. Classmates and professors referred potential 
participants. Finally, the student wrote several community leaders from ethnically diverse population groups requesting distribution of information about the study.

Despite extensive efforts to recruit a broad based, multiethnic, diverse group of mothers and fathers of children with $\mathrm{ADHD}$, recruitment proved to be very difficult. It was for that reason the inclusion criteria was changed slightly to include children who started on stimulant medication after the age of five, rather than limiting the interview process to parents of children who started on medication after the age of seven. All of the children took medication for over two years. For those who have discontinued medication, the mean length of time on medication was 5.63 years and for those who remain on medication the mean length of time on meds is 11.17 years. The first mean includes those children who refused to continue taking medication at some point in time.

\section{Data Collection}

Prior to being interviewed, parents were asked four questions, to ensure that their children had been diagnosed with ADHD, took stimulant medication between the ages of 5 and 12 and that the medication had been discontinued by a parent. Upon obtaining written informed consent, raw data was obtained by conducting individual, semistructured interviews with parents whose children with ADHD were treated with stimulant medication. Individual interviews with one parent from each family were conducted until the data was saturated or until the point at which information gathered from the interviews corroborated previously collected data provided no new information (Gillis \& Jackson, 2002). Demographic questions including current age of child, gender, ethnicity, relationship of the parent to the child (father/mother), whether medication was the only type of treatment utilized, the number of family members and parents in the 
home, number of siblings, identity of the person administering the medication, type of health insurance coverage, length of time the child took medication and whether the child attended a private or public school during the time he was taking medication were asked after the conclusion of the interviews.

Several open ended questions were asked during the interview to elicit information about what was occurring with the child prior to starting treatment with stimulants, to describe the experience of the parent, child and family when the child took medication, to learn about the parent's perception of any media coverage that had been encountered, to discover what a typical day was like for the family, to find out what happened after the medication was discontinued and to obtain information or suggestions that parents would like to provide for health care practitioners. Asking the questions in a chronological sequence enhanced recollection on the part of the parent and ensured a smooth flow to the interview. Some of the questions were piloted with a colleague before actual parents were interviewed. This exercise did not reveal a problem with the way in which one of the questions was asked, and as a result, the wording of the question was changed slightly to make it easier to understand. This was done to ensure the collection of adequate and appropriate data. Early in the study two additional questions were added to the interview guide.

\section{Data Analysis}

The interviews were tape recorded and transcribed. After this the data was coded or designated into dimensions, each with its associated properties as context, condition, action/process and consequences. Each one of the dimensions that emerged from the data was "tested" in the role of the central dimension to facilitate the choice of the dimension 
capable of offering the most promising explanation with which to structure the entire analysis and answer the question addressed by the study (Kools et al., 1996). Once the appropriate dimension was identified, the rest of the themes were assigned various roles. Further interviews were then conducted to achieve data saturation and validate theoretical analysis. A theoretical explanation describing parental decision making with stimulant medication treatment that was initiated at some point when the children were between the ages of 5 an 12 is offered in the following chapters.

\section{Protection of Human Subjects}

The study was approved by the Institutional Review Board (IRB) at the University of San Diego (USD) prior to selection of the parent sample. Inclusion criteria included (1) the ability to read, write and speak English, (2) signed an informed consent prior to participating in the study, and (3) gave stimulant medication prescribed for their 5 to 12 year old children diagnosed with ADHD.

Personal information and identification of parents participating in the study will be kept confidential to the fullest extent possible and protected by a coding procedure. All information provided is secured from general access. An explanation was provided to inform parents that information obtained during the interviews will be utilized for research purposes only and for facilitating a better understanding of decisions parents make about giving or not giving medication to their children. Parents were informed that they could withdraw consent to participate in the study at any time.

The risks of the study are few as there is no intervention involved, however discussion of the child's previous experience on medication prompted parents to ask about information about and resources for the treatment of ADHD. When there was a 
request for information or treatment, referrals were made. Participants were given a $\$ 10$ gift certificate for their participation in the study. The demographic questionnaire took about five minutes to complete and the interviews ranged in length from approximately 30 minutes to 90 minutes. The interview questions appear in Appendix A. 


\section{Chapter Four}

Results

The purpose of this study was to learn more about parental decision making with stimulant medication treatment of their children with ADHD. This chapter includes a description of the study results. The results of the study were unanticipated and enlightening, for what began as a study to find out more about parental experiences with stimulant medication treatment for latency age children with ADHD became a rather fascinating journey chronicling these 14 children's lives for a period of time of up to 35 years.

Sample

A convenience sample of fourteen parents of children with ADHD completed the study. All of the parents interviewed were mothers (13 biological and 2 adoptive) of children with ADHD, and all but one of the children who were the subject of the interviews were boys. The range in age at the commencement of medication was 5 to 11 years with a mean age of 7.43 . The youngest child in the study at this time is 10 years old, while the oldest is now 40 and married, with children of his own. Of the 14 children who were the subjects of the interviews, 6 are still taking stimulant medication.

Twelve of the 14 parents interviewed were Caucasian and 2 were Asian. It is not known whether the mothers were working during the entire time the children were taking medication. All of the families at the initiation of treatment were intact two parent families; however, during the time the children were on medication, three parents 
divorced and one family experienced the death of the other parent. Sixty four percent of the families had an annual income of more than $\$ 100,000$. The primary language spoken in all but one home was English.

The Interviews

The study was designed to gain a better understanding of parental decision making with stimulant medication treatment for their school age children with ADHD. The data were obtained 30 to 90 minute, audio taped, face to face, semi-structured interviews with parents. The interviews were transcribed verbatim and coded for comparison and to find major themes. Dimensional analysis (a type of grounded theory) was used for the data analysis. Several of the more salient dimensions were reviewed to evaluate the value of each as the central dimension. Those dimensions not assigned to the position of the central dimension were assigned to the categories context, conditions, processes or consequence for the purpose of providing the best explanation for "What all is involved here?' (Schatzman, 1991). The emergence of the central dimension, getting the best fit for the child specific to the school setting was identified as the central dimension of the interviews, for it was clear that many treatment decisions were made relative to this fit over time. It is important to note that "fit" was a dynamic, rather than static phenomenon, and as such resulted in parents engaging in a virtually continuous process of decision making regarding many different aspects of the child's treatment for $\mathrm{ADHD}$. In the following section, the matrix, or theoretical placement of the dimensions is explained. 


\section{The Context of Decision Making}

It was clear at the conclusion of the first interview that this study was unlikely to be limited to the decisions parents make about treatment with stimulant medication. Instead, the interviews revealed complex situations that evolved over time, replete with multiple decision and non-decision points about treatment in general. Decision making began at the time the decision was made to acknowledge that the child's behavior was sufficiently different from that of the child's peers to cause parental concern and continued through the transition period where the parent transferred the responsibility for decision making to the child. The transfer of the responsibility for decision making usually took place when the child was sufficiently mature or chronologically old enough to make decisions on his or her own. There were a few exceptions, for example, where the child absolutely refused all treatment, and when that occurred, parents had no recourse other than to discontinue treatment.

Some decisions were made as single decisions and followed a sequential pattern, as the process of evaluation, treatment and follow up took place, while at other times multiple decisions were made concurrently. The following example illustrates the sequential nature of decision making. Once a parent decided that the child's behavior needed to be evaluated by a health professional, the parent chose a provider and scheduled the evaluation appointment. Once the evaluation was completed, the parent had to decide on a course of action. Since the initial comprehensive evaluation is usually diagnostic, once the diagnosis is made, parents decide whether the diagnosis sounds reasonable, or whether it is even acceptable. The decision making process continues as parents must accept or reject recommendation(s) for treatment or do nothing. Sometimes 
the parent may be referred to a different provider for further diagnostic evaluation or for a medication evaluation. If the provider(s) conducting the initial evaluation either prescribed medication or referred the parent to a physician for medication, the parent is then faced with the decision whether or not to start the child on medication. Throughout years and years of treatment for ADHD, the parents who were interviewed made treatment choices that seemed to be related to the fit of the child specific to the school setting. Contrary to what might have been previously thought, decision making about treatment does not begin with the notion that the environmental context of the patient is fixed, for it was obvious that many parents changed various components of the child's environment, such as the actual school, type of school (public or private), physician, type of physician, teacher, the child's peer group or playmates, and the family's place of residence.

One issue regarding the environmental context of the patient that surfaced during the interviews merits further discussion. The DSM-IV criteria for the diagnosis of ADHD state that the symptoms of ADHD must be demonstrated in more than one domain. Typical ADHD behaviors are often seen at home and at school. When one thinks of a child's function in the school setting, the association is usually with the child's academic performance and behavior in the classroom. Many of the parents interviewed however, spoke about their concerns with the child's social functioning at school. These concerns seemed to be as important, if not more important than social functioning in the community and at home, so for these parents social function became an integral part of the school domain. This interesting finding has been woven into the context of the actual 
study. The following analysis of the data describes the complex task of parental decision making about medical treatment of the child with ADHD.

Analysis

The process of finding the central dimension that would provide the best explanation for parental decision making in children with ADHD was contingent upon the point at which treatment began. Although the researcher's interest was parental decision making regarding treatment with stimulant medication, the scope of the study was broadened to capture the more pressing concerns and more comprehensive narratives of the parents. Since the interview questions had a chronological orientation, the interviews had a similar construction. In dimensional analysis the choice of central dimension is specific to the phenomenon to be studied, and as the study focus broadened to better understand parental decision making regarding treatment for $\mathrm{ADHD}$, the actual phenomenon under study took on beginning and end points. The events prior to the initiation of treatment predated treatment and were therefore discussed as antecedents to the phenomenon and discontinuation of treatment either as a result of the child refusing treatment or shifting decision making responsibility to the child marked the end of parental decision making, or the end point of this particular treatment interval. In this study, getting the best the fit for the child specific to the school setting became the most salient dimension or perspective. The analysis includes a brief description of common themes outside the boundaries of the phenomenon being studied; however these themes are not included in the discussion of the matrix.

The central dimension providing the best explanation for what was occurring between the beginning and end points of parental decision making about treatment was 
the work done by the child's mother in getting the best'fit for the child specific to the school setting. A number of additional themes emerged, and they were assigned categorically according to the order in which they appeared, as antecedents to treatment or beyond the parental decision making treatment interval and within the study as context, conditions, processes and consequences. Themes that either recurred over time or that were consistently present (regardless of whether they changed or stayed the same) throughout the period of treatment, for example, the personal qualities of the child, were treated as part of the matrix.

\section{Antecedents to Treatment.}

The names of the children used to report the findings of the study were disguised to preserve the confidentiality of the families. The following names were chosen to represent the children, and the names are alphabetically arranged according to the order in which the interviews were conducted: Allen, Bob, Carter, David, Elaine, Fred, Gary, Harry, Ian, Jerry, Kevin, Leon, Martin and Nathan. It was apparent early in the interview process that many of these children had similar behavioral symptoms when they were young.

One of the first common themes identifying similarities among the children that were mentioned by parents was the cluster of symptomatic behaviors that brought the child to the attention of significant adults in the child's life. These behaviors were usually more problematic at school than they were in other settings, and many times even when noted by parents, they did not generate the same level of concern with parents as they did with teachers. Parents described behaviors consistent with hyperactivity, being disruptive in class, being irritating to others, acting impulsively and not being able to sustain 
attention on a task, as can be seen in the following statements: Allen's mother said he "was very wild at home....couldn't concentrate in class ... friendly but just out of control...couldn't get him to stop sit down". Bob's behaviors included: "having a hard time waiting his turn...climbing on the most amazing things ...talking non-stop”. According to Carter's mother he showed the following behaviors: "wasn't able to sit in class...very impulsive, very compulsive too... when he needed something he needed it badly...would run out into the street". David's mother noted these behaviors: "not able to concentrate on any certain subject... would not stay in his seat in the classroom...had a high level of energy and active and disruptive". Elaine, the only girl discussed in the study demonstrated the following behaviors: "couldn't sit still... would be bouncing off the walls...was hyperactive". Even Fred's mother alluded to some characteristic ADHD behaviors: "was really a pest...little boys - they bounce all over the place... was driven like a motor". Gary's mother indicated: “it was really difficult for him to focus...attention just wasn't there...disrupting the class...off thinking and doing his own thing". Harry's mother stated he was: “extremely impulsive...always in everybody's face...doesn't stay focused...talking when the teacher's talking". Ian was: "too friendly - didn't know the difference between classroom and recess....all the other kids are interfered with...could do five things at one time and not for longer than a minute... was bouncing off the walls...the attention span was bad". Jerry's mother reported these symptoms: “can't sit still...entertains himself by creating incidents...put himself in situations like jumping off something that was way too high". Even Kevin was symptomatic as seen in this description offered by his mother: "unable to be part of a group - would always just get up and walk around". Luke's mother said he: "would speak out of turn...would get easily 
distracted...always getting into trouble...(in preschool) climbed over this seven or eight foot chain link fence to get into the pool yard because a ball had gone in there". Martin's mother emphasized his activity level in the following description: "was pretty hyperactive... wasn't really focusing in on any of it... was very hyper". Even Nathan's mother said Nathan: "couldn't sit still...having trouble getting him to just stay focused at school...once he got hyped up it was difficult to get him to settle down so it took a lot of energy to keep up with him".

In almost every interview the parent mentioned some level of hyperactivity and as reported earlier, this is consistent with the literature reporting that hyperactive rather than inattentive children are more likely to come to the attention of teachers. Once the cluster of behaviors was identified, there was usually a prompt for evaluation. In eight cases the suggestion to have the child evaluated was initiated by school staff. The ways in which the school communicated with parents differed greatly, as seen where Ian's mother remarked: "she called me in and said either you do something about this or you've got to leave" to that in Bob's situation, where the parent reported: "the teacher finally said you know let's just see what's going on". Some of the families had already established relationships with the school staff and/or teachers by the time ADHD behaviors were noted and suggestions for evaluation were made, and this is discussed within the analysis as these relationships were often ongoing and impacted treatment decisions.

Another theme was the parent's acceptance of, or agreement with the diagnosis. The initial impression regarding the diagnosis was established once the evaluation was complete, however that did not mean that the thoughts parents had about the diagnosis were permanent. The responses to the interview question about looking back at the 
decision made to start medication, gives the impression that the parents' concerns about whether or not the child even has ADHD or a comorbid condition may have impacted decision making along the way. Questions or concerns about the validity of the diagnosis and etiology of the condition lingered on for some of these parents. Allen's mother said: "I wish I would have explored some other areas and maybe gone and looked to see if there was learning disabilities...". Ian's mother expressed a common sentiment of the era in which (early 1970s) he was diagnosed when she said: "he had a regular pediatrician - he knew how active he was anyway but he kept saying that's normal for a boy", and "no one was really familiar with really active children - they just said it is a thing with boys". Another mother wondered about the etiology of the condition as well as can be seen in the following statement: "you always second guess yourself is this my poor disciplining or poor parenting, or is this truly ADHD, something organic....". Jerry's mother commented on her husband's response to the diagnosis: "he was opposed to 'ADHD'... he doesn't believe that it's a problem for his kid and he still believes that if his son will just try harder and pay attention better everything will work out". Carter's mother said: "I just think his main problem is anxiety and not ADD." At the other end of the spectrum, there was full acceptance that the child had ADHD as succinctly stated by Bob's mother when she said: “I decided after I did some reading I thought they're right, he does have this", and by Fred's mother: "we went through the school counselor and did all that and figured out that yah, he was" (ADHD). Uncertainty about the diagnosis and hesitation in accepting it have the potential to impact decision making as parents with concerns about the diagnosis may not approach treatment choices or treat the condition as aggressively as the parent who believes the condition has been correctly identified. 
The Child's Own Decision Making Treatment Interval/Lifeways

Parents whose children had already reached their late teens spoke about what could be described as "finding his or her own way". According to Carter's mother: "when you are an adult you channel it differently - your energy - or you are able to work with it differently". David's mother commented on the role of medication and how it contributed to the child's finding his own way later on: "calm down enough to let them hear and listen and be able to learn and then that builds self esteem up and that they are learners, then they grow and then the brain kind of grows with them and then they find that way mentally to do it and then they're fine". Nathan's mother expressed her son's ability in this way: "as the years go by they learn to cope so by 18 you have given all the lessons". Another young man who was finding his own way was Jerry, whose mother said: "he had to fill in the lines for his Spanish class and he did all of it and he was studying and he never never ever in his - I had never seen that behavior before so all of a sudden it's like "I can do it mom"... so finally at 19 he has discovered he can do things". Parents who described the child finding his or her own way did not limit their comments to treatment for $\mathrm{ADHD}$, but extended them to finding their own way in life, but life in the context of a chronic condition.

Physicians sometimes gave older children some flexibility with taking the medication. For example, Nathan's mother spoke about his college situation: "now that he is away at college he only takes it when he wants and so for he is allowed by his doctor to have a certain dose for studying and then a slightly longer or higher dose for test taking - it's up to him...". Some parents remained marginally involved in treatment after the child turned 18 and some did not. 
The Parental Decision Making Treatment Interval.

The perspective providing the basis for the matrix was the mother's work in finding the best "fit" for the child specific to the school setting. At the point at which some other element of the situation was added, removed or changed, the fit was assessed as needing modification. The context or environment includes the perspective framework of each party to treatment (mother, father, relatives, teacher, school staff, physician and coach), doing what's right for my child, personal qualities of the child, parental assessment of intellectual abilities, not getting along with the other kids/not fitting in and public or private school setting. The conditions of the study that impacted actions included the relationship of the parent with the teacher (and school staff where applicable), stigma and having no choice/feeling pressured. The processes or intended or unintended actions within treatment included requesting and making modifications and learning curve. The consequences or outcomes of specific actions could be seen in making tradeoffs. In most cases, the consequences of parents finding the best fit for the child specific to the school setting are not yet evident. Of the 14 children described in the study, only Carter, Elaine and Ian have finished school and are working in the community. The rest of the children are still in the midst of the educational process.

Getting the best fit didn't necessarily mean getting all As on report cards, nor did it seem to mean being the star player of the school baseball team. Instead, it seemed to be more consistent with things like getting along with the teacher and other children, being accepted by classmates, being able to sit through classes and learn what was being taught, finishing homework, having a positive experience in a school activity or excelling in one area, not getting into trouble and building a good foundation for life. It was almost 
as if the parent "worked the system" to reduce the visibility of the child, or minimize the differences between the ADHD child and the rest of the children and improve their children's functional capabilities. A conceptual model illustrating the three chronological intervals of ADHD treatment over time follows.

Figure 1. Conceptual Model - ADHD Treatment Time Intervals

Antecedents (to diagnostic Treatment interval (to age 18 or when to treatment evaluation) refuses treatment)

Making Treatment Interval Lifeways

Decision

Finding the best fit for the child in the school setting $\rightarrow$

Time

\section{Context}

Everyone has a history and individuals bring their past experiences and education with them to the situations encountered in life. Each person involved with the ADHD child has a personal history that contributes to his or her own operational perspective frame. The significant parties to the child include parents, physicians, nurses, teachers, coaches, relatives and people parents spoke with about their child. The operational perspective frame may be associated with the diagnosis, a particular type of treatment, or some other aspect of ADHD, but in every case this perspective frame has the potential to affect decisions about treatment made by parents. One physician's perspective frame 
alluded to difficulty making the diagnosis of $\mathrm{ADHD}$ and appeared to have led to a decision not to prescribe medication for the child. This is seen in the following excerpt from the interview with David's mother describing a conversation with the doctor: "it is sometimes hard to determine as a pediatrician if it's truly ADD or AD whatever it is called and she said and/or it's part of who he is and a boy and could we find other methods...". Another physician had this to say about medication, to Nathan's mother: "the doctor we went to just said you know Ritalin has been studied for a long time and they felt it was safe...". Martin's mother said the following: "I went to see my own physician about it and he was totally against it".

Allen's mother described his coach's perspective frame in this way: "has an attitude sometimes with the coach but this coach said that Allen is exactly like he was at that age so that is a good thing". The fact that the coach could identify with the challenges experienced by the ADHD child, might have resulted in his having more patience or a better understanding of Allen's needs. Teachers had strong opinions about medication, and in most cases viewed medication either very favorably or very unfavorably. Their operational perspective frame was, on occasion, related to other treatments, as seen in this description articulated by David's mother: "the teacher in the third grade as far as evaluating how we could help him do better in school - we tried lots of things I mean the teacher the third grade seemed to empathize a little...so she tried things like having him wear earphones in the classroom that didn't have anything in them - they were just big earphones that would perhaps help him concentrate on what he was doing." Harry's mother made reference to one of her son's teacher's perspective frame regarding medication during the interview in her discussion about a school experience 
that did not go well: "it did not work for him there because they said oh, he doesn't need medication... and I could see he was unraveling and I told my husband we have to put him back on meds and we tried to give it to him one morning and he said my teacher doesn't want to".

There were a few other perspective frames that surfaced in the interviews. Teachers and nurses were grouped in what Elaine's mother had to say: "the teachers would forget to give it to - some teachers objected to giving it to her and the school nurse objected to giving it to her". The fact that the school staff members were reluctant to administer the medication may have been what led to the following decision regarding medication administration: "we used to give it to her in a little packet to take herself". Allen's mother had this to say after the neighbors complained about his behavior: “they thought we needed to discipline...". Fred's mother experienced other parents' disapproval of medication treatment as seen by her comment: "I hate hearing parents say how can you do that to your child?"

Parent perspective frames varied considerably. Harry's mother articulated the parental perspective frame in terms of treatment with medication: "I come from a very alternative you know treatment - you don't use meds unless you have to... and you have to understand that I don't give my kids antibiotics I take them to get their throats swabbed and their ears checked but I don't give them antibiotics". For Jerry's mother the perspective frame was related to the diagnosis as she reflected on her decision to accept it: "I think the biggest thing for me was not the medication but coming to grips with the fact that my son needed this kind of help because I was explaining it away by other you know the classroom stuff, well, he's bored". Another mother's comment reflected a 
familial perspective frame as in Allen's case: ‘there's a lot of Tourette's syndrome and those kinds of problems in my husband's family so it just wasn't a surprise".

The previous examples illustrate the perspective frames of the individuals in the child's life. The following examples illustrate the perception of the perspective frames of others, filtered through the parental perspective frame. Jerry's mother offered the following account of what the physician had to say: "we have to get him through his teenage years without committing suicide, without doing drugs or alcohol so he has to stay on the medication all the time - it terrified me". Fred's mother said the following about the perspective frames of other parents: "I hate hearing parents say "how can you do that to your child?' - they have not a clue as to what its like to live with a child with ADD and they don't know but like saying ok I'm going to take the medication away for two weeks and you take him for two weeks and do the routine I have to and then tell me what you think because they think that it's all here (pointing to her head) and it's not neurochemical and it just makes me nuts you know I hear oh you can do behavior modification ah you can but you are going to get better stuff with behavior modification if you take the medication because things are learned behaviors". Jerry's mother echoed the constant challenges of living with a child with $\mathrm{ADHD}$ and her perceptions of the perspective frames of teachers and health care providers: "nobody understands the 24/7ness of it nobody except another parent that's been there ...the suggestions in the real world probably make sense but the $24 / 7$ world is not the real world and the teachers don't know it the physicians may know it psychologists may know it a little bit but it is not the same as every waking moment being in it". 
In the following excerpt, conflict can be seen between the perspective frames of the teacher and physician. Ian's mother described her emotional response to integrating two perspective frames, that of the physician and school, with hers: "all they cared about was teaching the classroom and you would think if I paid the tuition - but they're not - they are worried about all 35 kids - they had large classrooms there was like 35 children - it was the school that initiated it and then I was shocked and then I went to the doctor and I told him and he said (inaudible) so that's where it started because he really didn't want to... he said they're going to outgrow it". Ian's mother had to work with the fact that the doctor did not want to prescribe medication for her child and at the same time deal with the pressure placed on her to start her son on medication by schoolteachers who had to teach with 35 children in the classroom. Ian's mother had come to this entire situation with both her own and her mother's perspective frame (it appeared that Ian's mother had adopted her mother's perspective frame) apparent in thinking the following about her son's condition: "my mom told me boys are active and I just kept thinking well he would mature...".

The following excerpt demonstrates Carter's mother's operational perspective framework and her interpretation of the physician's perspective frame where she says: "I think it is a lot of false hopes that the medicine and the doctors who prescribe the medicine - a lot of false hopes that are being pushed on parents guilt that you are not going to allow your child to succeed and false hopes that that's what will help him - it's really difficult - it's killing us...". In other words, by withholding treatment with stimulant medication Carter's mother would be depriving him of the opportunity to 
succeed and she thinks that physicians play on the guilt felt by parents by giving them false hope that treatment with medication will be successful.

The interpretation of the perspective framework of the significant others in the child's life is actually the parent's perception of their perspective frame so that this conceptually dense bundle of impressions is filtered, sorted out and interpreted by the parent. This is regardless of the type of perspective frame that is made apparent, or explicit. In other words, the parent may have a certain perspective about medication based on anecdotes offered by other parents.

Perspective frames have a number of characteristics. A psychologist may be committed to the value of behavioral interventions for children with ADHD. The physician may think that the child can benefit from medication based on good responses of his other pediatric patients. When the perspective frames are overt, the parent is more likely to have some awareness of these kinds of perspective frames, especially those of the teacher or the physician. The psychologist, the physician and the parent need not have perspective frames regarding the same component of the condition or its treatment, for example, the physician may have a perspective or perspective frame pertinent to the use of stimulant medication and have no strong opinion about any other kind of treatment. The psychologist might think cognitive behavioral therapy is beneficial since a few of her patients have found this to be the case. The psychologist may or may not have strong opinions about the use of stimulants, or may not have any opinion regarding the use of medication. For parents, the existence of multiple perspective frames is like having a savings account where a variety of people make large deposits. Parents can and do make withdrawals at any time and, when they make withdrawals, they take out specific 
deposits. The analogy to decision making is that even though the parental perspective framework is constantly present, the parent can make use of the perspective frames of others and incorporate them only when necessary, either to support or not support a particular decision. The parent may utilize one, or more than one other perspective frame to support decision making, however other perspective frames will always be filtered through the parent's perspective frame.

There will undoubtedly be times when perspective frame conflict occurs. Frame conflict can be external, for example where the teacher and physician disagree about raising the dose of the medication. In situations where there is perspective frame conflict the parent is charged with resolving the conflict by choosing between the two recommendations, or by doing something else. The situation can be an internal perspective frame conflict where another individual's perspective frame conflicts with the parent's perspective frame. A physician who does not believe that dietary modifications are helpful may say that directly to the parent, but the parent might believe that reducing sugar in the child's diet may help reduce hyperactivity. The parent is again faced with making a decision in the presence of perspective frame conflicts. There are times when this conflict must be resolved, and there are some decision situations where there is conflict in the external perspective frames and where none of the external perspective frames mesh with that of the parent. In these situations, the parent is forced to make a decision among what is perceived as less than ideal choices. Recognition of the various perspective frames involved in a particular situation and a better understanding of perspective frames related to the problem increases the complexity of decision situations, but at the same time makes the process much more transparent. 
Mothers were also doing what's right for my child. This was a very common theme in the interviews. David's mother expressed her thoughts in this way: "parents need to be very strong and put their child first". Fred's mother echoed this very common theme when she said: "you know it wouldn't have altered my decision because he is my child he is my responsibility". Harry's mother's statement was particularly poignant: "I said but I am not willing to stop them it's like you know I'd rather you know you will do anything for your child...I will sacrifice my life for my children to be healed - I can't believe this could - of all people I'm not kidding - it's really bad". Finally, Kevin's mother offered this: "I was not swayed with others opinions based on what I thought was right for my child and then I didn't have any misgivings...". Doing what is right for my child exemplifies the parental obligation to the child.

Another important aspect of doing what's right for my child in the context of this study involves the perspective framework of others. Mothers were, at times, limited in their ability to do what's right for their children by the perspective framework of others. For example, the mother who wanted to do the right thing for her child may have medication treatment and adherence compromised in a situation where the teacher and school nurse are opposed to treatment with medication.

In these interviews parents described the personal qualities and intellectual abilities of their children. In 9 of the 14 cases the child was described as being very bright or even "gifted". Allen's mother described his personal qualities in the following way: "he was funny and pleasant..." and he's very good at communicating". According to his mother: “Allen's teachers love him." In Kevin's case it was the physician who made reference to his intellectual ability, seen where his mother described what the doctor had 
said: “you know he is very gifted and that's probably why they didn't pick it up - he definitely had ADD...". Kevin's mother thought this about his personal qualities: "he is very likeable". David's charismatic qualities were easily seen in the interview with his mother and she gave the following examples: "he has too much self esteem..." and "he makes friends with adults - like they just love him just love him, so within a week the nurse thought he was the greatest thing ever", and regarding getting extra help his mother said: "it became this joyful thing because the resource specialist just loved him". Elaine's mother said that: "Elaine is not an outgoing child but she had friends, she always - she wasn't a loner". Her intellectual abilities were described by her mother in the following way: "Elaine read at an early age - she understood she was very bright - she tested way off the scores...". One parent with a child whose behavior was especially challenging commented on his personal qualities. Harry's mother said "he's very sweet". She described his intellectual capabilities in the following way: "he's a brilliant boy I mean on paper he's a genius..." and "he is at the most academically challenging school his passion in life is reading..." and "he should be the top student there because he never studies for tests and he'll spit back the answers almost verbatim...". Most parents described their children's intellectual abilities as being very high, but in many cases parents thought their school grades did not reflect their true potential.

Even when the children were described as likeable, or sweet or friendly, they were not getting along with other children nor fitting in. Gary's mother described his challenge in getting along with other kids in this way: "hard to get along or hard for him to socialize with the other kids because you know the way they played they he would just would not play by the rules the other kids would just be aggravated so it's hard to make 
friends when you are upsetting them all the time". Jerry's mother described the social situation at school: "I spent time going to the school and I noticed his social interaction and the social interactions are another thing that persuaded me - the self esteem issues and knowing who your friend was and not being invited over to other peoples houses, other people not wanting to come over and when I would go to the school and visit he was always - said he was involved but he was sitting on the outskirts of the games he would be outside the circle and that also worried me". Fred's mother had this to say about her son's experience: "he still has a hard time with relationships with peers he's very solitary but it was not that - he was very he was picked on a whole lot I think because he doesn't have the idea about that personal space". Luke's mother described his experience at school as well: "he didn't play real well with kids on the play yard... I guess it wasn't a matter of sharing but he was always getting into trouble", and "he still had problems in the school yard because he didn't know when to stop...things would escalate... a child would say I don't want to play anymore". In the interviews there were many other descriptions of children not quite fitting in, and it was evident that parents had emotional reactions to their children's experiences with other children.

The final part of context was whether or not the child attended a public or private school. This was a coded response in the demographic questionnaire and forms part of the context because of the legal differences between public and private schools regarding assistance that must be made available to children with ADHD. Public schools are required to provide services in the form of 504 plans and IEPs which were described earlier in the paper. Private schools however, are not bound by these laws so that any extra help offered to students is provided on a voluntary basis. Since parents approached 
treatment from a multimodal standpoint which included use of resources that were available through the school district, this contextual variable was a salient one. Kevin's mother spoke about the private school he attended: "that's a school for twice exceptional children... and that's a real good fit there for him...". Approximately $35.7 \%$ of the children with parents in the study attended public school, $35.7 \%$ attended private school and $28.6 \%$ attended both public and private schools.

\section{Conditions.}

Most of the mothers who were interviewed for the study were proactive when it came to mobilizing assistance for their children, and many had ongoing relationships with the school staff and teachers. Some parents had particularly noteworthy experiences with teachers with a mix of very good and not quite so good experiences. Regardless of the quality of the relationship with the school staff, conditions at the schools changed often. Almost all children have new teachers at the beginning of each school year and as the children reach the higher grades they usually have more than one teacher and move from class to class throughout the day. The dynamic nature of the relationship between the parent and the school has implications for decision making. Conditions at the school change, and even if this only occurs annually, the parent must re-evaluate multiple aspects of the child's life and treatment at least at this one point every year.

Bob's mother had this to say about her relationship with the school: "they were more than cooperative - they're the ones who volunteered - let's do this for him..." and "I was pretty involved at the school I was PTA president, pretty you know well liked and I think they wanted to do whatever they could to help me", and relationship with the school staff often remained positive, as seen in the following: "I never had to even hardly 
had to ask for it they just did everything they were so good, great, great people there". Sometimes parent's comments reflected both types of relationships with the school. Carter's mother said: "he was kicked out of two schools", and later, when the medication was not sufficiently controlling symptoms: "we went to a system where he would have to write out every step of the day like a 30 paragraph list and at school he had a very good teacher who was able to manage that list with him - like you sit down, you take out your suitcase, you put a pencil on - he had to put a mark next to each action - we just broke it down to five minute increments what had to be done and he worked with that list and he was doing better and eventually he was able to learn without Ritalin...". Elaine's mother had positive things to say about the public school her daughter attended: "they helped her informally - when she got into high school she took an extra class like a study hall and the teacher was an... we sat and talked with him through the school year - it turned out he was her study hall teacher for the next two years, three years that Elaine was there so I was very happy with it they called him ... he was there to help them with their studies and everything like that and if you became lax he checked up with the teachers to see how the students were doing...". Kevin's mother also had a close relationship with the school as was obvious from the following statements: "they knew me at the school you know really intimately and I would come into the nurses office sometimes he really didn't want to take it but they figured out ways to take it (the medication)... but the teacher all the teachers were pretty terrific and I would work with them and just say what do you think, and we pretty much got him at the right level and that was really how I always worked with it ... just one on one with the teachers". 
The extent of parental involvement with the school, and the dynamic and changeable nature of the relationship was evident in what was reported by David's mother: "my husband and I both volunteered in the classroom..." and "we have a public school here but it's a very small network of teachers and parents where we're very close and his third grade teacher and I had very close friends with so she and I had a dialogue a lot of dialogue talk about David and what we could do to help him and she had tried all sorts of things...", and later, "this new teacher in the fourth grade we started I felt was not trying all the different ways the third grade teacher had tried...". David's mother summarized the changeable nature of the relationship with the school in the context of the IEP where she says: "It always felt like to my husband and I at that point that we did our part and they didn't do their part and that was the frustrating - until the group of people kind of changed though - you know the psychologist on campus changes, and the teacher changes obviously and the principal, is what I am saying but that kind of changed through the years and when you got a good group of people together that really cared, things happen...".

Three parents initiated the relationship with the teacher by formally introducing themselves to the child's teacher at the beginning of a new school term. Nathan's mother described her introduction in this manner: "way back in elementary school the day before school started I know the teachers were there...would go in with that CHADD handbook... and said this might help you and all the pertinent points were underlined". David's mother said something similar: "I usually will introduce myself every year at the open house and say my name is so and so this is my child he has an IEP and it's not a big deal but you and I need to talk - 'oh thank you Mrs. ... I was wondering you know, who 
this child was or why he acted this way - what can I do?' you know I found that teachers you know if they just know about it they will work the best they can with it...". Luke's mother also introduced herself to the teachers each semester in the following way: "CHADD has some great videos so every you know all the teachers think they know everything about ADD kids, so I very gently would shove this video in their hands at the beginning of every semester that gave them little hints like he should be sitting by your desk or up at the front - things like that - they were willing - it was you know it was a very cooperative school - we were lucky in that regard...".

Parents often referred to feeling pressured to make a decision or having no choice other than to make a particular decision. Harry had issues in the school setting and despite the fact that his mother really did not want to use medication, he was started on stimulants. His mother verbalized her concerns about putting her son on medication: "I don't think we had a choice we didn't want to put him in special ed class - the boy is brilliant". Ian's mother said the following about feeling pressured: "he had me - I didn't care you know - I was bouncing off the walls too - I just did what the school wanted". Kevin's mother had this to say regarding choice: "over the years I've met people that have had those issues and not wanted to medicate their child and I've understood that but um for me after he went on the medication it wasn't really a choice - it was - it benefited him to such a great degree".

The third condition dimension is the problem of stigma. This was especially noticeable with those children who had to go to the school office or the nurse's office during the day to pick up medication. Long acting medications have eliminated the problem of having to go to the office to get a dose at lunch time or after school for most 
children, but some of these children took medication before the longer acting medications were available. There are also some children with ADHD who are not able to tolerate the long acting medications and for that reason may take short acting stimulants for the entire period of time they take medication. Stigma was also associated with being in the resource specialist program (RSP) and having to take one or more classes with the resource specialist.

Nine of the fourteen parents reported some type of stigma associated with the ADHD diagnosis or medication. Martin's mother made reference to not being able to talk to a colleague at work about her son and ADHD when she said: "(radio personality) on (X station) will talk about it on the air - you don't need to be medicating them there are other ways and my (work colleague) right there fortunately his children don't have any learning problems, well because he hears all this - these kids didn't need to be on Ritalin and I don't talk to him about it...". Gary's mother said: "at lunch time he did have to go to the nurse's office - all the kids you know - oh he's going to the nurse's office and so he didn't like that much but he did that". One mother experienced the effects of stigma after a disclosure to another parent as reported in the interview: "I remember feeling close enough to a mother to tell her my son was diagnosed with ADHD and like two days later my son came home and said 'what is ADHD mom?' so her kid had been apparently teasing him about it and the kids asked him why he needed to go to the office - the nurse's office ...I know that bothered him...". Another example was offered by Ian's parent in this description: "it's you're kind of a freak when you have to go to the nurse's every day...". Elaine's mother said the child addressed her own situation in a different 
way: "if anybody asked it was an allergy pill - it was nobody's business she felt and I wasn't going to argue with her".

Processes

There were two components related to the processes involved in getting the best fit for the child. The first was the learning curve. Parents had a variety of levels of knowledge related to diagnosis, treatment and other kinds of things associated with ADHD. Parents joined CHADD, checked out books from the library and spoke with family members and other parents whose children had ADHD to gain more information and improve their ability to obtain help for the child. The learning curve was different for each parent, but many spoke of the different ways in which they were able to access information. Two of the parents found CHADD to be a good source of information - for themselves as well as for their children's teachers. Bob's mother said she learned about ADHD in this manner: "after he was diagnosed with ADD I started studying it... I went to the library and checked out books and just read". Gary's mother educated herself about the condition and the medication: "I did a little research - I read a lot about kids with ADD and what the drug is". Nathan's mother said the following: "I'm one of those parents that reads the inserts". Jerry's mother seemed firm about her decision regarding treatment with medication after doing some research: "the more I read about ADHD the more I realized that I had to do that until he was old enough to make his own decision so there was no vacations, nothing, this was it". Fred's mother made reference to the more social, interactive aspect of the learning curve in the following statement: "it broke my heart every time he would come home... so you know learning, doing a little bit of 
reading, talking to people, talking to my ex's mom who is also a nurse and dealt with this and knowing how much it helped him when he took medication...".

The second component of the process section of the matrix central to getting the best fit for the child in the school setting was the process of requesting and making modifications. This could be related to any aspect of treatment or diagnosis. If a parent decided that the amount of academic assistance, the way in which it was offered, or the inability to obtain it affected the child adversely, a request for change might have been made. If the request was denied, or what was offered was seen as not being helpful or was inadequate, the parent may have decided to change the child's school. Sometimes parents changed the type of school the child attended, from public to private or vice versa. In other cases where the fit was still not acceptable, the parent might opt to change treatments, augment existing treatment, or change the mix of treatments or environment in some way to achieve a better fit.

Modifications can be broken down further to identify the kinds of things that were modified and could be either informal or formal. Formal modifications were programs or services resembled programs like the IEP or 504 plans. Formal modifications included school or academic interventions, such as the IEP, 504, RSP, tutoring, after school programs and educational therapy. Formal changes also included changing a child's teacher. The interventions described above may or may not have been provided by the school. Informal academic modifications included things like using earphones in the classroom to reduce stimuli (a rather unique intervention), adjusting the child's daily schedule so that non academic classes were at the end of the day, having a journal that was sent from the teacher to the parent and back on a daily basis to make sure both were 
aware of homework assignments and completion status, and sitting at the front of the room beside the teacher (when this was not part of the formal 504 plan).

Formal therapies included process therapy for the individual child or family, cognitive behavioral therapy, behavior modification with reward or incentive systems, social skills groups and parenting classes. Other kinds of therapy related interventions included neurofeedback, and physical/occupational therapy that helped with sensory and motor coordination. Some of the children did not participate in therapy, and this is not unusual for children with ADHD. Parents often made modifications on their own that were usually implemented by therapists. These modifications included reward programs, establishing behavioral contracts with children and constructing behavior modification plans specific to the child's needs. For example, some parents established set routines to help the child structure time in the morning so the child could get ready for school.

Some parents set up formal activities for the children including boy scouts, team sports, choir, and regular community outings. This was one way in which parents could increase opportunities for positive social interactions. Elaine's mother did the following: "we used to take a group of kids to see - they used to have Saturday for children you know with the orchestra at the ...I used to take a group of her friends because they never had the education and the knowledge and she did very well with them...". Even though Ian's mother noted that his difficulties with friendships was limited to the school setting, it was she who provided opportunities for socialization in the community: "it was the weekends and they were neighborhood kids that he grew up through school - he never had much friends but he had so many friends in our neighborhood - it was a big huge block cul de sac (inaudible) and the cub scout kids and we had them come to the house 
often because I was the leader...". Other parents tried to modify the school environment to get a more structured rather than unstructured school or vice versa, again, depending on the needs of the child. Nathan's mother spoke about his need to be in a classroom with a small number of students when she spoke about grades: "oh very high like As and Bs mostly As, but it wasn't ability, it was just controlling the environment so that he could be successful and so I felt a little guilty about that because it wasn't...manipulating the environment you know keeping it small, but as the years go by they learn to cope...". One parent made a contract (with a child who wanted to discontinue medication) which stipulated that if certain conditions were met, both the medication and RSP program would be discontinued. This was a unique example of a parent enlisting the cooperation of the child to assist in getting the best fit with the school. It very subtly suggests that there may be some element of motivation or effort on the patient's part that can be added to the mix, and offers some evidence that this level of motivation may be sufficient to impact the fit. Martin's mother spoke about the contract: "when he got into $7^{\text {th }}$ and $8^{\text {th }}$ grade middle school, we made a contract with him - if you can at least make a C in all of your classes you no longer have to be on the medication and you won't have RSP anymore - he just began to start it when he got into junior high but you know he was just so against it..." (the medication and RSP). Martin kept his grades high enough to come off the medication and the RSP program was discontinued. Other informal modifications made by parents included dietary changes, where parents either eliminated some type of food in the diet or supplemented it with a specific type of food or nutrient.

Formal modifications also included medication changes made by the physician. These modifications involved completely changing the medication, changing the 
formulation (short or medium or long acting), raising or lowering the dose, changing the times of administration and discontinuing the medication. Some physicians wanted the medication given on school days only, some wanted it given daily with the exception of summer and other holiday periods, and some changed the method of administration over time. Since some children cannot swallow medication, the option of opening the capsule and sprinkling the contents was another modification that was made by the physician.

Parents made their own modifications with medication. These included changing the time of the dose so it was convenient with the family's schedule, limiting the dose of the medication so that it was only present in the child's system during the school day, giving it only on school days and giving it to the child to administer by himself or herself instead of having the school administer it. Examples of the informal modifications made by parents included changing the dosing intervals as explained by Allen's mother: “second year we started spreading it out because we felt just didn't like the way it made him so...". This action, which impacted adherence, was taken as the child was experiencing side effects from the medication. Fred's mother did not give the medication on a daily basis and discussed this with the physician: "at first we gave it seven days a week and then the first summer we didn't give it and then the pediatrician or the psychiatrist said that's not a good thing, he needs to take it all the time...". In some cases the physician left the decision to the parent regarding how much of the medication to give, and even whether to give it at all. Gary's mother was given this responsibility by the physician and she had this to say: "they prescribed seven days a week but the doctor said you know, you have to monitor it yourself - only give it to him only when you think he needs it...". Side effects usually necessitated changes (but not necessarily 
discontinuation) to medication and side effects were evaluated formally by the physician and also informally by the parent. Requesting and making modifications were the processes that parents used to get the best fit. Once the modifications were made, they were evaluated by the parent as being helpful or not.

Reassessment of the fit by the parent took place once modifications were made. Sometimes a child will receive treatment and the fit seems to be good for a period of time. All of a sudden something changes (the cause may not be readily apparent), and the child does not seem to do as well as he did prior to the occurrence of this change. The treatment itself does not need to change for this to occur, for sometimes this can take place in response to a change in context or condition. For example, the child who grows two inches and gains 15 pounds may need a higher dose of medication to be able to sustain attention to a task. If the dose of medication remained the same despite a substantial increase in height and weight, the child would likely not do as well in school as he would if the dose of medication was increased.

\section{Consequences}

If the fit was assessed as being adequate, no further action took place, however if the fit was still not adequate, parents tried new things (modifications), or in some cases settled for tradeoffs. Unlike making modifications which is an ongoing process, making tradeoffs is an acknowledgement that a perfect fit for the child in the school setting may not be attainable. The recognition of a situation as a "tradeoff" implies that a parent has already evaluated the situation. Giving up one thing or settling for something that was not really optimal in exchange for something else was a common theme in the interviews. Allen's mother described the consequences associated with tradeoffs: "as soon as we took 
him off it those things ceased but his grades plummeted - so I don't know... he's having Cs and Ds and an F but he's getting along and his teachers love him...I don't know what the tradeoff is.". Fred's mother seemed certain that the tradeoff had a cost and a benefit: "I think he hasn't reached his full height potential because of the medication and that kind of makes me sad but the I you know the tradeoff is him not having any peers that really want to have anything to do with him so I think that's been an OK tradeoff". Gary's mother also alluded to the tradeoffs: "I think she understands the whole thing how it impacts the kids, you know they can't socialize and get along and does poorly in school their self esteem is just very bad and you know that probably has a worse effect on the kids than having the kids take the medication". Harry's mother also referred to a tradeoff when she said: "I hate drugs...they keep him conformed so he can be with the rest of the population and not drive the teacher and other children crazy". It is clear that not all parents thought about tradeoffs in the same way, for some parents thought that the benefit of the medication offset the social costs inherent in not taking it and another expressed the social value of the medication in being able to sit in a classroom without disrupting others.

How do parents know they have found the best fit? This question cannot be answered completely by this study. The process of finding the best fit is linear and according to the way in which the study was constructed, this evaluation would need to occur at the point where the child turned 18 , when the child refused to participate in treatment, or when the responsibility for decision making was transferred to the child. For this study the point at which consequences should be addressed is the end point of the parental decision making treatment interval. In most cases consequences would be able to 
be evaluated when the child has become an adult and when the formal educational process has been completed. One way in which parents may see the "consequences" of their work in finding the best fit for their child specific to the school setting is in terms of what is seen as the criteria required for success in life. Each parent, however, may have a different idea about what would constitute the best fit and how that should be assessed.

Although not a part of the formal results of this study, Nathan's mother provides a good example of this evaluative process, or what could be attributed to the consequences dimension. Although Nathan has not yet completed his education, his mother spoke about the three things articulated by his physician that can be used to measure an adult's success in life: "the doctor told me the ultimate test is if you finish school, if you can hold a job, and if you can get and stay married - those are the adult measures of success". Only Carter and Ian had completed their education and were working adults when this study was conducted. Ian was not interviewed for the study and his mother gave her impression of his overall success in life when she said: "that boy is amazing...he has had a very successful life now he's wanting to go back to school he graduated from University of...he wants to go back and do another venture to do a goal he just has big goals you know and he succeeds in them...". It would be helpful to interview these parents in the future to learn more about how they perceive the results of their work in finding the best fit and the level of success of their children at the point at which their role as decision makers ends. It would be very interesting to continue a program of qualitative research by interviewing the children described in the study and eliciting their perspectives about treatment. 


\section{Chapter Five \\ Conclusions and Implications for Practice, Education, and Research \\ Conclusions}

The initial intent of the study was to learn more about decision making and the experiences of parents with stimulant medication treatment for their children with ADHD; however parents seemed to be more interested in discussing treatment in the context of their child's educational experience. This research was very informative in the sense that few studies have had the opportunity to look retrospectively at treatment for $\mathrm{ADHD}$ over a long period of time, and many parents spoke about treatment over intervals that spanned many years. In fact, in one case this involved several decades. In addition, there is a paucity of qualitative studies examining decisions to use multimodal treatments concurrently for children with ADHD, and quantitative studies examining medication adherence have been conducted over relatively brief periods of time.

The treatment for ADHD takes on a different perspective when the condition is considered as a chronic illness. In this study it was clear that parents spoke about three separate time intervals in which to examine decision making; the first extending from the point at which symptoms were identified (including the prompt to obtain the initial evaluation) to the point where the diagnosis was made. The next interval, the focus of this particular study, began at the point where treatment was initiated and ended where either the child refused treatment completely or where decision making responsibility for treatment was transferred from the parent to the child. The third time interval includes the 
time period where the child or young adult assumes responsibility for decision making about medical treatment.

It is important to look at each of these three intervals separately and together. Together they form the chronological sequence of treatment over time specific to an individual child. In the event these time periods were to be studied as separate intervals, the matrix for each interval would likely differ considerably. This has implications for treatment, for example, had the interval for this study been the period between symptom identification and diagnosis, the parent's perspective framework might have been the central dimension, rather than getting the best fit for the child specific to the school setting. Had the focus of the study been going forward in time from the point of transition of decision making responsibility, the central dimension might have been finding his or her own way. This was an exploratory study and further research will serve to clarify more specific areas pertinent to $\mathrm{ADHD}$ treatment where additional research is needed.

The data obtained from the 14 interviews with parents were utilized to construct a matrix that helped explain parental decision making about ADHD treatment. It is clear that despite every effort made to obtain a multiethnic, diverse sample, the sample of mothers participating in this study was homogenous. These parents valued educational success and had a fairly high socioeconomic status. The average household family income exceeded $\$ 100,000$ in $64 \%$ of cases and over $\$ 75,000$ in $78 \%$ of cases. Twelve of the 14 mothers interviewed were Caucasian and the other 2 were Asian. More than $64 \%$ of the children attended a private school at some time during the treatment interval.

The central dimension of the matrix, or that which provided the best explanation for parental decision making about ADHD treatment was found to be getting the best fit 
for the child specific to the school setting. The contextual dimensions included the perspective framework of each party to treatment (parents, relatives, physicians, school staff, teachers, coaches), doing what's right for my child, personal qualities (identified by the parent), parental assessment of the intellectual abilities of the child, not getting along with other children/not fitting in and public/private school setting. The conditions included the relationship between the parent and teacher (or school staff where applicable), stigma, and having no choice, or feeling pressured. The processes involved with getting the best fit included requesting and making modifications and learning curve. Finally, the consequences of getting the best fit included tradeoffs.

In dimensional analysis consequences, or the results of actions relative to the choice of the perspective of the study, form part of the matrix. Since this study was exploratory, the fact that the youngest child is only 10 years of age and has not yet completed school, curtails the ability of this research to adequately address consequences. What would be beneficial in future would be to include additional interview questions about the criteria that parents would use to evaluate the fit as being a good one, and in terms of inclusion criteria, make sure that every child was at least 18 , finished with his education, working, and had had the decision making responsibility transferred from the parent for this evaluation to be able to take place. As the contents of the interviews were not anticipated, it is still somewhat premature to discuss the consequences of finding the best fit specific to the school setting for the children described in this study.

The other common themes however, have provided an explanation for the treatment decisions made by these parents. In every case, it was the mother who adopted the primary caretaking role, and while some fathers were involved in the initial 
discussion about treatment, the mother was clearly the decision maker when it came to the child's treatment for ADHD.

In addition to the links evident with the three quantitative studies examined previously, Bayes theorem, the lens model and the Theory of Reasoned Action, data analysis of the interview content lends itself to the construction of a conceptual model regarding the best fit of the child in the school setting. In this model, both the relationships between the physician, parent and school staff, and negotiation of modifications were mediated by power. The relationship between the physician and parent was a clear example of "power over" where the physician had power over the parent, whereas the relationship between the parent and the school was an example of "power to". The structure of power in the relationship between the parent and the teacher or school staff was mediated even further by the type of parental relationship that existed with the teacher and/or school, in terms of a personal relationship, working relationship in the classroom (volunteer), or as a member of a formal group (parent teacher association).

Figure 2. Power Relationships and Mediators

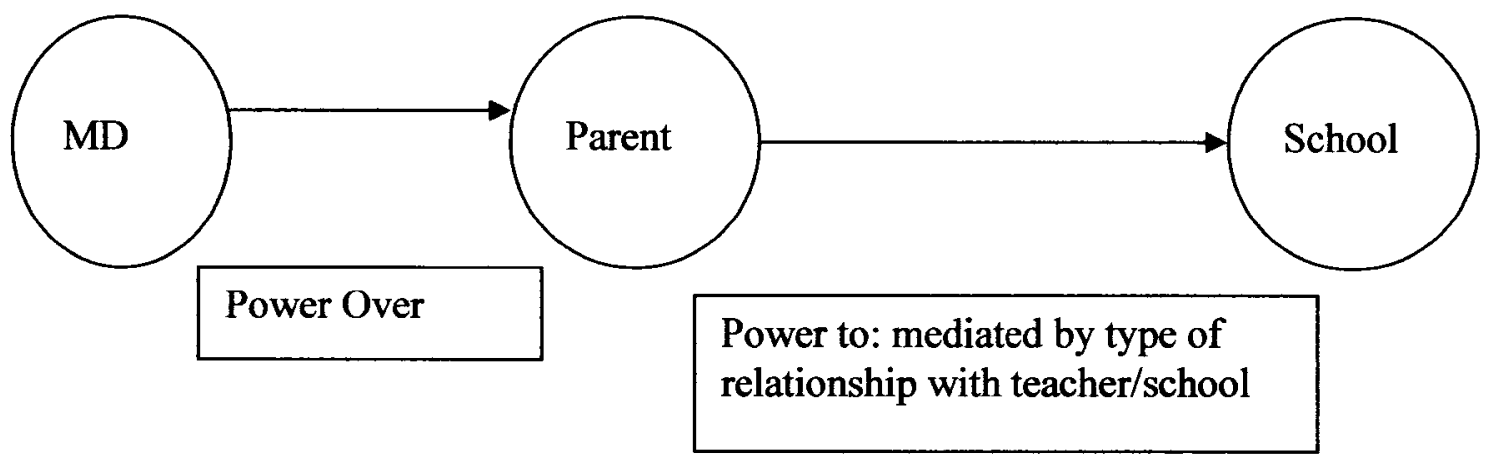


Cues relevant to the child's behavior are picked up by far the majority of the time by teachers or staff members at the child's school, and as a result, the parents are contacted and the suggestion (prompt) is made that the child should be evaluated for ADHD. The types of cues (cluster of symptomatic behaviors) picked up in the environment include impulsivity, hyperactivity, being disruptive in class and inability to sustain attention to a task. Once the prompt has been made, the child is referred for a formal evaluation where the diagnosis is established.

Since the standard of care for ADHD treatment at this time is stimulant medication, once the evaluation is made, the child is then referred to a physician for a medication evaluation. At that point it is up to the physician whether or not to prescribe medication. In spite of a longstanding history and increased awareness of a disparity in power in the physician/patient or physician/parent relationship, this inequality is still apparent. The inability to mitigate this positional disparity in power could account for parent's decisions to make modifications concerning medications on their own, as changing physicians entirely, changing medication doses, the timing of administration, or discontinuing medication treatment entirely without contacting the physician.

Once the diagnosis is confirmed, the parents have accepted or at least agreed with the diagnosis and there is some awareness on the part of relatives, significant others to the family, the school and the physician and parent, the perspective frames come into play. The initial treatment, usually medication, is filtered through the perspective frames of the parent, who views the factors affecting the child's "fit" in the public or private school setting. These factors include not fitting in/not getting along, stigma, feeling 
pressured, personal qualities of the child, parental assessment of the intellectual abilities of the child, and doing what's right for my child.

Around the time of the child's evaluation, the learning curve begins, and parents seem to actively seek out information about the condition, its treatment and resources that can be accessed to meet the needs of their children, particularly in the school setting. This activity is ongoing, and as the parent's knowledge base increases, this increase in knowledge adds to the parent's power to request and make modifications that affect the fit of the child in the school setting. Parents were seen to negotiate with the school for formal changes such as IEP and 504 plans, tutoring, additional time for testing and other accommodations, and for informal changes as preferred seating arrangements in the classroom, tutoring and changing the daily schedule for academic and non academic subjects. The ability to negotiate the changes also appeared to be related to the parent's relationship with the school staff or teacher. Where the relationship of the parent and the school was positive, the changes seemed to be easier to put into place.

In some instances parents looked for schools that may offer a good fit for the child and in instances where the parent and school were unable to work out the changes, the parent usually ended up changing the child's school. In situations where the physician recommended treatment that was inconsistent with the parent's perspective frame, the parent usually changed physicians or discontinued medication entirely. From the interview data, it was evident that negotiating changes with the school was an ongoing process, whereas meetings with the physician were intermittent and occurred less frequently. Communication with the physician seemed to be very limited. Many parents discussed the fact that the child had side effects from medication, however there were 
only a few references made to contacting the physician in between visits if this communication took place at all. Some parents indicated that they discontinued the medication and did not mention whether or not the physician was contacted.

From the conceptual model below, it is apparent that decision making is impacted by the perspective frames of all parties to the treatment of the child, that power relations govern interaction between the parent and physician and the parent and the school, that power relations between the parent and school are affected by the parent's relationship with the school, and that the result of parental reassessment of the fit of the child in the school setting results in tradeoffs in some situations. The power of the parent to negotiate changes with the school increases as the parent gains more information about the condition. The model works with a feedback loop since the changes made by the parent are reassessed and modifications are requested and changed on a virtually ongoing basis. The conceptual model is represented in the diagram below. 
Figure 3. Conceptual Model Best Fit

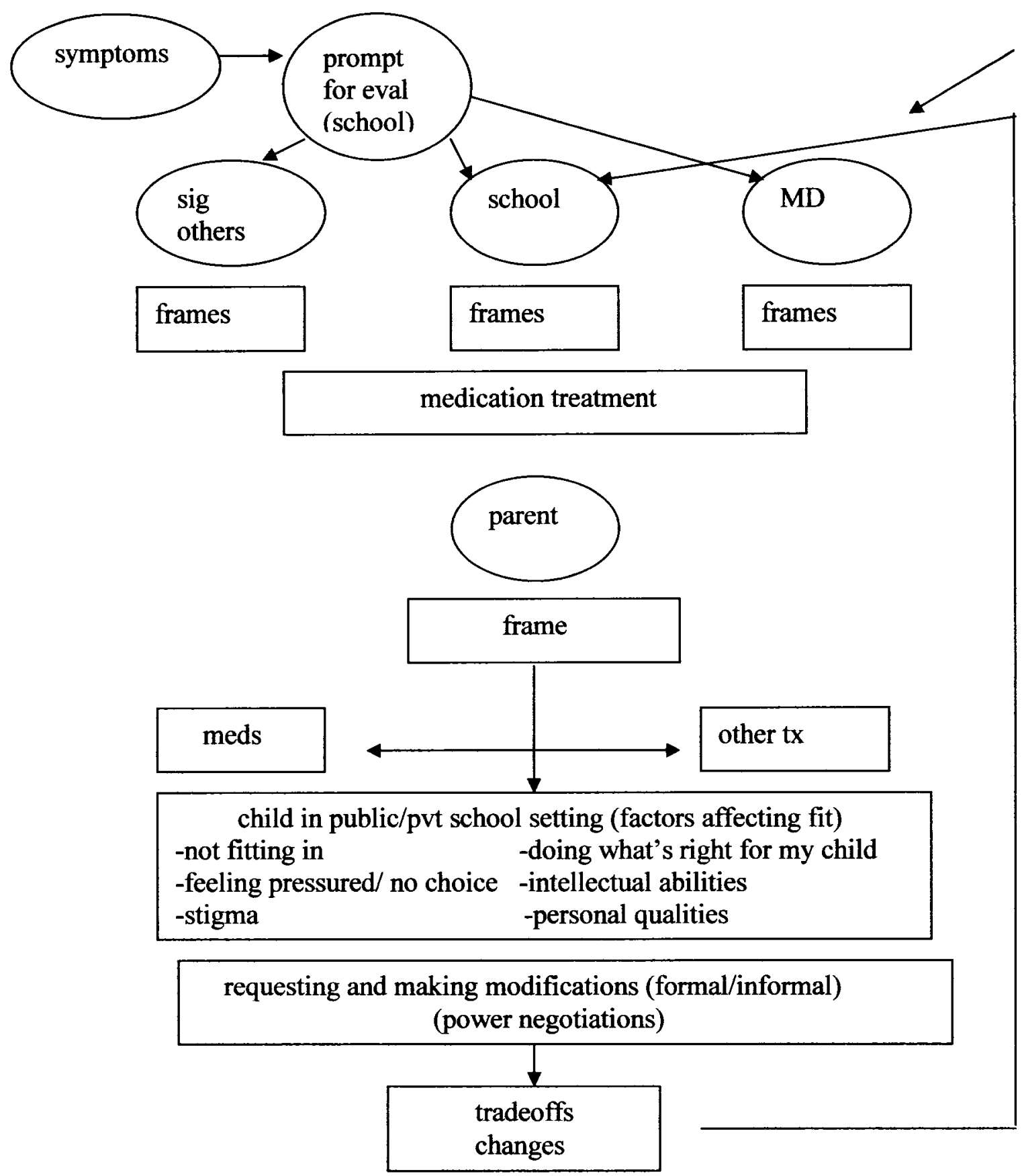




\section{Implications for Nursing Practice}

The findings of this study suggest that it might be helpful to monitor a child being treated for ADHD approximately every three months and even more often if needed. Even though the child may be stable on medication, other changes in the child's life may necessitate more frequent review since it was clear that change was not only ongoing but occurred frequently. Since the "perspective framework" of the various parties to the treatment of the child seemed to have an effect on parental decision making, it would be very helpful for the provider treating the child to have an understanding of these various perspectives. Having a good sense of "where everyone is coming from" is likely to give the primary provider an idea about pressing issues and also the kinds of issues that might surface in the future. This knowledge would enable the clinician to provide an adequate amount of useful information for the parents and patient. It also would give the provider an opportunity to clarify misconceptions, educate parents about the condition and available treatments, and even a chance to offer suggestions about how parents can respond to individuals who may not be supportive of treatment. Sharing this information with the provider opens up the communication between the parents and the clinician.

Understanding the perspective framework of the parents will also give the health care provider some idea about whether parents accept and agree with the diagnosis. When the health care provider is aware of the parent's level of agreement, communication is facilitated, and parents and providers can move forward because they are "on the same page". When the goals of the parent and the goals of the physician are not made explicit, there is a potential for conflict and uncertainty. The basis for both of those things may be beyond the awareness of both parties to the interaction. For example, a physician may 
want to maximize the child's dose of medication to improve his attention span and for the purposes of being able to complete homework in the evening; however the parent might have been reluctant from the outset of treatment to put the child on medication and may therefore want the child to take the lowest dose possible with coverage for school hours only. Adherence to a treatment plan is impacted when the parent and physician have different goals in mind.

The children discussed in the study were seen by physicians who were specialists, including: pediatric neurologists, pediatricians, behavioral physicians, child psychiatrists, psychiatrists and psychopharmacologists. There are times when a child may benefit from seeing a different physician from a second specialty area for another opinion or when other issues are raised in the course of treatment. When parents are not comfortable with the diagnosis and are encouraged to express their concerns at an appointment, the clinician has the opportunity refer the parent to a specialist. In cases where the parent has not accepted the ADHD diagnosis or thinks that there may be a comorbid disorder present, a referral or second opinion made early in treatment may resolve the problem so that treatment can continue. The health care needs of less complex ADHD patients can be met by advanced practice nurses and the staff nurse can provide the integral link with the school and critical case management services.

One of the rather unexpected and surprising findings of this study is the concern parents had about their children in the school setting. Although these findings cannot be generalized to other groups of parents of children with ADHD, they do support the need for better integration of care between the family, the health care system, the school and the community and increased communication within a multidisciplinary treatment team. 
Regular contact between parents, either by phone or in person between teachers and primary care providers can help provide a good "fit" for the child at school, may prevent the need to make frequent medication or dose changes and improve satisfaction with care among parents, physicians, teachers and patients. Medical clinics and schools within the same geographical catchment area can create confidentiality agreements so that regular contact about students from local schools who are being seen for ADHD treatment at community health clinics can be established. The child's social skills at school surfaced as an issue in many of the interviews and many mothers brought up concerns with self esteem, stigma and taunting or teasing by other children. Regular meetings with health care providers, parents, teachers and patients can serve to raise awareness of the problems associated with getting the patient to the nurse's office for medication at lunch time or after school. It may be beneficial to provide these children with constructive ways with which to handle uncomfortable situations at school. Role playing would be one way of equipping children to effectively handle this behavior. Group therapy with a social worker or family therapist could help children express their difficulties and practice methods to handle unwelcome behavior in a safe environment. Interventions like these might prevent children from avoiding taking medication at school and increase self confidence. This study underscored the need for the education of teachers and school staff about ADHD, its etiology and treatment. It is anticipated that increasing the knowledge base of staff in the school setting will have positive health outcomes for both the child and family, and these educational needs can be addressed very effectively by nurses. 
Parents chose many other types of interventions for their children with $\mathrm{ADHD}$, including social skills groups, physical/occupational therapy, parenting classes, individual therapy, family therapy, nutritional interventions, neurofeedback, cognitive behavioral therapy, reward systems, home routines, structuring time through sports and outings, IEPs, 504s, RSP, informal classroom modifications and medication. Many of these therapies were initiated by the parent. Clinicians can also provide information about complementary and alternative treatments to medication and explain studies that have examined their effectiveness. This is important for all parents but especially for parents who are not going to utilize medication or in cases where the parent is not interested in increasing the dose of medication to the most effective dose for a particular child.

The implications for nursing practice are numerous and include ensuring that appointments are scheduled at more frequent intervals than every six months, improving communication about parental interventions and other therapies in use, integrating care between the family, school, health clinic and community (liason activities), educating parents about the use of medication and what to expect from medication treatment, initiating referrals for a second opinion or further diagnostic testing when and if necessary, referring to psychiatry for family or individual counseling and case management functions where appropriate.

Implications for Nursing Education

It is unfortunate that few schools offer the opportunity for students to rotate through child and adolescent psychiatry. Pediatric clinical practicum for nurses often has a hospital focus. It is not uncommon therefore for graduate nurses to have little if any exposure to children who have this very common condition. Treatment of the child must 
always take the family into account, and nurses taking care of these young patients should have some formal education to be able to deliver effective care. This is true both at the entry level for registered nursing and at the university levels. This could be accomplished through preceptorships offered by advanced practice nurses who are responsible for the care of these children.

Educational needs include a good understanding of the stimulant, antidepressant and antihypertensive classes of medications including their indications, dosages and side effects. Nurses should be educated to monitor patients for symptoms that would necessitate discontinuation rather than a reduction in dose so that information can be given to the nurse practitioner or physician. Case management skills should be included as part of the education needed to be effective in the pediatric psychiatric or case management roles, as the nurse is often the first person contacted by the parent regarding medication effectiveness or problems. Better utilization of nursing knowledge and skills can mitigate many of the difficulties encountered by ADHD families.

Implications for Nursing Research

The last study that addressed adherence with medication and that was included in the original literature review was completed in 2002. Prior to the initiation of this study, the following areas looked to be the most promising in following an ongoing program of nursing research. Most of the previous research was conducted using short acting stimulants that required dosing at home and school. The development of time release intermediate and long acting preparations has facilitated single daily dosing. Only a few patients in the two most recent studies took intermediate acting preparations. It is likely that dosing once per day at home may increase adherence to medication treatment. 
Other important considerations for future research include noting who discovered the problem and how this was brought to the attention of the parents. This information has the potential affect treatment choices. Pressure placed on parents by school staff may affect medication adherence, especially where the school refuses to keep an unmedicated child in class. Pursuing this avenue of research presents the opportunity for collaboration between clinic and school based nurses to ensure continuity of care.

$\mathrm{ADHD}$ is a multifaceted problem involving chronic illness. Since children progress through a number of stages of growth and development and assume decision making responsibility for themselves as they get older, it may be more productive to study small segments of the ADHD population. The difficulties inherent in studying $\mathrm{ADHD}$ as a single problem are too significant to suggest the development of one unifying framework.

Another line of investigation may include examining medication administration as a process, particularly where there are multiple caregivers or shared custody. Morning routines may have implications for a family to be able to administer medication prior to the beginning of the school day. Finally, studying medication treatment of ADHD in the context of a chronic illness may be beneficial for making some assessments of this treatment and adherence over the long term.

\section{$\underline{\text { Conclusion }}$}

The results of this study indicate that a different approach to examining parental decision making regarding medication treatment for children with ADHD may be warranted. First, it appears that the suggestion made by Thiruchelvam et al (2001, p. 925) that studying adherence to stimulant treatment as an ongoing process where children start 
and stop medication at various points in time was supported by this research study. Parents often stopped medication over summer holidays and restarted it in the fall when the new school year began. In one instance, the teacher did not want medication administered (contrary to the wishes of the child's parent) and in order to restart the medication the parent resorted to changing the child's school. In another example where the parent had discontinued the medication due to side effects, the physician suggested the parent restart it after the child had grown taller and gained weight. One teenager discontinued the medication for a period of time to determine whether there was a continued need to take it and discovered that she was unable to function without it. The medication was then restarted.

Bayes theorem is a mathematical formula which establishes a rule for decision revision based on evidence. The objective of the rule is to narrow the gap between how decisions should be made and how they are actually made, and as a result Bayes theorem belongs to the prescriptive family of decision making theories and models. It is probable that the acquisition of new information will improve decision making and that this is mathematically predictable. The dimensions and areas identified in the study that are salient to this decision rule include learning curve, acceptance of or agreement with the diagnosis, communication of the various frames regarding the treatment of the child, including making covert frames overt, and tradeoffs.

Learning curve refers to the acquisition of new knowledge by the parent, whether this is related to knowledge about the diagnosis or any of the treatments for ADHD. The learning curve usually begins early in the child's life (with the identification that the child's behavior differs from that of his peers) and is lifelong. Parents utilized a variety of 
sources to gather information including CHADD, relatives, school staff and teachers, physicians from several specialty areas, libraries and various media sources. It is logical to think that as parents increased their knowledge about the disorder, the treatment and the medications utilized to improve focus and impulsivity, their ability to make better decisions improved. Sometimes it is not as necessary to gain additional information as it is to make the information one utilizes explicit. In an earlier discussion and in the model presented, it was apparent that the goals of parents and physicians and the frames of all the parties associated with the treatment of the child may be incongruent or covert. One way in which to increase the information available to the parent and to the physician is to improve communication by making what is covert, overt. When all of the information pertinent to treatment is made available to the decision makers, better decisions can be made. Since perspective frames may be psychologically oriented, some may be resistant to change, despite being challenged by the availability of new and reliable information or research. Perspective frame congruence can benefit treatment of the child, as the study results suggest that this is one of the reasons that parents change the child's school, teacher or physician.

Parents occasionally made tradeoffs after evaluating information, and giving up one thing to get another is contingent upon the quality of the information utilized to make these kinds of decisions. The ability to obtain an adequate amount of correct information with which to evaluate two courses of action cannot do anything but improve the ability of the parent to make difficult decisions. The theoretical link between Bayes theorem and this study supports the need to clarify information that may not be communicated overtly in terms of goals of the physician and parent, identify the perspective frames of the 
various parties to treatment to better understand the needs of the parent, child and clinician, and to strengthen the ability of the parent to make good choices in decision situations where tradeoffs are involved. The acquisition of new information would involve learning new information and making the unknown, known.

The association of the results of the study with the theoretical underpinnings of the lens model involves parental actions taken as a result of picking up cues from the environment, assigning various weights to the cues and utilizing this information in the exercise of judgment or decision making about medical treatment. At the very least, three separate studies could be conducted to examine parental decision making with stimulant medication. The first study could determine how well the cues in the environment picked up by parents to ascertain that their child's behavior warrants further investigation reflect the true picture of the condition. Medication efficacy could then be described in the context of changes in these cues.

The kinds of cues parents identify as being important in the school setting may provide the criteria used to assess fit. A parent could describe what she would like to see happen ideally, and what actually happens could be compared with what actually did happen. Although the study did not identify exactly what it is that parents utilized as the criteria constituting a good fit in the school setting, it appeared that when the situation was not seen as being a good fit, parents requested and made modifications regarding a number of different elements of treatment, including changing teachers, schools, physicians, friends, activities and medication.

Parents also picked up cues related to the use of medication, and this can be useful theoretically in examining how parents make choices about whether to give, not give or 
make changes to medications compared with the decisions of health care providers. In this instance, an optimal model can be created and parent decision making relative to continuing or discontinuing medication can be compared with that of physicians. The results of the qualitative study indicate that some of the changes made by parents may have been due to the perspective frame of the parent or other individuals, however parents still may not have sufficient information to be able to evaluate the real situation and pick up the correct cues related to medication use. If this was the case, covert perspective frames may add some uncertainty to the model and this may interfere with achieving a high correlation between the proximal and distal stimuli. An optimal model would not necessarily be a model common to all children, but a model created for one child.

The example above represents the double system lens design, where the left side of the lens represents the optimal model and there is good ecological validity, or where the value of proximal cues and value of the distal criterion have a high correlation to one another. The right side of the lens, the mirror image of the left, is the side where the parent assesses the real situation, picks up cues from the environment, assigns weight to the cues and makes a decision based on that information. Due to some naturally occurring uncertainty in the model, it is not possible to get exact congruence with "real" situation, unless this occurs purely by chance. This model may provide some utility for examining parental decision making quantitatively, however further qualitative work would be needed before more related qualitative studies could be conducted.

An example of how parents can better utilize cues in decision making follows. A parent goes to the school and observes that her child is not fitting in socially with the 
other children. The parent is not able to make the distinction between the child not being able to follow the rules of a game versus not picking up on social cues from peers. The intervention in terms of treatment for these two cues is likely to be very different. The inability of the child to follow directions may be due to inattention or distraction and this may be improved with the administration of stimulant medication. The inability of the child to pick up on social cues may indicate the need for the child to attend social skills groups. By educating the parent about symptomatology and what can be expected from various kinds of treatments, cue perception and subsequently adherence to treatment may improve. These interventions will help shift the decision making process from the real toward the ideal.

Cue weighting is also applicable to continued research with the lens model. Different parents have different ideas about what they expect from treatment. One parent wanted her child to feel like he was a good boy at school by not getting into trouble in the classroom. Another parent decided to give medication as a result of safety concerns as his impulsivity likely contributed to an accident where he was run over by a car. When parents identify goals they have in mind for the child, a more individualized and appropriate treatment plan can be established. A better interpretation of cues and improved correlation between cues and goals can be achieved with education about ADHD symptoms and treatment.

The perception of cues, whether from the school, from teachers or from physicians, was related to a number of dimensions identified in the interviews, including the cluster of symptomatic behaviors and prompt for evaluation. In the majority of cases, it was the school that prompted the parents to seek an evaluation of the child. Perhaps the 
symptoms were more visible in the school setting than at home, however improving the education of parents with children at risk for ADHD about symptomatology would improve the parent's ability to pick up specific environmental cues that indicate the child is having some difficulties with behavior. Parents may be able to intervene earlier and not have to depend on the school to pick up the cues and suggest the referral. The fact that the parent picks up the behavioral, diagnostic cues also has the potential to affect the parent's agreement with or acceptance of the diagnosis.

Increasing the level of knowledge about symptoms, the condition and treatment, is consistent with the dimension learning curve and this will undoubtedly assist the parent with improving cue perception and setting appropriate goals for the child. The correlation between high quality of information and cue perception, and the ability to pick up cues accurately from the environment may lead a parent to obtain further information or treatment that is more specific to the individual child. For example, one interesting finding of this study was that the children were seen by physicians from a number of specialty areas including pediatrics, developmental pediatrics, pediatric neurology, psychopharmacology and psychiatry. A child with difficulty picking up social cues might benefit from an assessment by a behavioral pediatrician whereas the child who is too busy running around to engage in a game with his peers might better be served by a pediatrician. Similarly, the teacher who is not responsive to a parental request for informal classroom modifications like having the child sit at the front of the class may benefit from education by a parent who is equipped with a handout explaining specific modifications that can be used to improve attention in the classroom setting. The parent however, must be able to make the distinction that the teacher is willing but lacks 
knowledge or whether there is frame conflict where the teacher does not believe in the diagnosis and may be attributing inattention and hyperactivity to volitional behavior on the part of the child. Equipping parents to be able to make these assessments early in the trajectory of treatment has the potential to affect health outcomes for the child. The utility of the lens model as a single or double model (with or without an optimal model) to improve the care of children with ADHD will be contingent upon further research assessing the benefits of both alternative treatments and mixed treatment approaches for the condition.

The Theory of Reasoned Action, is the third theory with applicability to the findings of the study. The emphasis of this theory is on the mental calculations involved prior to making a decision and how they bear upon the ability to understand and predict behavior. Attitude, belief and intent are concepts integral to the theory. According to the theory, a parent who believes that stimulants are effective in reducing impulsive behavior is more likely to give medication to an impulsive child. The opposite is also true, that a parent who believes that stimulants are not effective is not likely to give the medication. This is referred to as a behavioral belief, in contrast to a second type of belief, the normative belief.

The normative belief is related to the pressure exerted by significant others in the life of the parent to engage or not engage in a particular behavior. The analogy for this study would be whether the pressure placed on parents to decide whether to put a child on medication affected the parent's decision. The parent of a child with ADHD struggling with a decision about whether or not to give stimulant medication might act based on his perception of whether or not his father, brother or mother thinks he should give the 
medication. As seen in the study, several mothers alluded to the fact that they heard, but weren't concerned about the opinions of others when it came to making medication decisions for their children, as they were going to do what's right for my child.

Subjective norm also had some similarity to another dimension, feeling pressured or having no choice. A clear example of this was evident in Ian's case where the mother reported that the child's teacher said "you either do something about this or you've got to leave". At first there may seem to be some incongruence between doing what's right for my child and feeling pressured or having no choice. Doing what's right for my child was usually evident in response to significant others expressing negative beliefs about placing children on stimulant medication. Parents often felt pressured by others however, to engage in specific behaviors to do what was right for their child in spite of their own frame or as a tradeoff. For example, one parent from an "alternative" family with negative beliefs about giving children medication gave it despite the existence of a strong frame, but it is evident that this parent not only felt very pressured, but at the same time thought she was doing the right thing for her child. The existence of a frame makes decision making even more complex and difficult for parents.

Both attitude and subjective norm are considered together and are affected by one's intent to perform the behavior (Johnson \& White, 2004). Intent refers to the probability that the person will engage in a particular behavior. The authors go on to specify that intent refers to engaging in the general behavior, so that use of the model would preclude the ability to predict which parents would give a "low dose" of the medication, or those who might modify the dosing schedule or change the medication (Fishbein \& Ajzen, 1975). The model might be helpful in predicting and understanding 
medication behavior in general, however its ability to account for the nuances in specific behaviors that affect adherence is limited.

Of the three theoretical approaches described, the lens model offers the best application for improving parental decision making in the area of stimulant medication administration. This group of parents is not a representative sample of parents with children who have ADHD however, and the results of the study are not generalizable. This conclusion underscores to the need for additional research in this area.

Additional research placing ADHD in the context of a chronic illness is needed. Another study that could be considered based on the findings of this qualitative study would involve asking parents who were interviewed for this study whether they would be willing to participate in a second study and interview. The foci of the second study would be to identify the criteria the parent utilizes in determining that good fit for the child exists in the school setting, to gain more information about the parental perspective toward medication treatment relative to other treatments for ADHD, and to find out about the kinds of things parents use as measures of success for their young adult children. This effort would serve to clarify decision making for parents in this particular sample, however the results of the second study could not be generalized to all parents.

Despite limited research about alternative treatments for ADHD and initial research findings that treatments other than medication are not effective, it was found that parents are utilizing multiple treatments concurrently. The limited amount of research that has been conducted in the area of treatments other than medication to date does not support their effectiveness. More research, however, that addresses the use concurrent mixed treatment approaches may lead to different conclusions about their utility. The 
conclusions of this particular research study suggest that with a better understanding of the way in which parents perceive the condition, communicate about it with others, utilize treatments and make changes over time, nurses have the potential to improve patient care and outcomes for children with ADHD. 


\section{References}

Abbey, R. (2000). Charles Taylor. Princeton: Princeton University Press.

Allen, A. (1999). Solidarity after identity politics: Hannah Arent and the power of feminist theory. Philosophy and Social Criticism, 25(1), 97-118.

American Academy of Child and Adolescent Psychiatry. (1997). Practice parameters for the assessment and treatment of children, adolescents and adults with attention deficit hyperactivity disorder. Journal of the American Academy of Child and Adolescent Psychiatry, 36(Suppl. 10), 85S-121S.

American Academy of Child and Adolescent Psychiatry. (2002). Practice parameter for the use of stimulant medications in the treatment of children, adolescents and adults. Journal of the American Academy of Child and Adolescent Psychiatry 41(Suppl. 2), 26S-49S.

American Academy of Pediatrics. (2000). Clinical practice guideline: diagnosis and evaluation of the child with attention-deficit/hyperactivity disorder. Pediatrics, $105(5), 1158-1170$.

American Psychiatric Association. (1980). Diagnostic and statistical manual of mental disorders ( $3^{\text {rd }}$ ed.). (DSM-III). Washington, DC: American Psychiatric Association.

American Psychiatric Association. (1987). Diagnostic and statistical manual of mental disorders ( $3^{\text {rd }}$ ed., revised) Washington, DC: American Psychiatric Association. American Psychiatric Association. (1994). Diagnostic and statistical manual of mental disorders (4 ${ }^{\text {th }}$ ed.). (DSM-IV). Washington, DC: American Psychiatric 
Association.

American Psychiatric Association. (2000). Diagnostic and statistical manual of mental disorders $\left(4^{\text {th }}\right.$ ed., revised). (DSM-IV-TR). Washington, DC: American Psychiatric Association.

Andermahr, S., Lovell, T., \& Wolkowitz, C. (2000). A glossary of feminist theory. New York: Oxford University Press.

Anderson, B.F., Deane, D.H., Hammond, K.R., \& McClelland, G.H. (1981). Concepts in judgement and decision research: definitions, sources, interrelations, comments. New York: Praeger Publishers.

Arent, H. (1958). The human condition ( $2^{\text {nd }}$ ed.). Chicago: University of Chicago Press. Arrive, E., Anaky, M.F., Wemin, M.L., Diabate, B., Rouet, F., Salamon, R., et al. (2005). Assessment of adherence to highly active antiretroviral therapy in a cohort of African HIV-infected children in Abidjan, Cote d'Ivoire. JAIDS: Journal of Acquired Immune Deficiency Syndromes, 40(4), 498-500.

Austin, J.K. (1989). Predicting parental anticonvulsant medication compliance using the Theory of Reasoned Action. Journal of Pediatric Nursing, 4(2), 88-95.

Azjen, I., \& Fishbein, M. (1980). Understanding attitudes and predicting social behavior. Englewood Cliffs, NJ: Prentice-Hall Inc.

Baird, B.F. (1978). Introduction to decision analysis. North Scituate, MA: Duxbury Press.

Bachrach, P., \& Baratz, M.S. (1969). Decisions and non-decisions: an analytical framework. In R. Bell, D.V. Edwards, \& R.H. Wagner (Eds.), Political power: a reader in theory and research (pp. 100-109). New York: Free Press. 
Barkley, R.A. (1998). Attention - deficit hyperactivity disorder: a handbook for diagnosis and treatment. New York: The Guilford Press.

Barkley, R.A., DuPaul, G.J., \& McMurray, M.B. (1990). Comprehensive evaluation of attention deficit hyperactivity disorder with and without hyperactivity as defined by research criteria. Journal of Consulting and Clinical Psychology, 58(6), 775789.

Barkley, R.A., McMurray, M.B., Edelbrock, C.S., \& Robbins, K. (1990). Side effects of methylphenidate in children with attention deficit hyperactivity disorder: a systemic, placebo-controlled evaluation. Pediatrics, 86(2), 184-192.

Barnard, G.A., \& Bayes, T. (1958). Studies in the history of probability and statistics: IX. Thomas Baye's essay towards solving a problem in the doctrine of chances. Biometrika, 45(3/4), 293-315.

Beach, L.R., \& Connolly, T. (2005). The psychology of decision making: people in organizations ( $2^{\text {nd }}$ ed.). Thousand Oaks: Sage Publications.

Biederman, J. (2002). Practical considerations in the stimulant drug selection for the Attention - Deficit/Hyperactivity Disorder patient - efficacy, potency and titration. Princeton, New Jersey: Media for Education Inc. (Reprinted from Today's Therapeutic Trends, 20(4), 311-328)

Biederman, J., Kwon, A., Aleardi, M., Chouinard, V., Marino, T., Cole, H., et al. (2005). Absence of gender effects on attention deficit hyperactivity disorder: findings in nonreferred subjects. American Journal of Psychiatry, 162(6), 1083-1089.

Blumer, H. (1969). Symbolic interaction: perspective and method. Englewood Cliffs, NJ: Prentice Hall. 
Brown, R.T., Borden, K.A., \& Clingerman, S.R. (1985). Adherence to methylphenidate therapy in a pediatric population: a preliminary investigation. Psychopharmacology Bulletin, 21(1), 1985, 28-36.

Brown, R.T., Borden K.A., Wynne, M.E., Spunt, A.L., \& Clingerman, S.R. (1987). Compliance with pharmacological and cognitive treatments for attention deficit disorder. Journal of Child and Adolescent Psychiatry, 26(4), 521-526.

Brown, R.T., Borden, K. A., Wynne, M.E., Spunt, A.L., \& Clingerman, S.R. (1988). Patterns of compliance in a treatment program for children with attention deficit disorder. The Journal of Compliance in Health Care, 3(1), 23-38.

Brunswik, E. (1937). Psychology as a science of objective relations. Philosophy of science, 4(2), 227-260.

Brunswik, E. (1940). Thing constancy as measured by correlation coefficients. Psychology Review, 47(1), 69-78.

Brunswik, E. (1943). Organismic achievement and environmental probability. Psychological Review, 50(3), 255-272.

Brunswik, E. (1952). The conceptual framework of psychology. International encyclopedia of unified science, (Vol. 1, No. 10, pp. IV, 102). Chicago: University of Chicago Press.

Burkhart, P.V., \& Rayens, M.K. (2005). Self-concept and health locus of control: factors related to children's adherence to recommended asthma regimen. Pediatric Nursing, 31(5), 404-409.

Campbell, J.C., \& Bunting, S. (1991). Voices and paradigms: perspectives on critical and feminist theory in nursing. Advances in Nursing Science, 13(3), 1-15. 
Carroll, J.S., \& Johnson, E.J. (1990). Decision research: a field guide. Newbury Park: Sage Publications.

Cephalon Inc. (2006). FDA advisory committee recommends against approval of SPARLONTM for attention deficit/hyperactivity disorder in children and adolescents. Retrieved March 26, 2006, from http://phx.corporateir.net/phoenix.zhtml?c=81709\&p=irol-newsArticle\&ID=835182\&highlight $=$

Chan, E., Zhan, C., \& Homer, C.J. (2002). Health care use and costs for children with attention-deficit/hyperactivity disonder. Archives of Pediatric and Adolescent Medicine, 156, 504-511.

Charach, A, Ickowicz, A., \& Schachar, R. (2004). Stimulant treatment over five years: adherence, effectiveness, and adverse effects. Journal of the American Academy of Child land Adolescent Psychiatry, 43(5), 559-568.

Chinn, P.L., \& Kramer, M.K. (1995). Theory and nursing: a systematic approach (4 ${ }^{\text {th }}$ ed.). St. Louis: Mosby.

Chodorow, N. (1978). The reproduction of mothering: psychoanalysis and the sociology of gender . Berkeley: University of California Press.

Clark, C.D. (1998). In J. de Rivera \& Theodore R. Sarbin (Eds.), Believed-in-imaginings: the narrative construction of reality. Washington: American Psychological Association.

Cohen, N.J., \& Thompson, L. (1982). Perceptions and attitudes of hyperactive children and their mothers regarding treatment with methylphenidate. Canadian Journal of Psychiatry, 27(1), 40-42.

Collett, B.R., Ohan, J.L., \& Myers, K.M. (2003). Ten year review of rating scales, V: 
scales assessing attention-deficit/hyperactivity disorder. Journal of the American Academy of Child and Adolescent Psychiatry, 42(9), 1015-1037.

Concannon, P.E., \& Tang, Y.P. (2005). Management of attention deficit hyperactivity disorder: a parental perspective. Journal of Paediatric Child Health, 41, 625-630.

Conners, C.K. (2001). Conners' rating scales-revised: technical manual. North Tonawanda, New York: Multi-Health Systems Inc.

Conners, C.K., Sitarenios, G., Parker, J.D.A., \& Epstein, J.N. (1998). The revised Conners' parent rating scale (CPRS-R): factor structure, reliability and criterion validity. Journal of Abnormal Psychology, 26(4), 257-268.

Cooksey, R.W. (1996). The methodology of social judgment theory. Thinking and reasoning, 2(2/3), 141-173.

Coulter, R.A., Zaltman, G., \& Coulter, K.S. (2001). Interpreting consumer perceptions of advertising: an application of the Zaltman Metaphor Elicitation Technique. Journal of Advertising, 30(4), 1-21.

Crijnen, A.A., Achenbach, T.M., \& Verhulst, F.C. (1999). Problems reported by parents of children in multiple cultures: the Child Behavior Checklist syndrome constructs. American Journal of Psychiatry, 156(4), 569-574.

Crist, J.D., \& Tanner, C.A. (2003). Interpretation/analysis methods in hermeneutic interpretive phenomenology Nursing Research, 52(3), 202-205.

Crossley, N. (2005). Key concepts in critical theory. Thousand Oaks: Sage Publications.

Dahl, R.A. (1957). The concept of power. Behavioral Science, 2, 201-215.

Dahl, R.A. (1968). Power as the control of behavior. In S. Lukes (Ed.), Power (pp. 37-58) 
(Reprinted from The international encyclopedia of the social sciences, David L. Sillis (Ed.), vol. 12, pp. 405-415).

Davis, A.J., \& Aroskar, M.A. (1991). Ethical dilemmas and nursing practice ( ${ }^{\text {rd }}$ ed.). Norwalk, CT: Appleton Lange.

Deacon, S.A. (2000). Creativity within qualitative research on families: new ideas for old methods. The Qualitative Report, 4(3/4). Retrieved July 31, 2006, from http:// www.nova.edu/sss/QR/QR4-3/deacon.html

Denzin, N.K., \& Lincoln, Y.S. (Eds.). (1998). Strategies of qualitative inquiry. Thousand Oaks: Sage Publications.

Denzin, N.K. \& Lincoln, Y.S. (Eds.). (2000). Handbook of qualitative research. Thousand Oaks: Sage Publications.

Diamond, G.A., \& Forrester, J.S. (1979). Diagnosis of coronary heart disease. New England Journal of Medicine, 300, 1350-1365.

Doherty, M.E., \& Kurz, E.M. (1996). Social judgement theory. Thinking and reasoning, 2(2/3), 109-140.

Dopheide, J.A. (2005). ASHP therapeutic position statement on the appropriate use of medications in the treatment of attention-deficit/hyperactivity disorder in pediatric patients (American Society of Health-System Pharmacists), American Journal of Health-System Pharmacy, 62, 1502-1509.

Edwards, W., \& Tversky, A. (1967). Decision making: selected readings. Harmondsworth, England: Penguin Books.

Efron, D., Jarman, F.C., \& Barker, M.J. (1998). Child and parent perceptions of stimulant medication treatment in attention deficit hyperactivity disorder. Journal of 
Pediatric Child Health, 34, 288-292.

Elia, J. (2005). Attention deficit/hyperactivity disorder: pharmacotherapy. Psychiatry, $1,27-35$.

Falkenstein, K., Flynn, L., Kirkpatrick, B., Casa-Melley, \& Dunn, S. (2004). Noncompliance in children post-liver transplant: who are the culprits? Pediatric Transplantation, 8, 233-236.

Firestone, P. (1982). Factors associated with children's adherence to stimulant medication. American Journal of Orthopsychiatry, 52(3), 447-457.

Fishbein, M., \& Ajzen, I. (1975). Belief, attitude, intention and behavior: an introduction to theory and research. Menlo Park: Addison-Wesley Publishing Co.

Flaskerud, J.H. (2002). Editorial: new paradigm for health disparities needed. Nursing Research, 51(3), 139.

Foucault, M. (1977). Discipline and punish: the birth of the prison. New York: Random House Inc.

Foucault, M. (1978). The history of sexuality: and introduction (Vol. 1). New York: Random House Inc.

Gerace, L.M. (1989). Using family photographs to explore life style changes. Nursing and Health Care, 10(5), 245-249.

Gibson, J.L., Ivancevich, J.M., \& Donnelly, J.H. (1976). Organizations: behavior, structure, processes (Rev. ed.). Dallas: Business Publications, Inc.

Gilligan, C. (1982). In a different voice: psychological theory and women's development. Cambridge, MA: Harvard University Press.

Gilligan, C. (1993). In a different voice: psychological theory and women's development. 
Cambridge, MA: Harvard University Press.

Gillis, A., \& Jackson W. (2002). Research for nurses: methods and interpretation. Philadelphia: F.A. Davis.

Gillis, J.S., Lipkin, J.O., \& Moran, T.J. (1981). Drug therapy decisions: a social judgment analysis. The Journal of Nervous and Mental Disease, 169(7), 439-447.

Gillis, J.S., \& Moran, T.J. (1981). An analysis of drug decisions in a state psychiatric hospital. Journal of Clinical Psychology, 37(1), 32-42.

Glantz, S.A., \& Slinker, B.K. (2001). Primer of applied regression and analysis of variance. New York: McGraw-Hill.

Glaser, B.G., \& Strauss, A.L. (1967). The discovery of grounded theory. Chicago: Aldine. Graham, F.K., \& Kendall, B.S. (1960). Memory-for-designs test: revised general manual [Monograph Supplement 2-VII]. Perceptual and motor skills, 11, 147-188.

Habermas, J. (1990). Moral consciousness and communicative action (C. Lenhart \& S. Weber Nicholsen, Trans.). Cambridge, MA: The MIT Press.

Hack, S. \& Chow, B. (2001). Pediatric psychotropic medication compliance: a literature review and research-based suggestions for improving treatment compliance. Journal of Child and Adolescent Psychopharmacology, 11(1), 59-66.

Hammersley, M., \& Atkinson, P. (1995). Ethnography: principles in practice ( ${ }^{\text {nd }}$ ed.). New York: Tavistock Publications.

Hammond, K.R. (Ed.). (1966). The psychology of Egon Brunswik. New York: Holt, Rinehart and Winston, Inc.

Hammond, K.R.. (2000). Judgements under stress. New York: Oxford University Press. Hammond, K.R., Hursch, C.J., \& Todd, F.J. (1964). Analyzing the components of 
clinical inference. Psychological Review, 71(6), 438-456.

Hammond, K.R., McClelland, G.H., \& Mumpower, J. (1980). Human judgment and decision making: theories, methods and procedures. New York: Praeger.

Herr, P.M. (1995). Whither fact, artifact, and attitude: reflection on the Theory Reasoned Action. Journal of Consumer Psychology, 4(4), 371-380.

Holroyd, K.A., Holm, J.F., Penzien D.B., Cordingley, G.E., Hursey, K.G., Martin, N.J., et. al. (1989). Long-term maintenance of improvements achieved with (abortive) pharmacological and nonpharmacological treatments for migraine: preliminary findings. Biofeedback and self-regulation, 14(4), 301-308.

Ibrahim, E.S.R. (2002). Rates of adherence to pharmacological treatment among children and adolescents with attention deficit hyperactivity disorder. Human Psychopharmaccology, 17(5), 225-231.

Isaac, S., \& Michael, W.B. (1995). Handbook in research and evaluation: for education and the behavioral sciences. San Diego: Educational and Industrial Testing Services.

Jadad, A.R., Boyle, M., Cunningham, C., Kim, M., \& Schachar, R. (1999). Treatment of attention-deficit/hyperactivity disorder. (AHRQ Publication No. 00-E005). Rockville, MD: U.S. Department of Health and Human Services.

Jensen, P.S., Garcia, J.A., Glied, S., Crowe, M., Foster, M., Schlander, M., et al. (2005). Cost effectiveness of ADHD treatments: findings from the Multimodal Treatment Study of children with ADHD. American Journal of Psychiatry, $162(9), 1628-1636$.

Johnson, K. L., \& White, K.M. (2004). An examination of the individual-difference 
approach to the role of norms in the Theory of Reasoned Action, Journal of Applied Psychology, 34(12), 2524-2549.

Johnston, C., \& Fine, S. (1993). Methods of evaluating methylphenidate in children with attention deficit hyperactivity disorder: acceptability, satisfaction, and compliance. Journal of Pediatric Psychology, 18(6), 717-730.

Johnston, C., \& Freeman, W.S. (2002). Parents' beliefs about ADHD: implications for assessment and treatment. The ADHD Report, 10, 6-9.

Johnston, C., \& Patenaude, R. (1994). Parent attributions for inattentive-overactive and oppositional-defiant child behaviors. Cognitive Therapy and Research, 18(3), 261-275.

Johnston, C., Seipp, C., Hommersen, P., Hoza, B., \& Fine, S. (2004). Treatment choices and experiences in attention deficit and hyperactivity disorder: relations to parents' beliefs and attributions. Child: Care, Health \& Development, 3I(6), 669-677.

Kaplan, M.F., \& Schwartz, S. (Eds.). (1975). Human judgment and decision processes. New York: Academic Press, Inc.

Kauffman, R.E., Smith-Wright, D., Reese, C.A., Simpson, R., \& Jones, F. (1981). Medication compliance in hyperactive children. Pediatric Psychopharmacology, 1(3), 231-237.

Kim, H.S., \& Kollak, I. (Eds.). (1999). Nursing theories: conceptual and philosophical foundations. New York: Springer Publishing Co.

Kolmar, W.K., \& Bartkowski, F. (Eds.). (2005). Feminist theory: a reader. New York: McGraw Hill. 
Kools, S., McCarthy, M, Durham, R., \& Robrecht, L. (1996). Dimensional analysis: broadening the conception of grounded theory. Qualitative Health Research, 6(3), 312-330.

Lawrence, G.L., Hull, B.P., MacIntyre, C.R., \& McIntyre, P.B. (2004). Reasons for incomplete immunization among Australian children. Australian Family Physician, 33(7), 568-571.

Lowes L., \& Prowse, M.A. (2001). Standing outside the interview process: the illusion of objectivity in phenomenological data generation. International Journal of Nursing Studies, 38, 471-480.

Lukes, S. (1974). Power: a radical view. London: MacMillan.

Lukes, S. (Ed.). (1986). Power. New York: New York University Press.

Mackey, S. (2004). Phenomenological nursing research: methodological insights derived from Heidigger's interpretive phenomenology. International Journal of Nursing Studies, 42, 179-186.

Maggs-Rapport, F. (2001). 'Best research practice': in pursuit of methodological rigour. Journal of Advanced Nursing, 35(3), 373-383.

McClellan, J.M., \& Werry, J.S. (2003). Evidence-based treatments in child and adolescent psychiatry: an inventory. Journal of Child and Adolescent Psychiatry, $42(12), 1388-1400$.

McElearney, C., Fitzpatrick, C., Farrell, N., King, M., \& Lynch, B. (2004). Stimulant medication in ADHD: what do children and their parents say? Irish Journal of Psychological Medicine, 22(1), 5-9.

McHoul, A., \& Grace, W. (1993). A Foucault primer: discourse power and the subject. 
New York: New York University Press.

McNeil Consumers \& Specialty Pharmaceuticals. (2002). Concerta: package insert. Fort Washington, PA: McNeil Consumer Healthcare.

McQuaid, E.L., Kopel, S.J., Klein, R.B., \& Fritz, G.K. (2003). Medication adherence in pediatric asthma: reasoning, responsibility and behavior. Journal of Pediatric Psychology, 28(5), 323-333.

Meadows, L.M., \& Morse, J.M. Constructing evidence within the qualitative project. In Morse, J.M., Swanson, J.M, \& Kuzel, A.J. (Eds.), (2001). The nature of qualitative evidence (pp. 187-200). Thousand Oaks: Sage Publications.

Meichenbaum, D. \& Turk, D.C. (1987). Facilitating treatment adherence: $a$ practitioner's guidebook. New York: Plenum Press.

Mellins, C.A., Brackis-Cott, E., Dolezal, C., \& Abrams, E. (2004). The role of psychosocial factors in adherence to antiretroviral treatment in human immunodeficiency virus-infected children. The Pediatric Infectious Disease Journal, 23(11), 1035-1041.

Milgrom, H., Bender, B., Ackerson, L., Bowry, P., Smith, B., \& Rand, C. (1996). Noncompliance and treatment failure in children with asthma. Journal of Allergy and Clinical Immunology, 98(6), 1051-1057.

Miller, D., Coleman, J., Connolly, W., \& Ryan, A. (1987). The Blackwell Encyclopedia of Political Thought. Cambridge, MA: Blackwell Publishers.

Miller, E.J., \& Rice, A.K. (1967). Systems of organizations: the control of task and sentient boundaries. New York: Tavistock Publications.

MTA Cooperative Group. (1999). A 14 month randomized clinical trial of treatment 
strategies for attention-deficit hyperactivity disorder [Electronic version]. Archives of General Psychiatry, 56(1), 1073-1086.

Myers, S.M., Eisenhauer, N.J., \& Ryan, M.E. (2003). Medications that provide relief to children with ADHD. Cortlandt Forum, 3, 43-52.

National Institutes of Health. (2000). National Institutes of Health consensus development conference statement: diagnosis and treatment of attentiondeficit/hyperactivity disorder (ADHD): special communication. Journal of Child and Adolescent Psychiatry, 39(2), 182-193.

Neufeldt, V. (Ed.). (1994). Webster's New World Dictionary (3 ${ }^{\text {rd }}$ ed.). New York: Prentice Hall.

Novartis Pharmaceuticals. (2006). Focalin XR: dexamethyphenidate hydrochloride extended release capsules: prescribing information. Retrieved March 26, 2006, from http: www.pharma.us.novartis.com/product/pi/pdf/focalinXR.pdf

Phelan, S. (2001). Foucault and feminism. American Journal of Political Science, 34(2), $1990,421-440$.

Pooya, A.A. (2005). Drug compliance of children and adolescents with epilepsy. Seizure, 14, 393-395.

Post, S.G. (2004). Encyclopedia of bioethics $\left(3^{\text {rd }}\right.$ ed., Vol. 1). New York: Thomson Gale. Powers, B.A., \& Knapp, T.R. (1995). A dictionary of nursing theory and research $\left(2^{\text {nd }}\right.$ ed.). Thousand Oaks: Sage Publications.

Pusey, M. (1987). Jurgen Habermas. New York: Tavistock Publications.

Reynolds, P.D. (1971). A primer in theory construction. Indianapolis: The Bobbs-Merrill Co., Inc. 
Rodgers, B.L., \& Cowles, K.V. (1993). The qualitative research audit trail: a complex collection of documentation. Research in Nursing \& Health, 16, 219-226.

Sandberg, S. (Ed.). (2002). Hyperactivity and attention disorders of childhood. New York: Cambridge University Press.

Santosh, P.J., \& Taylor, E. (2000). Stimulant drugs: a review. European Child and Adolescent Psychiatry, 9(Suppl. 1), 27-43.

Saul, J.M. (2003). Feminism: issues and arguments. London: Oxford University Press.

Schachar, R.J., Tannock, R., Cunningham, C., Corkum, P.V. (1997). Behavioral, situational and temporal effects of treatment of ADHD with methylphenidate Journal of the American Academy of Child and Adolescent Psychiatry, 36, 754763.

Schachar, R.J., Jadad, A.R., Gauld, M., Boyle, M., Booker, L., Snider, A., et al. (2002). Canadian Journal of Psychiatry, 47(4), 337-348.

Schatzman, L. (1991). Dimensional analysis: notes on an alternative approach to the grounding of theory in qualitative research. In D.R. Maines (Ed.), Social organization and social process: essays in honor of Anselm Strauss (pp. 303314). New York: Aldine De Gruyter.

Schrag, P., \& Divoky, D. (1975). The myth of the hyperactive child and other means of child control. New York: Pantheon Books.

Schwartz Gould, M.S., Wunsch-Hitzig, R., Dohrenwend, B. (1981). Estimating the prevalence of childhood psychopathology. Journal of the American Academy of Child Psychiatry, 20, 462-476.

Seidman, S. (Ed.). (1989). Jurgen Habermas on society and politics: a reader. Boston: 
Beacon Press.

Shemesh, E. (2004). Non-adherence to medications following pediatric liver transplantation. Pediatric Transplantation, 8, 600-605.

Shire Pharmaceuticals Inc. (2005). Adderall XR: package insert. Wayne, PA: Shire Pharmaceuticals.

Silver, L.B. (2004). Attention deficit hyperactivity disorder: a clinical guide to diagnosis and treatment for health professionals and mental health professionals $\left(3^{\text {rd }} \mathrm{ed}\right.$.). Washington, DC: American Psychiatric Publishing Inc.

Simpson, R.L., Reece, C.E., Kauffman, R., \& Jones, F. (1980). Stimulant medications and the classroom attention-to-task and deviant social behaviors of twelve hyperactive males. Learning Disorder Quarterly, 3(1), 19-27.

Singh, I. (2000). A crutch, a tool: how mothers and fathers of boys with ADHD experience and understand the work of Ritalin. (Doctoral dissertation, Harvard University, 2000). Dissertation Abstracts International, B 61/02, p. 1114, Aug. 2000.

Singh, I. (2003). Boys will be boys: fathers' perspectives on ADHD symptoms, diagnosis, and drug treatment. Harvard Review of Psychiatry, 11(6), 308-316.

Singh, I. (2004). Doing their jobs: mothering with Ritalin in a culture of mother-blame. Social Science and Medicine, 59, 1193-1205.

Singh, I. (2005). Will the "real boy" please behave: dosing dilemmas for parents of boys with ADHD. American Journal of Bioethics, 5(3), 34-47.

Slatter, A., Francis, S.A., Smith, F., \& Bush, A. (2004). Supporting parents in managing drugs for children with cystic fibrosis. British Journal of Nursing, 33(19), 1135- 
1139.

Sleator, E.K., Ullmann, R.K., vonNeumann, A. (1982). How do hyperactive children feel about taking stimulants and will they tell the doctor? Behavioral Pediatrics, $21(8), 474-479$.

Smalley, S.L., Kustanovich, V., Minassian, S.L., Stone J.L., Ogdie, M.N., McGough, J.J., et al. (2002). Genetic linkage of attention-deficit/hyperactivity disorder in chromosome $16 \mathrm{p} 13$, in a region implicated in autism. American Journal of Human Genetics, 71, 959-963.

Strauss, A. (1978). A social world perspective. In Strauss, A. (1991). Creating sociological awareness: collective images and symbolic representations. New Brunswick, NJ: Transaction Publishers.

Strauss, A.L. (1987). Qualitative analysis for social scientists. New York: Cambridge University Press.

Strauss, A., \& Corbin, J. (1990). Basics of qualitative research: grounded theory procedures and techniques. Newbury Park: Sage Publications.

Sudan, D.L., Shaw, B.W., \& Langnas, A.N. (1997). Transplantation Proceedings, 29, $430-431$.

Swanson, J, Schuck, S., Mann, M., Carlson, C., Hartman, C., Sergeant, J., et al. (2001). Over-identification of extreme behavior in the evaluation and diagnosis of $A D H D / H K D$. Retrieved March 14, 2006 from http:www.adhdnet.

Swanson, J. (2003). Compliance with stimulants for attention-deficit/hyperactivity disorder: issues and approaches for improvement. CNS Drugs, 17(2), 117-131.

Taylor, C. (1991). The ethics of authenticity. Cambridge, MA: Harvard University Press. 
Taylor, M., O'Donoghue, \& Houghton, S. (2006). To medicate or not to medicate: the decision making process of Western Australian parents following their child's diagnosis with an attention deficit hyperactivity disorder. International Journal of Bioethics, 53(1), 111-128.

Thiruchelvam. D., Charach, A., \& Schachar, R.J. (2001). Moderators and mediators of long-term adherence to stimulant treatment in children with ADHD. Journal of the American Academy of Child and Adolescent Psychiatry, 40(8), 922-928.

Thompson, J.B. (1981). Critical hermeneutics: a study in the thought of Paul Ricoeur and Jurgen Habermas. New York: Cambridge University Press.

Uliman, D.G, \& Doherty, M.E. (1984). Two determinants of the diagnosis of hyperactivity the child and the clinician. Advances in Developmental and Behavioral Pediatrics, 5, 167-219

U.S. Department of Health and Human Services. (1999). Diagnosis of attention-deficit hyperactivity disorder (ACHPR Publication NO. 99-0050). Rockville, MD: Green, M., Wong, M, Atkins, D., Taylor, J., \& Feinlieb, M.

U.S. Department of Health and Human Services. (2001). Mental health: a report of the Surgeon General; chapter 3, children and mental health. Rockville, MD: U.S. Department of Health and Human Services.

U.S. Food and Drug Administration. (2004, December). FDA talk paper: new warning for Strattera. (Publication No. T04-60). Retrieved November 6, 2005, from FDA Online.

Access: http:/www.fda.gov/bbs/topics/ANSWERS/2004/ANS01335.html.

U.S. Food and Drug Administration (2005a). FDA alert for healthcare professionals: 
Adderall and Adderall XR. FDA alert [02/09/05]: sudden death in children. Access: www.fda.gov/cder/drug/advisory/adderall.htm.

U.S. Food and Drug Administration. (2005c). Alert for healthcare professionals:

Pemoline tablets and chewable tablets (marketed as Cylert): FDA alert: [10/2005]: liver injury and market withdrawal.

U.S. Food and Drug Administration. (2005b). FDA issues public health advisory on Strattera (Atomoxetine) for attention deficit disorder. (Publication No. P05-65). Retrieved November 2, 2005, from FDA Online. Access: http://www.fda.gov/bbs/topics/news/2005/new01237.html.

Volkmar, F.R. (2003). Changing perspectives on ADHD. American Journal of Psychiatry, 160(6), 1025-1027.

Wartenberg, T.E. (1990). The forms of power: from domination to transformation. Philadelphia: Temple University Press.

Werry, J.S., \& Quay, H.C. (1969). Observing classroom behavior of elementary school children. Exceptional Children, 35(6), 461-470.

Whalen, C.K., \& Henker, B. (1980). Hyperactive children: the social ecology of identification and treatment. New York: Academic Press.

White, J.M., \& Klein, D.M. (2002). Family theories ( ${ }^{\text {nd }}$ ed.). Thousand Oaks: Sage Publications.

Wigton, R.S. (1996). Social judgment theory and medical judgment. Thinking and reasoning, 2(2/3), 175-190.

Wilens, T.E., Biderman, J., \& Spencer, T.J. (2002). Attention deficit/hyperactivity disorder across the lifespan. Annual Review of Medicine, 53, 113-131. 
Willis, T.J., \& Lovaas, I. (1977). A behavioral approach to treating hyperactive children: the parent's role. In J.G. Millichap, Learning disabilities and related disorders: facts and current issues ) pp. 119-140. Chicago: Year Book Medical Publishers, Inc.

Winnick, S, Lucas, D.O., Harman, A.L., \& Toll, D. (2004). How do you improve compliance? Pediatrics, 15, e718-e724.

Wolraich, M.L., Lambert, W., Doffing, M.A., Bickman, L., Simmons, T., \& Worley, K. (2003). Psychometric properties of the Vanderbilt ADHD Diagnostic Parent Rating Scale in a referred population. Journal of Pediatric Psychology, 28(8), 559-567.

Wright, G. (1984). Behavioral decision theory: an introduction. Beverly Hills: Sage Publications.

Zaltman, G., \& Coulter, R.H. (1995). Seeing the voice of the customer: metaphor-based advertising research. Journal of Advertising Research, 35, 35-51.

Zametkin, A.J., Nordahl, T.E., Gross, M., King., Semple, W.E., Rumsey, J, Hamburger, M.S., et al. (1990). Cerebral glucose metabolism in adults with hyperactivity of childhood onset. The New England Journal of Medicine, 323(20), 1361-136. 
Appendix A

Interview Code:

$$
\text { Interview Guide }
$$

Informed Consent

-introduce the researcher

-explain the purpose of the interview and ask if the parent agrees to participate

-sign the informed consent

-encourage participant to respond to questions freely, explain that participant can ask questions at any time, ask for clarification, decline to answer any questions and withdraw from the interview at any time

-inform the participant that confidentiality will be maintained to the extent possible -ask for verbal consent to begin the interview

\section{$\underline{\text { Interview Questions }}$}

1. "What was happening with your child just before he/she started treatment with stimulant medication?"

-problems at school/problems at home/peer relationships/problems in community -nature of the problems

-consequences for child, parents, other siblings

-how old was child when started med

-child male or female?

-who made the decision to start medication

-any immediate precipitant?

-any other treatments attempted - informal/non conventional/formal

2. "Please tell me about the process of decision making when your child started the medication"

-who suggested the child start treatment with medication

-who made the decision to start the medication

-who took the child to medical appointments

-what were the thoughts/feelings of participant after meds started

-anyone family/non family disagree with giving medication

-how long did it take from time meds suggested or requested to actual time started -decided to give daily/school days only

-parental agreement/disagreement

3. "What were the things that influenced the decision to begin treatment with medication"

-other family members/non family members

-experiences of others

-previous knowledge of ADHD and treatments 
-school influence/request of school to have child on meds

-health care providers

-media

-effects of ADHD on child

-family difficulties

-safety issues for child

-insurance coverage for child

4. "What was your experience when your child was taking stimulant medication?" -was this parent administering med/who administered

-convenience

-schedule

-cost

-adherence

-school involvement

-IEP/504 plans at school

(this question was changed to "What was it like for you when he/she was taking stimulant medication?" after interview \#1)

5. "What was your child's experience when he/she was taking stimulant medication?"

-improvement

-lack of improvement

-side effects

-comments of child

-stigma

-special ed classes

-community activities

-safety

(this question was changed to "What was it like for your child when he/she was

taking stimulant medication?" after interview \#1)

6. "What was your family's experience when your child was taking stimulant medication?'

-family relationships

-family functioning/communication

-financial

-emotional

-family type/custody/residence

-therapy

-cooperation

-family type

-changes in family structure

(this question was changed to "What was it like for your family when your child was taking stimulant medication?”) 
7. "What was a typical morning like in your home when your child was on medication?"

8. "Looking back, what do you think now of the decision to place your child on stimulant medication"

-evaluative

9. "What do you see in the future for your child with ADHD?"

-grows out of it

-fewer symptoms

-productivity

-need for ongoing treatment

-treatment holidays

-context as chronic illness

-symptoms manageable as gets older

-no need for meds/need for meds/prn meds

10. "Have you seen any recent media coverage about stimulant medication - print, TV or radio? What are your thoughts about that?"

(question added after interview \#2)

11. "Have you anything to add, anything you might think we might need to know as nurses or health care providers, or anything you would like to tell us?"

(question added after interview \#2) 
Appendix B

Interview Code:

Inclusion/Exclusion Criteria

Inclusion Criteria (all answers must be yes)

1. Was your child diagnosed with ADHD?

2. (What kind of clinician diagnosed your child with ADHD - circle response:

pediatrician, psychiatrist, nurse practitioner, psychologist, social worker)

3. Was your child more active than most other children his/her age or more impulsive than most other children his/her age or less able to pay attention than other children his/her age before he/she was 7 years old?

4. Was your child between the ages of 7 and 12 when he/she took medication? (later between 5 and 12)

5. Did your child take Ritalin, Ritalin SR, Ritalin LA, Metadate CD, Methylin, Methylin ER, Adderall, Adderall XR, Focalin, Focalin XR, Dexedrine or Concerta?

6. Are you the biological parent of the child?

7. Were you living with the child at the time the child was taking stimulant medication?

8. Are you able to read, speak and understand English and sign your name?

Exclusion Criteria (all answers must be no)

1. Was your child diagnosed with any kind of psychiatric disorder, like depression, anxiety disorder, psychosis or bipolar disorder? 
2. Was your child taking any other kind of psychiatric medicines when he/she was taking the stimulant medication - medicines like Prozac, Depakote, Risperdal or Seroquel?

(Strattera is not exclusionary despite its classification as an SNRI (antidepressant) since the FDA indication is ADHD, however is not a stimulant medication.

3. Had your child been diagnosed with Autism, Mental Retardation, Pervasive Developmental Disorder or a Learning Disorder? 
Appendix C

Interview Code:

\section{Demographic Questionnaire}

Please circle responses or fill in the blanks. Thank you.

1. What is your relationship to the child?

biological mother biological father step mother step father adoptive mother adoptive father

2. Is your child:

male female

3. Age of your child when he/she started the medication:

$\begin{array}{llllll}7 & 8 & 9 & 10 & 11 & 12\end{array}$

4. Age of your child now:

5. For how long did your child take stimulant medication?

less than 3 months 3 months to 6 months 6 months to 1 year 1 year to 2 years more than 2 years

6. Were your child's medications changed during the time he/she took stimulants? yes no

7. Were the doses of your child's medication changed during the time he/she took stimulant medications?

yes no

8. Who gave the medication on a usual day? (please circle all that apply) mother father sister brother grandparent child took own medication 
school staff school nurse

more than one person (please specify below)

9. Were different people giving the medication each day - for example, one day a parent would give the medication and the next day the child would take his own medication?

yes no

10. What kind of school did your child attend at the time he/she was taking medication?

public private

11. Did your child participate in a school breakfast or lunch program?

yes no

12. What is your ethnicity?

Latino or Hispanic Caucasian African American Asian Pacific Islander American Indian Other

13. What is your primary language, or that spoken in your home?

English Spanish Chinese Tagalog Japanese French

Other

14. At the time your child was taking medication, how many other family members lived in the home?

$\begin{array}{lllllllll}1 & 2 & 3 & 4 & 5 & 6 & 7 & 8 & \text { more than } 8\end{array}$

15. Please identify who these family members were, and how many of each resided in the home: for example, one grandfather, one aunt 
parents

brothers

sisters

step brothers

step parents

grandparents

aunts/uncle

cousins

other relatives

16. Did your child have health insurance at the time your child took stimulant medication?

yes no

17. If your child had health insurance at that time, what type of insurance did he/she have?

HMO PPO fee for service Medi Cal had insurance but type unknown 18. Did your child's health insurance cover prescriptions?

yes no

19. Did you have copayments for prescriptions?

yes no

20. Approximately how much did you spend per month on medicine for your child?

21. What is your occupation? 
22. What is the occupation of the other parent of the child?

23. What is your total annual family income? (please circle)

less than $\$ 50,000 \quad \$ 50,000$ to $\$ 75,000$

$\$ 75,000$ to $\$ 100,000$ more than $\$ 100,000$

10. Conclude the Interview

- ask any questions that have not been answered

- ask the participant if he/she has any questions or comments

- thank the participant for completing the interview

-give the parent a gift card as a token of appreciation for his/her time and contribution 
Appendix D

Attention Deficit Hyperactivity Disorder (ADHD)

$\underline{\text { Research }}$

Parents of Children who took Stimulant Medication

when they were between 7 and 12 years of age

Graduate nursing student at the University of San Diego

would like to ask parents about their experiences with

stimulant ADHD medication. Children do not need to be

taking stimulant medication at this time.

Interviews will take approximately an hour and a half and

will be conducted at a convenient time for you. Parents

who are interviewed will receive a gift certificate for their participation.

Please contact Randye Kay, RN at (626) 4415641 or (626)

7102201. 
Appendix E

Informed Consent

Research Participant Consent Form

Parental Decision Making in the Administration of Stimulant Medication for their Latency Age Children With Attention Deficit Hyperactivity Disorder (ADHD)

Randye Kay is a doctoral student in the Hahn School of Nursing at the University of San Diego. You are invited to participate in a research project she is conducting for the purpose of exploring the decision making process of parents in utilizing stimulant medication for their children with ADHD.

The project will involve one interview that asks questions about the decision making process used in administering stimulant medication for your child with ADHD. The interview will last about 90 minutes and also will include some questions about you and your family, such as your income and occupation. The interview will take place at a time and place convenient to you. Participation is entirely voluntary and you can refuse to answer any question and/or quit at any time. Should you choose to quit, no one will be upset with you and your information will be destroyed right away. If you decide to quit, nothing will change about your access to health care or the way in which doctors or nurses care for you.

The information you give will be analyzed and studied in a manner that protects your identity. That means that a code number will be used and that your real name will not appear on any of the study materials. All information you provide will remain 
confidential and locked in a file cabinet in the researcher's office for a minimum of five years before being destroyed.

There may be a risk that participating in the interview may make you feel tired. Sometimes people feel anxious or sad when talking or reflecting on the things you will be asked about. If you would like to talk with someone about your feelings, you can call the Los Angeles County Department of Mental Health at 1-800-854-7771. Remember, you can stop the interview at any time you feel tired or for any other reason.

The benefit to participating will be in knowing that you helped nurses learn how to better help people with the decision making process they use in the choice of stimulant medication treatment for their children with ADHD. If you complete the study you will receive a gift card for gas, a local restaurant or coffee shop worth $\$ 10$. If you have any questions about the research, please contact Randye Kay at (626) 4415641 or (626) 710 2201 or Dr. C. Connelly at the University of San Diego at (619) 2604548.

I have read and understand this form, and consent to the research it describes to me. I have received a copy of this consent form for my records.

Signature of Participant

Name of Participant (Printed) 
Appendix G

Copyright Approval Letter

SAGE PUBLICATIONS, INC.

REPRINT PERMISSION AGREEMENT/INVOICE

CORWIN PRESS, INC.

PINE FORGE PRESS

\author{
2455 TELLER RD., THOUSAND OAKS, CA 91320 \\ OFFICE: (805) 410-7713 FAX: (805) 376-9562 \\ E-MAIL: PERMISSIONS@SAGEPUB.COM \\ FEDERAL TAX ID\#95-2454902
}

Between Sage Publications, Inc. and

Randye Kay

on this date of 31-May-06, with regard to the following:

BOOKJJOURNAL TITLE: Behavioral Decision Theory

AUTHOR/EDITOR: George Wright

VOLUMEISSUE \#:

USE OF MATERIAL: For use in dissertation.

TITLE OF SELECTION: Table 3, p. 93

LANGUAGE DESCRIPTION: English, American

EXCERPT:

MAXIMUM PRINT RUN:

AMOUNT DUE: no fee

REQUESTOR'S REF \#:

REQUESTOR'S PUBLICATION: Nursing Dissertation

Acknowledgement of your source must appear in every copy of your work as follows:

Author(s), Book/Journal Title (Journal Volume Number and Issue Number) pp. xx-xx, copyright 20xx by (Copyright Holder), Reprinted by Permission of (Publisher - either Sage Publications, Corwin Press or Pine Forge) Inc.

The permission does not apply to any interior material not controlled by Sage Publications, Inc. If the selection is intended for use in a Master's Thesis and Doctoral Dissertation, additional permission is granted for the selection to be included in the printing of said scholarly work as part of UMP's "Books on Demand" program. Requestor will make a copy available within 10 (ten) days of Publishers request.

Your signature below constitutes full acceptance of the terms and conditions of the agreement herein.

Signature of Requestor

Date 6120106
Your signature below constitutes your rejection of the terms and conditions of the agreement herein.
Signature of Requestor

Date APPLICABLE PAYMENT TO THE ADDRESS LISTED ABOVE. THANK YOU. 